\title{
IntechOpen
}

\section{Modern Perspectives in Business Applications}

Edited by Syed Abdul Rehman Khan and Selay Ilgaz Sümer 



\section{Modern Perspectives in Business Applications}

Edited by Syed Abdul Rehman Khan and Selay Ilgaz Sümer 

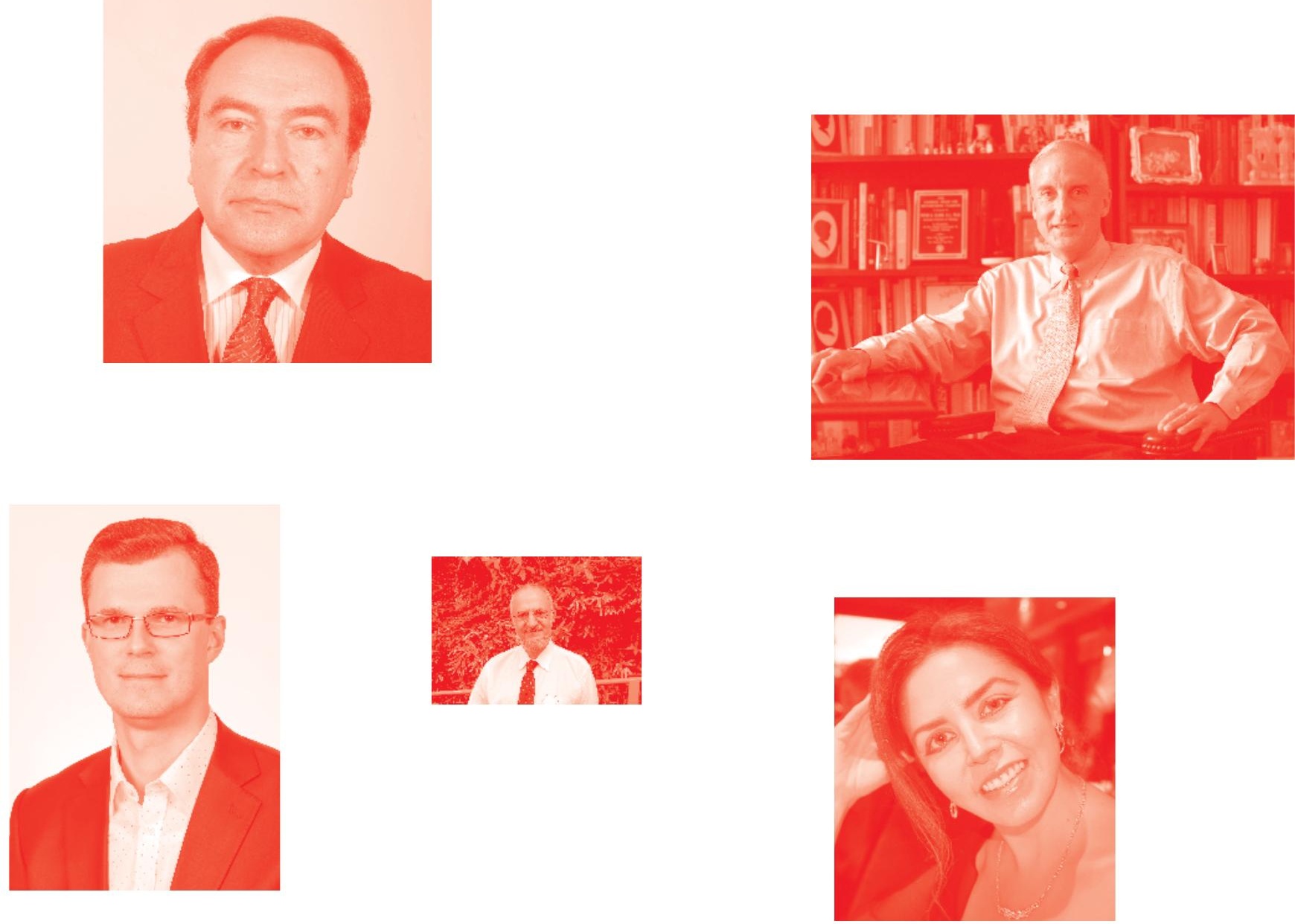

Supporting open minds since 2005
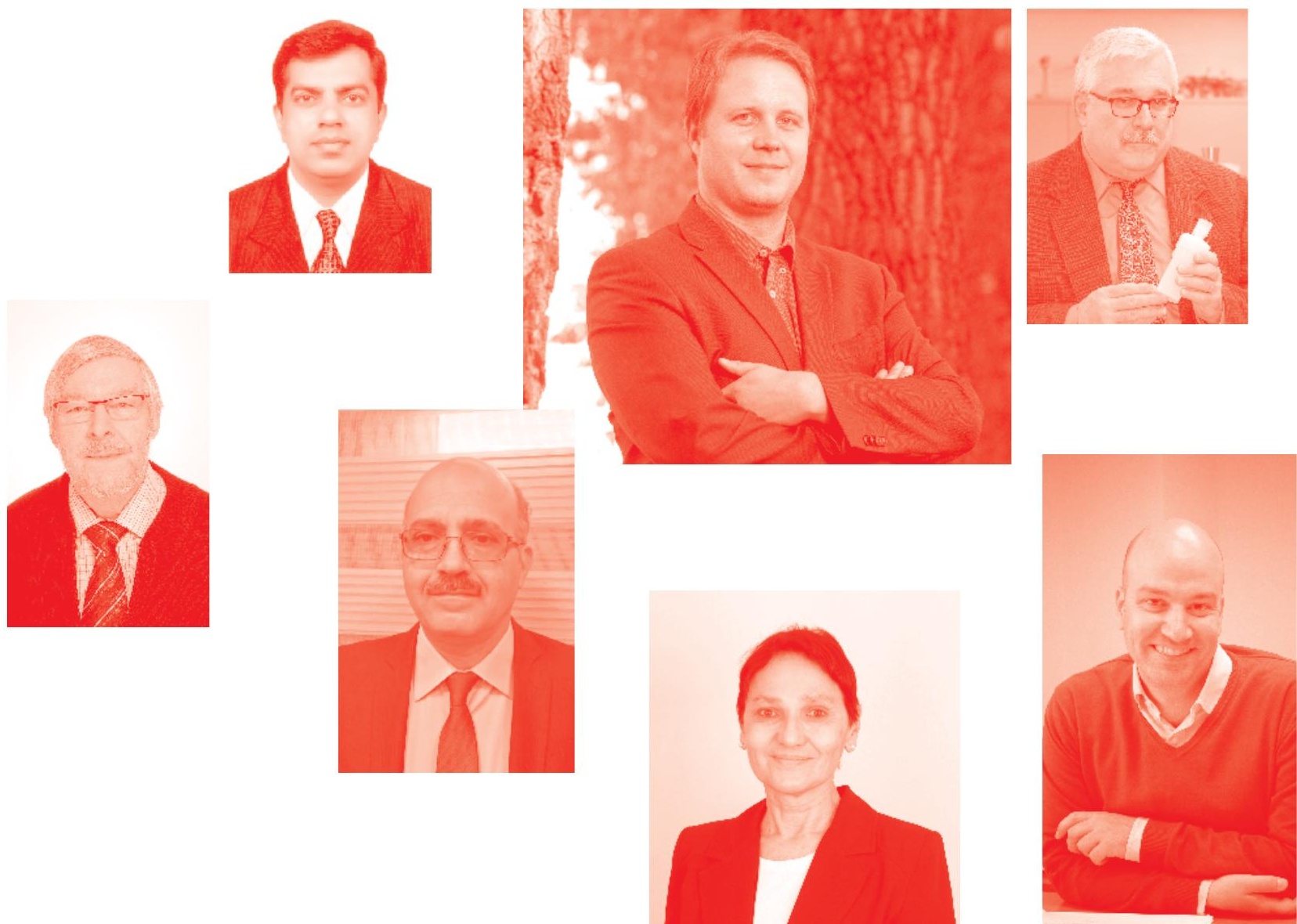
Modern Perspectives in Business Applications

http : //dx . doi. org/10.5772/intechopen . 82778

Edited by Syed Abdul Rehman Khan and Selay Ilgaz Sümer

\section{Contributors}

Leslier Valenzuela-Fernández, Francisco Javier Villegas Pinuer, Natacha Peñaloza, Hesham Dinana, Chihiro Shimizu, Takeshi So, Zulkaif Ahmed Saqib, Khubaib Ahmed Saqib, Jane Oh Jin, Syed Abdul Rehman Khan, David Newlands, Fawaz Baddar Al Hussan, Selay Ilgaz Sümer

() The Editor(s) and the Author(s) 2020

The rights of the editor(s) and the author(s) have been asserted in accordance with the Copyright, Designs and Patents Act 1988. All rights to the book as a whole are reserved by INTECHOPEN LIMITED . The book as a whole (compilation) cannot be reproduced, distributed or used for commercial or non-commercial purposes without INTECHOPEN LIMITED's written permission. Enquiries concerning the use of the book should be directed to INTECHOPEN LIMITED rights and permissions department (permissions@intechopen.com).

Violations are liable to prosecution under the governing Copyright Law .

\section{(cc) BY}

Individual chapters of this publication are distributed under the terms of the Creative Commons Attribution 3.0 Unported License which permits commercial use, distribution and reproduction of the individual chapters, provided the original author(s) and source publication are appropriately acknowledged. If so indicated, certain images may not be included under the Creative Commons license. In such cases users will need to obtain permission from the license holder to reproduce the material. More details and guidelines concerning content reuse and adaptation can be found at http : //www . intechopen . com/copyright-policy . html.

\section{Notice}

Statements and opinions expressed in the chapters are these of the individual contributors and not necessarily those of the editors or publisher. No responsibility is accepted for the accuracy of information contained in the published chapters. The publisher assumes no responsibility for any damage or injury to persons or property arising out of the use of any materials, instructions, methods or ideas contained in the book.

First published in London, United Kingdom, 2020 by IntechOpen IntechOpen is the global imprint of INTECHOPEN LIMITED, registered in England and Wales, registration number: 11086078 , 7th floor, 10 Lower Thames Street, London, EC3R 6AF, United Kingdom

Printed in Croatia

British Library Cataloguing-in-Publication Data

A catalogue record for this book is available from the British Library

Additional hard and PDF copies can be obtained from orders@intechopen.com

Modern Perspectives in Business Applications

Edited by Syed Abdul Rehman Khan and Selay Ilgaz Sümer

p. cm.

Print ISBN 978-1-78984-972-1

Online ISBN 978-1-78984-973-8

eBook (PDF) ISBN 978-1-78985-225-7 


\section{We are IntechOpen, \\ the world's leading publisher of Open Access books}

Built by scientists, for scientists

\section{$4,800+$}

Open access books available

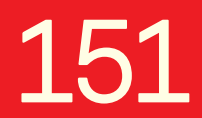

Countries delivered to

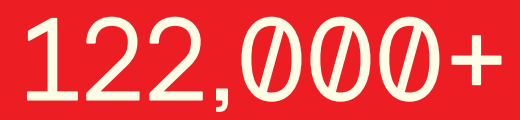

International authors and editors

Our authors are among the

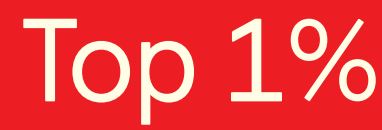

most cited scientists

Contributors from top 500 universities
40010

Downloads

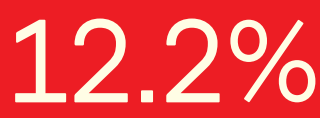

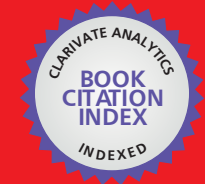

WEB OF SCIENCE ${ }^{\text {MM }}$

Selection of our books indexed in the Book Citation Index in Web of Science ${ }^{\mathrm{TM}}$ Core Collection (BKCI)

Interested in publishing with us?

Contact book.department@intechopen.com

Numbers displayed above are based on latest data collected.

For more information visit www.intechopen.com

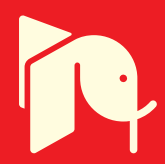





\section{Meet the editors}

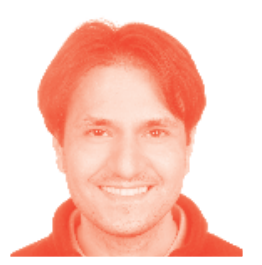

Syed Abdul Rehman Khan is a teacher of supply chain and logistics management. Dr Khan achieved his Certified Supply Chain Professional (CSCP) certificate from the United States and successfully completed his Ph.D. in China. Since 2018, Dr Khan has been affiliated with Tsinghua University as a postdoctoral researcher. He has more than 9 years' core experience of supply chain and logistics at industry and academic levels. He has attended several international conferences and also has been invited as a keynote speaker in different countries. He has published $70+$ scientific research papers in different well-renowned international journals and conferences. He is a regular contributor to conferences and workshops around the world. In addition, Dr Khan has received two scientific innovation awards, consecutively, from the Education Department of Shaanxi Provincial Government, China. Also, Dr Khan holds memberships in the following well renowned institutions and supply chain bodies/ associations: APCIS, USA; Production and Operations Management Society, India; Council of Supply Chain Management Professionals, USA; Supply Chain Association of Pakistan; and Global Supply Chain Council, China.

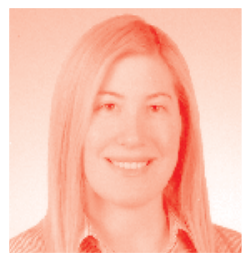

Dr Selay Ilgaz Sümer is an Assistant Professor at the Department of Management in the Faculty of Economics and Administrative Sciences at the Baskent University, Ankara, Turkey. She received her $\mathrm{PhD}$ in Business Administration from Gazi University, Ankara, Turkey in 2011. She has published several articles, conference proceedings, and book chapters. Dr Ilgaz Sümer is a member of various referee boards of national and international journals. Her primary research interests are consumer behavior, marketing strategies, international marketing, sales management, digital marketing, and services marketing. 



\section{Contents}

Preface

Section 1

Introduction

Chapter 1

Introductory Chapter: Purchasing and Supply Management by Syed Abdul Rehman Khan and Zhang Yu

\section{Section 2}

Supply Management Practices and Strategies

Chapter 2

Role of Visibility in Supply Chain Management

by Zulkaif Ahmed Saqib, Khubaib Ahmed Saqib and Jin Ou

Chapter 3

Sourcing and Manufacturing in the Market Region

by David J. Newlands and Fawaz Baddar Al Hussan

Chapter 4

Supply Management of Rental Housing Facilities: Effect of Changes in the Quality of Housing Equipment in the Tokyo Housing Rental Market

by Takeshi So and Chihiro Shimizu

\section{Section 3}

Sales Management in the New Age

Chapter 5

Prologue: Marketing in the Modern Age

by Selay Ilgaz Sümer

Chapter 6

Insight-Driven Sales Management

by Hesham O. Dinana 
Organizational Capabilities, Value Cocreation, and Marketing

Innovation: How Well Are We Prepared to Face Future Challenges?

by Leslier Valenzuela-Fernández and Natacha Peñaloza-Briones

Chapter 8

Empowerment of the Sales Forces in 2000s

by Leslier Maureen Valenzuela Fernández

and Francisco Javier Villegas Pinuer 


\section{Preface}

Along with developments in technology and globalization movements in recent years, significant changes have occurred in the activities of businesses. These developments have also led to the diversification of consumers' demands and expectations. This situation required the needs of the consumers to be met faster than the competitors. In addition, it has become necessary for companies to attract the attention of consumers in a highly competitive environment. As a result, the importance of sales management and supply management has increased.

In the context of marketing, businesses should plan their activities carefully. At this point, sales management activities and coordination of sales forces are very important. Besides, some of the concepts such as being customer-oriented and creating value, which have become very important in the planning of activities related to sales management, should be taken into consideration. Within the scope of sales management, in addition to organizing sales-related activities, some points related to the training, motivation, and planning of sales forces should be arranged within the framework of today's modern perspectives.

For most of its history, procurement has been focused primarily on transactional processing, with virtually no strategic decision-making responsibilities. The typical purchasing routine has been simple: receive a requisition from the user, place the purchase order with the supplier, expedite when necessary, and resolve invoice discrepancies. In this process, there was very little room for decision-making such as supply sourcing and even less discretion.

Today, this is certainly no longer the case, procurement and supply management has evolved into a strategic element in the competitive arsenal of most organizations. There is now a justifiable movement toward centralized control of corporate spending for compliance, risk management, and cost reduction.

This book is unique! Until now, purchasing and supply management books have had a primarily domestic outlook. However, in this book, important issues related to sales management and supply management are handled with a modern perspective. This book has global vision tied into management principles based on an understanding of the sales management and basic job of purchasing and supply management, as all authors have held high-level positions directing the effort. Distinguished researchers from prestigious universities have written chapters and case studies from real-world events that challenge the brightest minds.

In the end, we would like to thank the contributors/authors of the book for their extraordinary hard work to submit their valuable and innovative work in the form 
of chapters. We would also like to thank the author service manager Mr. Mateo Pulko for his milestone coordination and facilitating of the authors. We also extend our thanks to the IntechOpen publisher for all of their support.

Syed Abdul Rehman Khan, PhD

Tsinghua University,

Beijing, China

Dr. Selay Ilgaz Sümer

Assistant Professor,

Baskent University,

Ankara, Turkey 
Section 1

\section{Introduction}





\title{
Chapter 1
}

\section{Introductory Chapter: Purchasing and Supply Management}

\author{
Syed Abdul Rehman Khan and Zhang Yu
}

There is no doubt that each and every firm have their purchasing department/ professionals. Purchasing is the process of acquiring materials, components, and services from another firm. Professional purchasing have addresses following main rights: purchase of the right material, component or service, in the right quantity and quality, at the right place and time [1]. Purchasing gives the foundation of supply management, which tends to have a wider scope of activities [2]. The focus shifts from price to the total cost of ownership.

Supply management is a five-phase process that starts with the identification of the materials or components required to fulfill the requirement of the enterprise. During this phase, the need is to convert into a statement describing the materials or components required to fulfill the need. It is projected that around $85 \%$ of the cost of material is determined during this phase $[3,4]$. In sophisticated and multinational firms, supply management professionals and pre-qualified vendors are involved in this phase. The second phase of supply management contains identifying the supplier who will best fulfill the need. The third phase comprises the process of establishing a reasonable and fair price for the material to be purchased. The fourth phase results in an enforceable contract for the purchase that fulfills the requirement of both firms (supplier and buyer). The last phase needs managing the relationship to guarantee quality and delivery time of the material. During this last stage, the supply management firm may work with the supplier in an effort to enhance the efficiency of the supplier with the objective of reducing cost and/or improving quality $[2,5]$.

\section{Definition of supply management}

There is a long list of definitions on supply management and procurement management (Figure 1). But the most common definition of supply management is as follows:

\footnotetext{
"The process of obtaining and managing of materials, components or services needed to operate a business or other type of firm. The elements of supply management contain the actual materials/components, budgets, information, and employees. The key purpose of this procedure is to keep costs stable and use resources effectively to increase the efficiency of the business and profits" [6].
}

Following are the basic responsibilities of an effective purchasing and supply management team. 


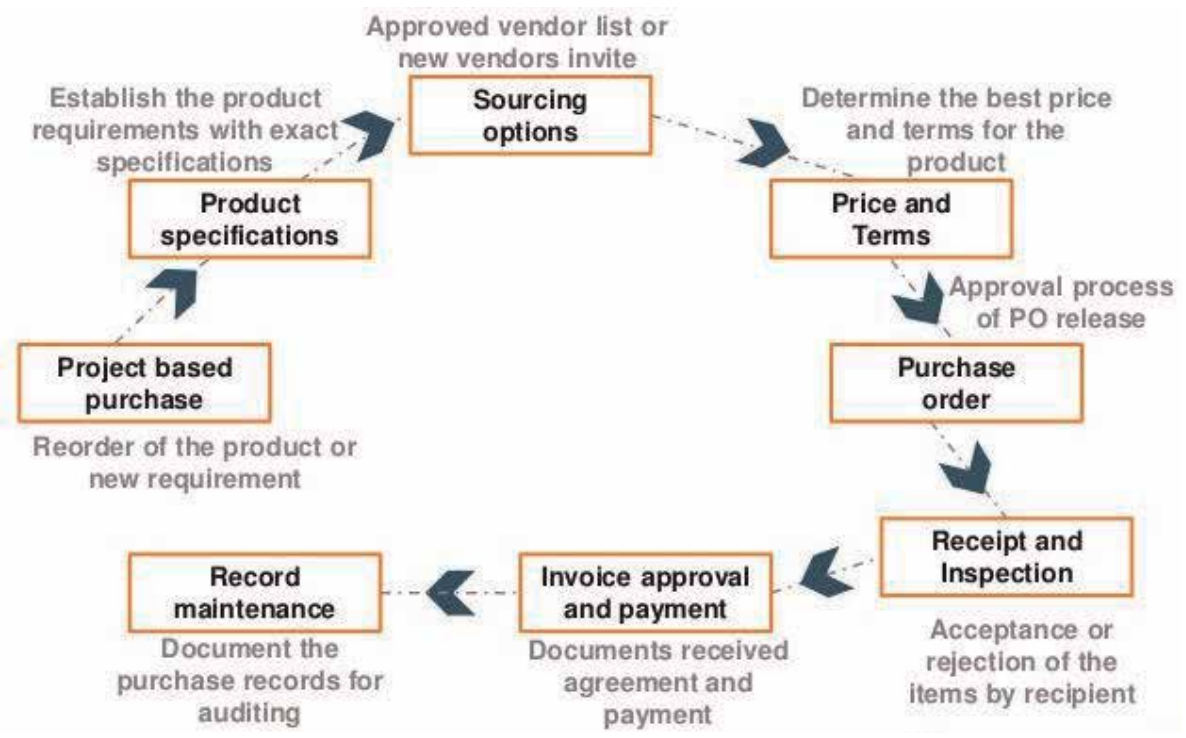

Figure 1.

The complex procurement process.

\section{Reducing cost}

Purchasing has a direct impact on firms' profitability and expenditure. The procurement professional task is to reduce the cost of product, material or service through supplier relationship development and negotiations [7]. In addition, procurement professionals have a responsibility to create value for the firm in terms of cost reduction and improving the quality of the item. Generally, the material cost is two and a half times the payroll costs $[1,8]$. It is the key reason firms see great value in procurement professionals who are able to increase the quality of products and savings.

\section{Negotiation}

Negotiation plays a vital role in the reduction of cost and enhancing the quality of the item. Procurement professionals are tasked with negotiating terms with suppliers that benefit to the firm in terms of delivery time, quality of materials, and reduction in price/cost of material $[1,9,10]$. Undeniably, this not only affects the sales and revenue of firms but also create a competitive advantage. The successful supply management professionals' team is relying on the ability to foresee longterm business relationship and strong negotiation skills.

\section{Developing supplier relationships}

Usually firms require suppliers on an ongoing basis due to one-off purchases is very costly and as a result, it is crucial to building a long-term relationship with suppliers. A supplier-buyer good relationship can create flexibility in the supply chain $[6,11]$. In addition, by working with the supplier on a long-term basis, firms may increase competitive edge, higher cost savings, and fine-tune schedules. 
Further, buyer-supplier relationships benefit both and build trust and collaboration, which allowing both parties to succeed [12].

\section{Mitigating risk}

Purchasing and management have a responsibility to understand the potential risks and develop innovative strategies to manage them. An effective risk mitigation strategy may protect firms from a big loss $[1,13]$. Potential risks contain transparency and fraud, counterfeit materials and intellectual property. Further, supply management professionals need to have a plan B in place if supplies are delayed from the suppliers' side or due to changes in schedule.

\section{Author details}

Syed Abdul Rehman Khan ${ }^{1 *}$ and Zhang $\mathrm{Yu}^{2}$

1 School of Economics and Management, Tsinghua University, Beijing, China

2 School of Economics and Management, Chang'an University, Xi'an, China

*Address all correspondence to: sarehman_cscp@yahoo.com

\section{IntechOpen}

(c) 2019 The Author(s). Licensee IntechOpen. This chapter is distributed under the terms of the Creative Commons Attribution License (http://creativecommons.org/licenses/ by/3.0), which permits unrestricted use, distribution, and reproduction in any medium, provided the original work is properly cited. (c) BY 


\section{References}

[1] Khan SAR, Dong Q. Impact of green supply chain management practices on firms' performance: An empirical study from the perspective of Pakistan. Environmental Science and Pollution Research. 2017;24:16829-16844. DOI: 10.1007/s11356-017-9172-5

[2] Khan SAR, Qianli D, SongBo W, Zaman K, Zhang Y. Environmental logistics performance indicators affecting per capita income and sectoral growth: Evidence from a panel of selected global ranked logistics countries. Environmental Science and Pollution Research. 2017;24(2): 1518-1531. DOI: $10.1007 / \mathrm{s} 11356-016-$ 7916-2

[3] Khan SAR. Introductory chapter: Introduction of green supply chain management [online first]. IntechOpen. 2018. DOI: $10.5772 /$ intechopen.81088. Available from: https://www.intechopen. com/online-first/introductory-chapterintroduction-of-green-supply-chain-ma nagement

[4] Sarkis J, Zhu Q, Lai K. An organizational theoretic review of green supply chain management literature. International Journal of Production Economics. 2011;130(1):1-15

[5] Andic E, Yurt O, Baltacioglu T. Green supply chains: Efforts and potential applications for the Turkish market. Resources, Conservation and Recycling. 2012;58:50-68

[6] Khan SAR, Dong QL, Yu Z. Research on the measuring performance of green supply chain management: In the perspective of China. International Journal of Engineering Research in Africa. 2016;27:167-178. DOI: 10.4028/ www.scientific.net/JERA.27.167

[7] Luthra S, Garg D, Haleem A. The impacts of critical success factors for implementing green supply chain management towards sustainability: An empirical investigation of Indian automobile industry. Journal of Cleaner Production. 2016;121:142-158

[8] Gunasekaran A, Spalanzani A. Sustainability of manufacturing and services: Investigations for research and applications. International Journal of Production Economics. 2012;140(1): $35-47$

[9] Mangla S, Madaan J, Chan FT. Analysis of flexible decision strategies for sustainability-focused green product recovery system. International Journal of Production Research. 2013;51(11): 3428-3442

[10] Omkareshwar M. Green marketing initiatives by corporate world: A study. Advances in Management. 2013;6(3): 20-26

[11] Zhu Q, Sarkis J, Lai KH. Green supply chain management: Pressures, practices, and performance within the Chinese automobile industry. Journal of Cleaner Production. 2007;15(11): 1041-1052

[12] Awasthi A, Kannan G. Green supplier development program selection using NGT and VIKOPR under fuzzy environment. Computers and Industrial Engineering. 2016;91:100-108

[13] $\mathrm{Hu} \mathrm{AH}, \mathrm{Hsu} \mathrm{CW}$. Critical factors for implementing green supply chain management practice: An empirical study of electrical and electronics industries in Taiwan. Management Research Review. 2010;33(6):586-608 
Section 2

\section{Supply Management Practices and Strategies}





\title{
Role of Visibility in Supply Chain Management
}

\author{
Zulkaif Ahmed Saqib, Khubaib Ahmed Saqib and Jin Ou
}

\begin{abstract}
It is substantial for manufacturing industries to enforce and seek out new strategies regarding supply chain management to endure within the current competitive and capricious business climate which is critical. We try to underlie a policy for manufacturers to connect all operational issues related to the supply chain. This chapter suggests a concept of visibility that represents a beneficial role among business partners such as manufacturers, supplier, and customers. The categorization of several types for uncertainties in the supply chain such as demand, quality, broader variety, time, and customization of a product are related to the decision-maker. Management of uncertainties applicable with the help of sharing the information creates visibility among supply chain partners. Implementing supply chain visibility becomes easier just because of passing information about products globally which is more a matter of priorities and investment, which is not the case when sharing "official data" about people. As social technologies become more prominent, this may change over time. So, supply chain visibility is beneficial for supply chain partners.
\end{abstract}

Keywords: visibility, information sharing, manufacturing industries, supply chain management, customers

\section{Introduction}

Different appliances for manufacturer and distributor are facing at a crossbreeding in the supply chain network. Throughout the years, the appliance producer haunted to build up a considerable connected network among supply chain partners to sustain its high criteria for customer support. Nevertheless, different manufacturing industries controlled neither visibility into nor control over how to sanctioned peculiar service center's operations [1]. The manufacturer ran out from an efficient and competent procedure for sharing data about replacement parts as well as warranty. The manufacturer has known that if it keeps further on its direction as regards worldwide growth, it had to discover new ways in favor of surviving in this competitive environment and need to increase its supply chain visibility with the help of sharing information and data to monitor, supervise, as well as amalgamate the critical piece from its own business [2,3].

Mostly, manufacturers' focus on several projects for supply chain visibility is to equipping more accurate, precise, faithful, and rigorous real-time portrait of demand, quality, and price indications or information about supplier's inventory levels [4]. However, manufacturers are the commencement to strengthen visibility while facing an increasingly complex directive climate which is a support to encounter compliance and obedience guidelines which are associated with different kinds 
of business practices, ecological mandates, forthcoming serialization approach, as well as track-and-trace laws and regulations. Classified and more conspicuous domains are important for sustainable development where the advanced shape of supply chain visibility intervenes as regards to play for ecological compliance [3, 5-8]. Rules, regulations, and laws for provisions like Evaluation, Registration, Restriction, and Authorization of Chemical Substances elicits the manufacturers toward responsibility in favor of monitoring and handling the hazardous chemical materials as well as substances.

These mandates might be entirely considerably costly to redesigns, discarded components, pluggable consignment, feasible consumer's disappointment, and perhaps extortionate charges as regard the implications for manufacturers that are not on top. Most manufacturers are remaining utilizing the manual processes to retrieve spreadsheets, even indigenous databases for domestic companies to accomplish and organize this data according to their supply chain network. On the other hand, a huge assortment of several products provided by enterprises from supply chain network which declared as suites or sets for product lifecycle management (PLM) that are appending functionality to promote manufacturers automate according to their processes.

Moreover, a successful track system and controllable monitoring system might be enhancing the environmental performance of their products with the help of sharing information (visibility) as regards to supplying chain management.

In this chapter, we will try to explain the answers of questions which are related to visibility role in the supply chain. These questions are: What is visibility? How could all these terms on supply chain visibility, logistics, sustainability, traceability, planning, the inventory level of supplier, and execution be identified? Why is visibility important for the supply chain? What is the value of visibility for supply chain network? And lastly, what are the benefits of SCV?

\section{Supply chain management terms}

Supply chain management (SCM) can help maximize customer satisfaction and boost profitability, but it is also rather complicated and requires collaboration across the entire enterprise and beyond. SCM covers the several kinds of processes in the supply chain from planning, controlling, organization, and procurement of raw material to production and distribution level to the final destination that is necessary to get a product out of the warehouse and to the customer most efficiently and effectively. Because SCM lies at the core of many businesses, it is crucial to have a strong understanding of the processes involved and how they differ. To start, we have compiled a list of seven supply chain management terms to be explained to both organizations and customers which they should be familiar with:

1. Logistics: logistics and SCM are often used interchangeably, whereas SCM covers an extensive scope of operations and activities required to organize as well as produce life of a product's journey from the factory to the warehouse and then to the consumer; logistics only focuses on two essential constituents in the supply chain: transportation and warehousing.

2. Sustainability: supply chain sustainability focuses on the big picture about ecological, social, and economic issues, including legal issues related to supply chain. Organizations have to consider several problems that could affect SCS, such as air pollution, wastage of hazardous material, leakage of carbon footprint emissions $\left(\mathrm{CO}_{2}\right.$ gasses, etc.), labor violations, and desertification related to health and safety issues of workers. The final intention is to implement 
all practices related to environmentally, social-friendly as well as to improve the encouragement as regards positive brand awareness within a competitive environment.

3. Traceability: companies can benefit from implementing traceability, the ability to identify and track the components that make up a final product. It essentially allows a producer, distributor, or supplier to inspect for any issues that may arise before or after a product reaches the consumer. The recent contamination outbreak that was linked to romaine lettuce in the USA is a great example. This is the most accurate and efficient way to find out what went wrong and where and, in some cases, prevent the problem in the first place. Without proper traceability and best practices, companies especially larger businesses would not be at danger level of failure about millions in production costs, sales, different kind of charges, as well as legal bills, although all these businesses will necessarily put and invest to their final consumers at any level of danger as well. Fortunately, national and international laws address economic, health, or environmental concerns and enforce traceability across several industries.

4. Planning: supply chain planning is used to balance supply and demand, forecast future needs, and ensure adequate supply to meet those needs. It starts with a demand plan, which gathers all the necessary data and information in one place before translating it into the respective planning, execution, and distribution processes. Once approved, you can then create a master production schedule that will monitor items across the supply chain by location, inventory, order, production time, and quantity. Other critical elements of SCP that help the business plan for the future are consumer forecasting and supply collaboration.

\section{Inventory management: tight control of inventory can be crucial to a com-} pany's success. By implementing inventory management software, you can keep detailed records of every product or material that goes in and out of the warehouse, whether it is new or returned. The lot and serial numbers, quantity of goods, and cost of goods are just some of the data employed in inventory management. There are also specific techniques or methodologies to inventory management such as stock review, just-in-time method, and ABC analysis that ensure you have the right amount of materials to meet demand at the lowest possible cost.

6. Execution: one of the more common supply chain management terms, SCE, focuses on all of the actions needed to get a product to the customer before or on the estimated date of arrival. That includes the monitoring procedure for the goods as well as materials as they arrive and move through the warehouse and scheduling of transportation services to deliver the final product, as well as the financial transactions. By doing so, SCE applications, which are often connected to SCP systems, also give customers the ability to track a product and receive updates.

7. Supply chain visibility: SCV is one of the more valuable supply chain management terms because it offers companies and their customers more time and actionable information about their supply chain orders. Manufacturers and retailers can pull information from SCV software that they can share with customers so they can track their orders in real time. If there is a disruption or issue while a product is in transit to its final destination, SCV will quickly provide data that give manufacturers the fastest option to redirect the supply. 
To put it simply, SCV's main objective is to enhance as well as intensify the supply chain by providing accurate real-time data to all parties involved. Furthermore, manufacturers remain employing SCV to encounter conformity enforcement such as those associated with business practical exercises, environmental demands, upcoming serialization, and track-and-trace laws.

Today, all best practices for supply chain management are regarding the development of the imagination of the big picture as well as all sustaining deeds and actions required to comprehend that situation. Different objectives such as a prosperous aqueduct strategy, sustainability (environmental, social, and economic), as well as supply chain visibility are faultless models for accomplishments that are the impossible absence of a major rank of orchestration, instrumentation, collaboration, and leadership. A supply chain operating smoothly could also progressively incorporate complicated technology, machinery, as well as the methodology that could provide bigger insight, visibility with regard to sharing information, implementation, inventory management, planning, and traceability from the association of digital supply chain and manufacturing procedures to analytics.

Visibility: the strategic importance of supply chain for manufacturing sectors of an economy makes it paramount that companies measured their performance. Performance measurement in the context of the time, quality, and cost are of high importance to manufacturing companies [9]. Each manufacturing company competes with large companies within different industries such as textile, cement, sports, garments, furniture, auto, electronics, and agriculture. Competitive advantage is an arduous task for companies to gain within a competitive environment. There is increasing attention within the ground of supply chain management. Furthermore, also attention has deemed toward the importance of information sharing.

\section{Information sharing about components or products, raw material components, during carriage out to transit could be tracked from the manufacturer to their final destina- tion or consumer called as visibility in supply chain or supply chain visibility (SCV).}

By collecting and sharing information from multiple organizations, information sharing (visibility) can present their members with a detailed picture of malicious activity taking place within a specific sector or geographic region. Member organizations can then use this information to individually and collectively block attacks they may not have known about otherwise. Organizations can get benefit from joining some information sharing activities in several different ways. By sharing and receiving actionable cyber threat information, organizations can gain an enhanced understanding of their threat environment and make better and more timely decisions about how to allocate cybersecurity resources to defend themselves [9-11].

The final destination of SCV turns into enhancement and effectiveness of the supply chain network by developing data directly accessible to all interested business parties, including the customers, suppliers, buyers, as well as producers. SCV contains additional momentous roles among companies. Companies should have delocalized different components for the whole supply chain as well as lost the control and the visibility achieved over what used to be part of operations. In supply chain network the visibility (information sharing), technology facilitates and quickly responds to the transformation which is allowing to favored users to take action and reshape product demand or divert supply. The integration of the chain, both internally and externally, through information sharing (visibility) could bring an improvement for the supply chain achievement. On the other hand, visibility becomes a fundamental thought for logistics activities according to supply chains; it establishes appropriate information sharing process among supply chain 
managers such that it permits them to be experienced and knowledgeable to all appearances of trade. It enables the manufacturers, shippers, retailers, suppliers, as well as consumers to possess an opinion precisely about the supply chain and their products that are located.

The concept of the exercise of new technology, methodology, and procedures to accomplish comprehensive visibility across the whole supply chain is not a new concept; because in 2000, all appearances were not initiated as regarding to the supply chain sustainability management and the exercise of a different kind technology get more control to maximum level. Furthermore, the development of these exercises related to different kinds of technologies showed up at about a point in time when each manufacturing company was searching a fresh supply chain technology, strategy, and process by means of resolution to the provision of world peace and world hunger [12]. Visibility within supply chain enables the suppliers, manufacturers, retailers, shippers, and even final consumers to have that concept of accurately where conjointly the supply chain their products positioned. At each indication point conjointly to the supply chain, the flow of information from the termination line of the raw material from the supplier side to the launching point of customer contact (final destination) approached.

A business instance about procurement in supply chain and visibility software requires to concentrate on alleviation torment queries in a specific supply chain management system in the business. For example, the basic preference in favor of a producer who makes basic arrangements according to agreements and commitments with the subcontracting condition could be obtaining perfect visibility into disruptions that might create a serious strike to product delivery, whereas the priority for a producer of wrapped finished goods could also be obtaining profile into supplier inventory shortages that could have a negative effect because of order fill rates (see Figure 1). Furthermore, visibility could be obtained from the convenience of economical sensors and connectivity through Internet components which have created supply chain visibility which is easier for producers in the last few years. Exactly, it's feasible to understand about the location, time, and surety. For example, in many cases consumer want to track at any time about where are goods, and what condition the goods could join.

In addition to offering a correct, real-time image of requirement indication as well as supplier's stock inventory levels, producers are utilizing the visibility concept as a strategy to help satisfy acquiescence instructions relevant to business practices and practical, ecological demands as well as forthcoming serialization and different kinds of track-and-trace laws. In various industries, supply chain visibility applications are arranged with misfortune healing plans. For instance, the consolidation of supply chain visibility of different techniques and new technologies as a resource for enhancing on-time delivery set out an apparatus that might be offered considerable achievements to consumers contentment and satisfaction level. In a latest research on supply chain superior methods for the survey, the results showed that to carry out $100 \%$ on-time delivery satisfaction, manufacturing firms had to have elevated inventory level in hand for several weeks [13]. The closing inventory is directly influenced the holding and operational costs overall. The fundamental perception as to whether or not visibility provides several resources for advancement as regards delivery time becomes very crucial to the supply chain industry with these

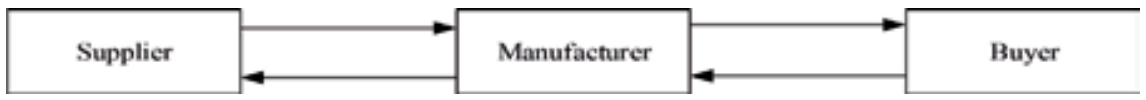

Figure 1.

Supply chain management and visibility (information sharing). 
difficulties. Supply chain performance indication has an excellent function with respect to the company's strategies.

Moreover, the buyer's contentment is indispensable to the diplomatic practicability of a manufacturing firm and conventional to the ambitions for the buyers which could be offering a durable business association for a firm (see Figure 1). Part of congregation a consumer's anticipation includes harmonizing the output to measure the supplier performance with the strategic goals; this means if a consumer worth is unfluctuating delivery as distinguished from fast delivery, then it is essential as a supplier to have delivery done on time as distinguished from concentrating on short lead times [14]. Visibility (information sharing) in which buyer and suppliers share non-incident information, such as cybersecurity best practices, training opportunities, and unbiased product information, can help organizations develop more effective vulnerability mitigations and reduce the frequency and impact of security incidents., Visibility is all about sharing information. The central issue is people often of diverse business, demographic, or national cultures, working to find shared value. As we know, no information system can operate without people. Implementing any system requires change management. If policies are in place and people do not use the data, it is of no value.

Why is supply chain visibility important? You are unable to manage a business sightlessly or blindly in a competitive environment. Today, supply chain visibility is an essential instrument for the accomplishment of a company. However, deficiency of synchronization within the performance of the different tasks often occurs when the individuals within an organization did not completely understand and comprehend all activities, operations, production process, and work in process one level below or above their position within the supply chain network $[10,11]$. Nevertheless, it is feasible from the enhancement of transparency and visibility throughout the whole phase of the supply chain. Produce opportunities and possibilities for individual's motivation within several departments to share ideas and collaborate [15]. Furthermore, there are several types of technology and tools that help to make it simpler and simple to the enhancement of supply chain visibility in an organization. However, we examine three different types of factors that might be helpful in the process:

1. Reduce risks and costs: visibility (information sharing) will guarantee that there are no stoppages within operations as regards the supply chain. Organizations would be possible to speedily answer all requirements across the whole supply chain, such as reorientation of supply. Subsequently, the implementation of visibility in supply chain will be guaranteed to all manufacturing companies which would create the possibility to re-evaluate portions of inefficiency and, in turn, minimization of all kinds of risks such as defective products and different kinds of faults as well as blunders. Supply chain visibility has been demonstrated to present a return on investment. Also, manufacturing firms that provide supply chain management would be able to find a reliable, trustworthy, as well as costeffective service plan.

2. Improve performance: enhanced supply chain visibility will be helpful for the greater performance expectations and estimate future demands, ensuring an organization which can help out to meet future goals. The performance will be optimizing through communication among all partners throughout the supply chain network. Also, visibility in the supply chain will provide that firm is maintaining stride with modifications in rule, legislation, and control system approximately transportation and transmission services. Employing the up-to-date technology in supply chain management can provide a better 
solution to continue at a high level of the respective task as well as accomplish an analyzable performance.

3.Identify problems: A basic consequence of supply chain is enlarged communication which will be improved by visibility correspondingly accommodating to industrial firms to understand someplace gaps occur in the structure. Sharing information between organizations and departments might offer an overall view of the entire process. In a competitive market, customers are less likely to tolerate delivery or product errors. Supply chain visibility is crucial in preventing order errors and will prevent customers from taking their business elsewhere.

Supply chain visibility guarantees that the company is enlightened about each feature of inventory as well as permit to better help consumers by enhancing the performance and minimizing all errors. The remitter in place and the correct infrastructure might be support to a manufacturing system among all parties to accomplish better supply chain visibility and consequently improve performance, reduce costs as well as identify problems, in conclusion improving company's growth and reputation. If producers are not sure about the flinch point, about inspection and analytics professional then who can analyses the current position in the supply chain and who can implement a plan that suits to an organization.

\section{Achieving strong supply chain visibility}

The term supply chain visibility is so widely used; it has almost lost its meaning, so some clarity is vital up front. When most people use the term, they mean interenterprise, current state, or real-time information about the product from creation and as it moves and transforms across the chain. Compiling data from potential data sources is not visibility.

Other characteristics of visibility may include transaction data-like purchase order and source destination or metadata about the product, such as price, rev, part, or SKU number. Data about the supply chain, the supplier, the carrier, or customer may also be necessary. This data would be application- and user-specific to support the specific process needs. Today we can access a broader range of data about the supply chain provided by streaming location-based data such as GPS/GIS and temporal data, weather, temperature, and social events. That is important to understand how current conditions interact and affect the operation of the chain or the product.

On the other hand, offering a better faithful, real-time picture of mandate indications or supplier inventory levels is the concentration of majority of the producer's projects for sharing information according to supply chain visibility. Nevertheless, in confronting increasingly complex regulatory surroundings, producers are the commencement to desire improved visibility among all parties to help meet compliance directives related to trade practices, environmental mandates, and upcoming serialization and track-and-trace laws. One of the more conspicuous regions where improved visibility in the supply chain arrives into play is environmental compliance.

\footnotetext{
"Compliance is an up-and-coming factor, and manufacturers are expecting a lot more regulations for environmental compliance, around packaging for trade compliance and things like pedigree, for understanding where your product is coming from," said by Noha Tohamy, vice president of research at AMR Research, a Gartner company.
} 


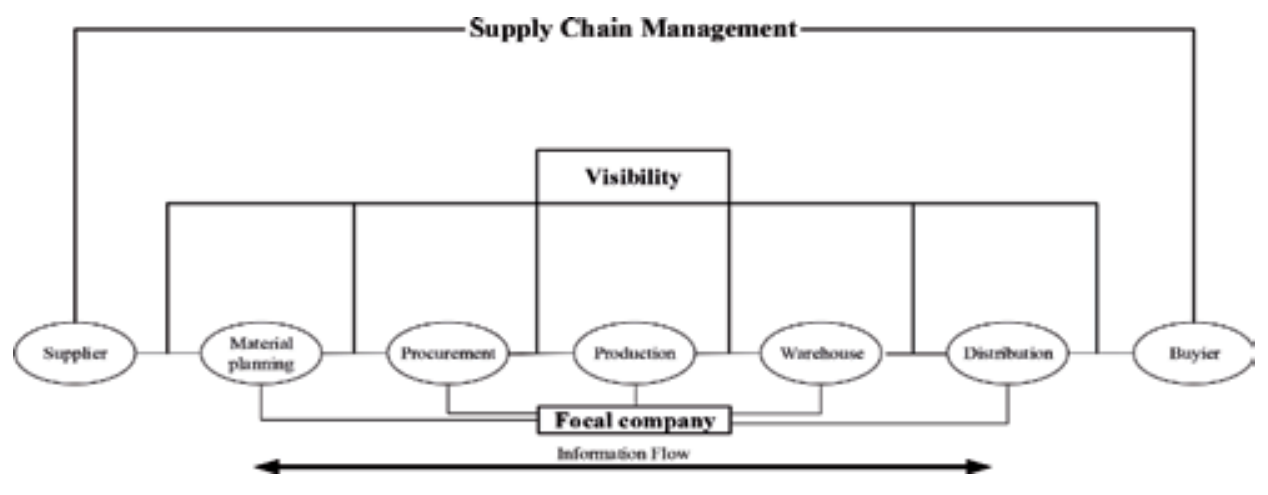

Figure 2.

Product life cycle management.

The bifurcations for producers that are not on top of these demands might be entirely considerably expensive scrapped parts, redesigns, potential customer dissatisfaction, blocked shipments, and perchance steep extra charges (see Figure 2) [16]. Majority producers are peaceful utilizing manual processes, spreadsheets, even homegrown databases to redeem and supervise to handle this data with the whole supply chain. However, an assortment of manufacturing systems is inserted progressively functional capability to support all producer's computerization all manufacturing procedures as well as more efficiently track as well as enhance the environmental performance of their products. The supply chain offerings continuations related to product lifecycle management (PLM). Approaching the environmental rules and regulations approximately carbon emissions will be the authentic game changer for producers, redoubling the required for visibility resources for better solutions to assist in gathering acquiescence. For an instant, you look at what Walmart is demanding with regard to having to minimize the carbon footprint of the products that are provided in Walmart stores. On the other hand, visibility is a tremendous portion which has an opportunity to track that information because there are several parties engaged in producing carbon footprint from each product.

According to previous research, the Business Performance Management Forum and E2open, $42 \%$ of manufacturing firms have evaluated yet to take in the account about greenhouse gas emissions due to carbon footprint throughout their prolonged supply chain augmented by a supplier of on-demand supply chain management services. Furthermore, while conducting interview $76 \%$ of respondents declared to their consumers had not required such information, two-thirds anticipate them to required such information from a valid data forthcoming several years in future. Alongside ecological observance, new laws associated with the global business environment are a supplementary area where producers could get benefit from improved visibility in their supply chains [16]. Extensive business management clarifications like those from Management Dynamics, Oracle, and others automate the processes that allow producers to trade with high collaboration and efficiency throughout borders and also make sure that they pay the rectified amount of duty for the protection against penalties, fines, as well as the loss of business licenses.

\section{The value of supply chain visibility}

We can see the visibility value in the supply chain as few parts of enterprise operations have transformed more radically over the years than supply chain as companies struggle to navigate globalized sourcing, the rise of just-in-time delivery 
models for manufacturing, and, most importantly, unprecedented customer expectations for product availability and speed of delivery [17]. To note as well, the supply chain has a "dirty underside" of fraud and theft. In these environments, owners or workers are resistant to implementing visibility solutions. We always recommend inspections and background checks of trading partners before engaging in the business of any type [18].

Ironically, while companies are using extended supply chain networks and massive outsourcing to meet these challenges, the solutions they come up with create a significant new problem of their own in the form of lost visibility. As we will see in the post, lost visibility into your supply chain means lost value. The good news is that the right telematics and related technologies can help maintain great visibility and control over even the most complex supply chain networks in service today.

Visibility creates value among the many impacts of the different store manufactures, supplier, etc., and the effect is the heightened demand for consumer visibility into availability and shipping logistics, from the first mile to the last. Not surprisingly, businesses see value in getting the right supply chain visibility to meet those customer expectations and ensure efficiencies in their operations [19]. The hurdles come in trying to implement in some severe supply chain use cases. For instance, think about the Amazon (book store) effect and the prototypical example of a book. Supply chain visibility into that book is one thing, but what if your supply chain involves highly volatile, highly valuable pharmaceutical cargo that is environmentally sensitive? You would want nuanced, real-time, and real-world data and analytics to keep that kind of sensitive cargo on track. Smart sensors and granular data mean we can provide real-time operational intelligence to not only reduce the risk of cargo theft and spoilage but also document compliance with regulations and drive operational efficiencies that benefit everyone, from shippers to the end consumer.

Supply chain visibility is connecting systems for stronger solutions for problems. Or many, additional possibilities come to life when you realize that, rather than scrap all your existing, limited capabilities in favor of some brand-new system, you can create new visibility by integrating and strategically augmenting many of the skills you already have. For instance, look at any tractor-trailer on the highway today, and you will likely see a telematics device in the cab to track location, a separate system that is monitoring cargo temperature and a third system for security to protect the valuable cargo from theft or tampering. That is a lot of duplication of systems and services for what remains silos of uncoordinated insight (see Figure 3).

What if we instead choose to fold in point solutions and targeted capabilities

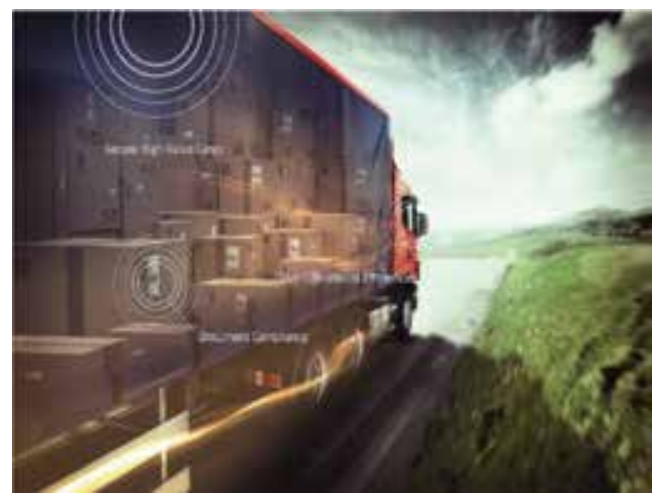

Figure 3.

Systems of system. 
together with more extensive "system of systems" integrations that create more sophisticated outcomes like the difference between assisted braking and full autonomous drive?

That last auto analogy is not random. Tesla took years of laying the sensors, telematics, actuators, and other infrastructure into its vehicles; the cars were preemptively designed to operate and engage these sophisticated systems that would not be enabled for more than a year into the future. That point in the future came when Tesla finally downloaded its first Auto-Pilot program to users who overnight were able to enable new capabilities from the underlying technology suddenly.

So, now that we realize we are not starting from scratch that we can use some of the same capabilities we might already have, but in more integrated and orchestrated ways, "how do we make this transition while keeping our business running?" In other words, once we realize we do not need to reinvent the wheel, we are still faced with having to change the wheels for supply chain visibility, while our business is moving at full speed. The best way to go about it is to focus on the infrastructure first and then introduce the capabilities when the time is right. Think back to our tractortrailer example: we are faced with having to pick the best system perhaps see whose contract is up for renewal or whose existing infrastructure is most interoperable and weighs everything as a business decision. One way or another, try to introduce some coordinated technical standards and interoperable infrastructure for the telematics throughout your supply chain. Through real-time event architected systems, you will learn information about what is happening now that might negatively affect the people, facilities, or products. That provides the value of supply chain visibility or the ability to respond and mitigate adverse effects or seize upside opportunities.

\section{Conclusion}

Implementing supply chain visibility becomes easier just because passing information about products globally is more a matter of priorities and investment, which is not the case when sharing "official data" about people. As social technologies become more prominent, this may change over time. When you think about it, these ideas make total sense. So, why have not we seen more people connect the dots? My understanding is that sometimes you do not see an advanced solution until you have made enough progress in the industry to uncover the difficult business problem behind that solution, to begin with [20].

At least, that is why supply chain visibility is on our minds so much here. We are in a position as a market leader in telematics not only to see what connectivity and telematics can do today for supply chain visibility but also connect the dots on what those capabilities can be tomorrow if we bring the right vision, strategies, and tools to the market.

Benefits of SCV: on the upside, productivity and data accuracy can be enhanced significantly to benefit workers. I have worked in several plants where multiple languages were being spoken, and it was hard for workers to communicate their needs or work status. If one worker speaks Laotian and the other Spanish, they cannot explain their challenges or requests for more material to support their work centers, report quality issues, or route parts to another process. Simple scanning technologies can allow the systems to operate and the workers to communicate their needs [21]. As countries like China also become concerned about product quality and purity, they have shown a greater interest in implementing standards and technology for product trace and visibility. Global regulations in many industries have various requirements for data collection and reporting. Though collected, often, this data is not being made available for a visibility system. 
In conclusion, cultural acceptance or resistance to visibility can be national, social, or organizational. These are reflected in existence or not of local regulation or industry standards efforts. Within supply chains, profile and data sharing is more about current priorities as well as assessing the technology and its value. For the worker, consumer, and resource protection, supply chain visibility may be something we want to embrace. From preserving scarce resources and providing worker safety to making sure the products we use are safe, the trend is moving toward both visibility and transparency.

\section{Conflict of interest}

The authors declare no conflict of interest.

\section{Author details}

Zulkaif Ahmed Saqib ${ }^{1,3 *}$, Khubaib Ahmed Saqib ${ }^{2}$ and Jin $\mathrm{Ou}^{3}$

1 Research Institute of Business Analytics and Supply Chain Management, Shenzhen University, Shenzhen, China

2 Institute of Business Management Sciences, University of Agriculture Faisalabad, Pakistan

3 College of Management, Shenzhen University, Shenzhen, China

*Address all correspondence to: zulkaifsaqib@outlook.com

\section{IntechOpen}

(C) 2019 The Author(s). Licensee IntechOpen. This chapter is distributed under the terms of the Creative Commons Attribution License (http://creativecommons.org/licenses/ by/3.0), which permits unrestricted use, distribution, and reproduction in any medium, provided the original work is properly cited. (cc) BY 


\section{References}

[1] Moon LL, Mo Phyllis LY, Chan Rita KLK. Enterprise risk management: Insights from a textile-apparel supply chain. International Journal of Risk and Contingency Management. 2014;3(2):18-30. DOI: $10.4018 /$ ijrcm.2014040102

[2] Ali Z, Sun H, Ali M. The impact of managerial and adaptive capabilities to stimulate organizational innovation in SMEs: A complementary PLSSEM approach. Sustainability. 2017;9(12):2157. DOI: 10.3390/ su9122157

[3] Brandenburg M, Rebs T. Sustainable supply chain management: A modelling perspective. Annals of Operations Research. 2015;229(1):213-252. DOI: 10.1007/s10479-015-1853-1

[4] Okhuysen GA, Eisenhardt KM. Integrating knowledge in groups: How formal interventions enable flexibility. Organization Science. 2002;13(4): 370-386. DOI: $10.1287 /$ orsc.13.4.370.2947

[5] Fahimnia B, Sarkis J, Gunasekaran A, Farahani R. Decision models for sustainable supply chain design and management. Annals of Operations Research. 2017;250(2):277-278. DOI: 10.1007/s10479-017-2428-0

[6] Jabbour CJC, Maria Da Silva E, Paiva EL, Almada Santos FC.

Environmental management in Brazil: Is it a completely competitive priority? Journal of Cleaner Production. 2012;21(1):11-22. DOI: 10.1016/j. jclepro.2011.09.003

[7] Jabbour CJC, Neto AS, Gobbo JA, Ribeiro MDS, De Sousa Jabbour ABL. Eco-innovations in more sustainable supply chains for a low-carbon economy: A multiple case study of human critical success factors in Brazilian leading companies.
International Journal of Production Economics. 2015;164:245-257. DOI: 10.1016/j.ijpe.2014.11.015

[8] Marshall D, McCarthy L, Heavey C, McGrath P. Environmental and social supply chain management sustainability practices: Construct development and measurement. Production Planning and Control. 2015;26(8):673-690. DOI: $10.1080 / 09537287.2014 .963726$

[9] Francis V. Supply chain visibility: Lost in translation? Supply Chain Management. 2008;13(3):180-184. DOI: $10.1108 / 13598540810871226$

[10] Diez JR. Innovative networks in manufacturing: Some empirical evidence from the metropolitan area of Barcelona. Technovation. 2000;20(3):139-150. DOI: 10.1016/ S0166-4972(99)00112-1

[11] Holcomb MC, Manrodt KB. The relationship of supply chain visibility to firm performance. Supply Chain Forum: An International Journal. 2011;12:32-45

[12] Mccrea BYB, editor, C. Putting the Spotlight on ERP. Logist. Manag. 2011

[13] Best Practices, L. Supply chain management best practices. Benchmarking Reports, ID OP-87. 2002

[14] Beamon BM. Measuring supply chain performance. International Journal of Operations \& Production Management. 1999;19(3):275-292. DOI: $10.1108 / 01443579910249714$

[15] Cao M, Zhang Q. Supply chain collaboration: Impact on collaborative advantage and firm performance. Journal of Operations Management. 2011;29(3):163-180. DOI: 10.1016/j. jom.2010.12.008

[16] Du X, Jiao J, Tseng MM. Architecture of product family: 
Fundamentals and methodology.

Concurrent Engineering. 2001;9(4):309-325. DOI: $10.1177 / 1063293 X 0100900407$

[17] Wu Z, Pagell M. Balancing priorities: Decision-making in sustainable supply chain management. Journal of Operations Management. 2011;29(6):577-590. DOI: 10.1016/j. jom.2010.10.001

[18] Burke J. Bangladesh Factory Fires: Fashion Industry's Latest Crisis. Bangladesh The Guardian. 8, 2013

[19] Tu Q, Vonderembse MA, RaguNathan TS, Sharkey TW. Absorptive capacity: Enhancing the assimilation of time-based manufacturing practices. Journal of Operations Management. 2006;24(5):692-710. DOI: 10.1016/j. jom.2005.05.004

[20] Fisher MSR, Cui JWL.

Environmental performance evaluation with big data: Theories and methods. Annals of Operations Research. 2016;270(2):459-472. DOI: $10.1007 /$ s10479-016-2158-8

[21] Barratt M, Oke A. Antecedents of supply chain visibility in retail supply chains: A resource-based theory perspective. Journal of Operations Management. 2007;25(6):1217-1233. DOI: 10.1016/j.jom.2007.01.003 



\title{
Sourcing and Manufacturing in the Market Region
}

\author{
David J. Newlands and Fawaz Baddar Al Hussan
}

\begin{abstract}
It has been a common practice to transfer making goods to faraway low-laborcost countries. For many managers, this seemed to make commercial sense. Sourcing in remote corners of the world takes advantage of reduced labor hour cost. This can be the most significant direct cost. This chapter focuses on the emerging trend to bring manufacturing back, via reshoring within the nation state or near(er) shoring where production is closer by taking advantage of lower cost neighboring locations. Financial analysis presented is based on differential wage rate and pipeline liability. The financial case analysis indicates overall profit that may be reduced due to labor cost; however, risk-free profit can be significantly higher. Four supply chain configurations can be determined using a simple two-bytwo matrix: long and short distances between supplier and plant, and between plant and market/customer. Typically, longer distances increase the end-to-end time that is taken and increase inventory. Activity-based cost models (ABCDM) and cases originally focused on internal plant operations now are applied along the supply chain. Long inbound supply and long outbound distribution increase pipeline liability risks and typically increase the inventory due to less frequent and larger volume consignments.
\end{abstract}

Keywords: local sourcing, risk to profit, reducing obsolescence risks

\section{Price-based location decision and effects}

Some polluting or "dirty" industrial processes may be moved to other locations where environmental and health and safety legislation is not as strict [1]. Financial penalties for infringements may be inconsequential compared to massive margins. Businesses operate to create value and maximize contribution to profit. They should do so in an ethical, environmental, and resilient manner. It is purchasing responsibility to design new supply chains that enable work to be outsourced, while fulfilling all these criteria $[2,3]$.

Purchasing is based on a dyadic contract between customer and supplier. Direct comparisons between vendors supplying the same products and specification tend to be restricted to price and confidence that the delivery will be made to schedule. Purchase price can be low when most of the direct cost of production is derived from low-cost labor. With thin margins, most suppliers demand high-volume orders from their customers in order to breakeven. This can imply significant surplus inventory or increased mean inventory.

Purchasing agents are rewarded by reducing purchasing spend. However, once the good is bought, a significant proportion of purchase spend may end up as 
obsolete goods. Some orders that are placed may have delivery cancelled late, resulting in payments to suppliers under supply chain pipeline liability causes. Contract clauses allow suppliers to have placed orders for materials and incurred costs prior to payment in order to fulfill the order. The agreement may include a maximum value of inventory, an agreed tooling cost, and incurred expenses that the customer is liable to pay for in event of a cancelation.

Less evident is for the corporations to require purchasing agents to make positive impacts on the top line, for example by helping to reduce the number of goods sold with discounted prices, and to change focus "from price to total costs of ownership" [4]. To do this, purchasing must reappraise their impact on each line of business' performance. Beyond financial return, purchasing may contribute economic and environmental performances that together are evaluated as overall enterprise performance $[2,3]$.

It remains the case that high labor requirements and high wages typically are major contributors to decisions to source goods from lower labor cost regions. A significantly lower labor hour cost may become the headline figure to justify switching supplier. This research shows this may be a folly because high volumes may be delivered infrequently, resulting in increased risk to profit. The thesis of this chapter is that although lower total profits may be achievable due to more frequent deliveries using JIT and higher wages in near(er) regions, the risk to these profits is lower than sourcing from low-labor-cost regions where delivery is much less frequent and consignment volumes are much larger.

Making purchasing decisions to source from any location around the world where the unit prices are lowest is a tantalizing proposition, in order to meet purchase spend on reduction targets. While low unit prices are attractive to the customer, the supplier typically compensates by demanding significant order quantities. The margin per unit may only be a few percent. Hence, to make a large profit from an order, large volumes provide many contributions to profit. The volumes demanded by the supplier may be inappropriate for the customer. They may have to stockpile finished goods and wait for orders to use up the inventory. Large corporations may force suppliers to produce and stock pile inventories for delivery on a specific date. Capacity constraints and the lead times to produce goods mean that production could have started more than half a year before the delivery date. This can create cash flow issues for the supplier. They have to buy materials, pay workers, and operating costs, while revenue is delayed by the delivery date and payment conditions that could push the payment back months.

While purchase price per unit is a headline metric, total pipeline liability based on a loaded inbound and distribution network represents a significant investment in working capital. Working capital represents the investment in materials and value-adding processes that increase the value of the material. Long pipeline lead times increase the cash-to-cash time. A related metric is inventory turns. This is the number of times inventory is bought and sold in a time period. Increased inventories reduce turnovers for a given demand per period. In order to increase the return on capital employed, managerial accounting prefers to increase inventory turns and reduce working capital. This may, however, be achieved at a higher total direct cost where labor is the most significant cost differentiator between local manufacture and outsourcing to low-labor-cost regions. The reduced profit margin may deter businesses from producing locally. Higher potential profits may be sought; however, these may be put at risk from significant obsolescence risks associated with slow end-to-end inventory turns. Profits also may not be as great as planned as a result of discounting residual inventory in order to raise revenue.

Outsourcing to low-labor-cost countries affects economies. The balance of payments (BOP) for a nation state is made up from exports and imports. The BOP can be either a surplus or deficit. Long-term excess of imports tends to weaken an 
economy. Long-term surplus can lead to economic prosperity. Workers may start to demand higher wages and a cycle of inflation can develop. Higher wages reduce the attractiveness of purchasing from such locations because it was their low-labor-cost hour rate that attracted the orders in the first place.

Economic development rates in many emerging countries are astounding; however, it is important to do so with low environmental impact [5]. Development of urban living and burgeoning middle classes increase mean labor cost and reduce the number of individuals available to do manual work. Low cost is relative and increasingly temporary. Catching the wave early requires maintaining a set of back-up plans based on alternate low-cost countries. Some regions in developing countries are more advanced than others. Seeking low-cost areas in these regions can raise the mean economic power of a nation or trading block. Cultural and linguistic differences between Western customers and Eastern suppliers, lack of language abilities, and long haul travel can increase the difficulty of doing business. Making in the home market avoids currency rate variations, cultural differences, and longdistance purchasing and expediting trips. Despite McJob-type work availability, federal legislation may set a minimum on the lowest cost labor available in a nation or region. This minimum may result in monthly wages many times higher than other countries. The British Chancellor has set a gradual increase over the current UK parliament term to raise the minimum wage. This could drive down management appetite to reshore manufacturing and administrative jobs [6].

Making in the home region may reduce pipeline liability at the most; however, margins may be squeezed too much due to labor rates. Buying from lower labor cost neighbor states can reduce unit costs in comparison with making in the market region where wage rates are much higher. Ultimately, quality of goods is a higher priority than cost. If lower cost goods are made to lower specifications and these are identified by customers, lower prices will be demanded to compensate. Otherwise, volume demand may reduce for consumer purchases. B2B purchases may reduce or be suspended, and claw back penalties may be imposed.

\section{Location, location, location}

Where should a company be? This question affects owned and subcontract plants. Final assembly entrepreneurs like Henri Ford, Soichiro Honda, Sir James Dyson, Sir Richard Branson, and Lord Alan Sugar grew their businesses initially inside their home economy. Ford corporation rapidly expanded internationally. Ford initially opened Dagenham and Frankfurt plants as assembly sites that were supplied with kits from Detroit. Rapidly it became clear to Ford that it was more efficient to establish end-to-end integrated product manufacture and assembly campuses. Despite the theoretical and actual efficiency performance, it was noted [7] that internal suppliers were more expensive, were of lower quality, and were less efficient than external, independently owned vendors. Vertical integration, where the corporation owned supplies, ensures that those suppliers are isolated from competitive pressures. Meeting budget rather than being an efficient and well-run business become the norm. As a result, many companies decided not to make all materials and parts themselves.

Outsourcing companies are focusing on their core competencies. This may be a form of "cherry-picking" whereby they choose to specialize on their strengths and competitive advantages. Other activities that are required become noncore competencies. These may be obtained from other companies that focus on providing such benefits to their clients. Specialization can reduce unit cost as a result of increased economies of scale. Companies may provide their goods and services to many clients. 
They in turn compete in the market place, despite having many of the same basic elements. From the perspective of small- and medium-sized enterprises, providing services and related goods to satisfy customer contracts, will find it easier to locate close to their key account customer' sites. For purely durable, shelf-life product-based contracts, where there is no service element, production can be located offshore.

Offshoring: materials can be bought and delivered to virtually any site with minimal price differences due to transportation. Some materials import and export duty that may be charged, including value-added tax (VAT) and port taxes. The trade war between US President Trump and China has seen the US impose $25 \%$ duty on a wide range of goods, with threats to impose tariffs on billions of dollars more of goods.

Energy may cost different rates in different locations due to the abundance of gas, coal, nuclear and noncarbon-based electricity generation. Some governments subsidize energy. Other governments levy higher prices and supplementary charges that create higher gross prices for energy. Despite the presence of open market competition in energy sectors, net prices tend to be the result of many influences including the ability to buy at higher prices. The bill of materials and energy costs of production can be insignificant in some products. Labor hour rates, therefore, become a major consideration when deciding to move production to lower cost countries. Purchasing price paid for products with high labor requirements can be reduced consecutively by undertaking searches for suitable vendors in order to buy from suppliers located in the other locations where labor is found to be cheaper. Landed piece price is the top line issue for management attention and decision making. Optimizing the price-paid criteria, purchasing typically continues to search and monitor the situation, switching whenever necessary to access the cheapest offer.

It seems counter-intuitive, and therefore illogical, to make the decision to purchase from suppliers that are located considerably closer, that have much higher labor cost, that purchase higher cost energy, and that are located in high-cost industrial locations. The United States is determined to become the low-cost manufacturing country. Allen [8] reported US customers are increasingly choosing onshore suppliers. Some national governments are concerned by the de-industrialization associated with outsourcing to low-cost countries. Donati [9] found more emphasis on maintaining existing industry than on encouraging reshoring.

\section{Supply chain designs: Dell versus Hewlett-Packard}

Friedman [10] reported on differences in strategy between Dell Corp and HP. Dell Corp established final assembly plants for laptops and desktop blocks close to major population regions. For mature markets where most customers already tend to have a computer to order replacements, Dell focuses on final builds using an "assemble and configure to order strategy." Suppliers for variant modules are geographically close enough to produce and deliver overnight for next day assembly. Standard modules can be mass produced in a range of lower labor cost countries. From OEM suppliers of major modules including processors and memory systems, Dell's supply chain can flow end to end in 11 days. The customer typically can place orders for products 8 days after the OEM released the new iteration or specification. Dell's distribution system collects a set of boxes for delivery to the customer. Dell does have mass production facilities for emerging mass markets like India. This market by and large is made up of first-time computer purchasers.

By contrast, Hewlett Packard's supply chain for consumer units exclusively relies on production of the core computer unit in China. End-to-end supply chain flow of similar OEM parts to point of sale is in the order of 85 days. CNN reviewed the train journey taken by HP computers from China to Germany. Just that train journey 
takes 17 days (CCTV [11]). To reduce transport empty train returns, parts made in Europe are sent to China rather than sourcing there.

HP's end-to-end time leaves Dell with a virtual monopoly on a specification release for 74 days. The net effect of this is that Dell can sell at a higher price to early adopters. HP brings the same specification to market later as a standard product made to forecast rather than assembled to order. Price decay and fewer product updates can reduce mean revenue.

\section{Defining re- and nearshoring}

Reshoring focuses on bringing manufacturing back to the brand's country of origin. This does not require the corporation to move back to the same city and region. Lower cost areas in the country can be identified that still yield the legitimacy of being made in that nation. Tax holidays and other capital investment subsidies may be on offer. A reverse bidding war may ensue as regions offer more and more incentives and benefits. The federal government may intervene, in much the same way as Mrs Thatcher's government offered Nissan land to build plants and a supplier campus.

Nearshoring focuses on locating capacity within economic zones. The aim is to benefit from tax-free border crossings and relatively faster distribution than remote manufacturing. Goods can be distributed from comparatively lower cost locations to markets in neighboring countries that are members of the same economic region. As an example, new plants established in any EU country compete against existing plants and imports for orders in the common market and as exporters to nonaffiliated countries.

It is possible to offshore and near- or reshore simultaneously [12]. Some work that has been done abroad may be reintroduced. Some work that currently is done in-house or locally may be relocated to locale with lower costs.

\section{Nearshoring cost justifications}

Uncompetitive prices within a market ensure that the work remains overseas. Full cost analyses and strategic responsiveness to market fluctuations and technology sales window closures can focus CFO's attention on costs stemming from pipeline liability - the amount of inventory in the supply chain that has contractually to be paid for regardless of sale demand and may become obsolete. Total cost of acquisition takes into account many factors, not just the absolute lowest labor costs. Total cost can be reduced by buying from low-cost locations that geographically and logistically are nearer the market. Making fast-moving consumer goods in Eastern Europe for Western European consumption, and making in Mexico's Yucatan for NAFTA sales are examples of production inside the trading region. These strategies take advantage of integrated logistics and distribution to deliver materials to plants and distribute finished goods across the economic zone. The relative lower costs in the production region compared to the sales region as a whole enable purchase prices per unit to be kept low, while ensuring minimized pipeline liability that is a risk to profit from obsolescence and quality problems.

Nearshoring can aid in reducing duty overheads and charges. An example of this is Ford Motors opening of an engine assembly plant in Russia. The company aims to purchase at least $60 \%$ of requirements in the country in order to qualify for duty exemption on imported parts (Automotive [13]). Adil Shirinov, Ford Sollers' Chief Operating Officer reportedly stated "Our main target in line with our long-term 
localization strategy was to launch engine production with a significant level of localization ... We are fully committed to this strategy which is key for our business in the current environment" (Ibid).

Reshoring: this strategy involves bringing manufacturing back to the brand's home nation. They do not necessarily need to return to the same sites or cities they previously had shed. Near- and reshoring choices can carry significant risks or can provide competitive advantages. Tactics can be used to mitigate direct risks to the company. Reshoring does not imply bringing activities back in-house. As a result, capital investments can be avoided because suitable vendors already exist that can supply at lower cost, higher quality, and more responsively than internal suppliers would be able to achieve. Suppliers take the risk that demand is volatile. If they have alternate customers, this may enable released capacity to be used for such accounts.

\section{Purchasing and logistics}

Traditional purchasing focuses on purchase price paid. Lower unit prices are demanded by purchasing. To achieve this, suppliers typically require much higher volumes in order to generate viable margins. This creates an imbalance between the rate the goods are produced and the rate consumed by the customers. Large volumes ensure transportation costs that are spread across the goods. For high-value goods, transportation costs may be less than a quarter of $1 \%$.

Price of landed goods is the prime metric many purchasing departments use. This omits a significant issue: pipeline liability. Pipeline liability relates to the total amount of investment in working capital inventory, work in process, and finished goods, made by suppliers on behalf of their customer. If materials are bespoke for a client's products, the supplier's supplier, or lower tier materials producer, will have invested in producing and storing materials for a specific client. The immediate buyer may be tier one or tier two suppliers. Typically, it is tier one suppliers that have to reserve materials at their highest value prior to part production and subassembly. Pipeline liability is the total amount of financial exposure the brand owner has against the commitments made on their behalf by their suppliers.

Purchasing also wants to reduce the purchase spend. Price paid may reduce at a constant rate each month during production window. Sales price may decay equally fast. It is vital for companies to pay and ensure that they do not buy too much too early and, therefore, be left with high-cost finished goods that are commanding lower sales prices. Spot purchases at lower and lower prices can offset lowing constant spot sales prices. While price decay at the point of sale is noted, $\mathrm{B} 2 \mathrm{~B}$ contracts over as much as a 10 year horizon tend not to permit any price rises. In many cases, the aim is to reduce price per unit via total quality, supplier development, reengineering, scrum, and any other improvement scheme that is "flavor of the month." The argument here is that by eliminating unnecessary costs, these benefits may be divided between the participants that helped achieve them. Customers that help their suppliers reduce costs can agree to share half or third of these reductions.

Logistics aims to transport materials and goods at the lowest cost per unit. Cost of transport for small, high value, goods can be in the order of $<0.3 \%$ of the cost of the goods being transported. More costs of transportation per unit maybe incurred by the consumer going to the retail point of sale and returning home than the goods' entire logistics costs incurred through the supply chain. In the pursuit of ever lower logistics costs per unit, greater volumes are required in order to divide the administrative and transport service costs to the desired level. 
Costs of organizing a container movement from low-labor-cost manufacturing base to distribution center or customer in the market region can vary, typically in the region of $€ 9000-€ 15,000$. These costs typically include carriage and insurance elements. These costs are carried as part of the resale price or as a separate transportation contract agreed between sender and receiver. INCO terms will be agreed in advance.

With potentially $<10 \%$ of the pipeline liability — cost of materials in the supply chain, and many smaller deliveries, transportation costs can rise dramatically as a percentage of costs of materials in the supply chain. However, percentage is misleading. The real saving as a result of lean manufacturing is the $90 \%+$ reduction in pipeline liability. Lean aims to reduce risk to profit, rather than increasing profit per se.

The result of outsourcing to low-labor-cost countries is to turn the operation located in the original country into a reseller. Goods printed with the US' stars and stripes, and the UK's union flag may be made in China or other Asian countries. Moves to change the law to ensure Nations' flags are printed only in the nation start to emerge.

The Government of the nation, with massive spending power, may change purchasing policy. They may insist that purchases made on behalf of the people for the benefit of the people should have proven local content. "Local jobs for purchased goods that service local needs" can become a mantra, political, and fiscal policy.

Lean manufacturing focuses on eliminating waste by minimizing effort, movement, space, raw materials, work-in-process materials, finished goods, human effort, rework, and scrap. There is a vast difference between lean processes and a lean supply chain. Lean processes have very small material waiting buffers, produce rapidly without defects, and have very small buffers that have undergone the process. These goods are moved to the next process in very small lots, typically one at a time. To achieve this, they may be transferred via robots, conveyors, or gravity feed. Goods may be produced in the sequence they are required, rather than produced in batches. Key to this is the ability to change the setup economically between units. Single minute exchange of dies (SMED) may be used, combined with computer numerical control (CNC) part production program direct feeds from a synchronizing controller. Use of fully integrated flexible manufacturing cells has become relatively rare. The investment cost of automated cells and systems reduces the return on investment. Use of robots continues as a means of learning how to manipulate and orientate parts. Once learned, these lessons maybe taught to people in order that they may become more efficient. Learning does not stop there. The workers in time will develop their own ways of doing the work with less effort. In effect, people can outperform robots.

From a cost perspective, employing low-labor-cost employees has been considered by offshoring proponents as a means of reducing unit costs. If suppliers exist in low-labor-cost regions, then the investment on new plant and equipment can be avoided. Unit costs come closer to the variable cost element as a result.

Each unit produced may have a very slight margin between costs and price they are sold for. In order for suppliers in such locations to generate profit for themselves, they must rely on multiplying the margin per unit. This is achieved by requiring their customers to place very large orders. A consequence of this strategy is that there are a lot of products to ship. This in turn requires efficient packaging and space utilization in containers and other types of vessels. The benefits of efficient interprocess movements using one-piece flow within lean manufacturing plants can be written off against the huge volumes of finished goods that are stock piled because the customer does not want delivery yet. Months of production output can be held pending the dispatch. 


\section{Plant location as a key factor}

Governments represent their electorate in constituencies located in their national boundaries. It is in the individual representative's own self-interest to ensure that existing plants and businesses located within their constituencies remain viable and employment opportunities are not lost due to outsourcing. Corporations typically are managed by professionals that aim to maximize returns for their investors. Other stakeholders, including local and state government (tax revenue) and employees (salaries and wages) may be secondary to the commercial exploitation of opportunities.

Outsourcing all value-adding activities including part production, subassembling, and final assembly to low-cost countries can reduce the unit cost. Content sourced from the final market may be significantly reduced as a result. The knock-on effect of outsourcing final assembly to low-cost countries halfway round the world can also be to transfer part production work undertaken by suppliers in the market to suppliers closer to the new low-labor-cost manufacturing center. The effect is to strip out many of the supply chain jobs that had existed. If the economy is fully open for business, new jobs will emerge to replace the old ones. Entire regions may undergo periods of deindustrialization, depression, and then regeneration.

Intellectual property (IP) rights in the form of knowledge process may be transferred to franchisees, only to be disseminated locally without consent of the IP owner. Other risks become apparent when outsourcing to countries that have widely divergent cultures. Quality expectations may differ. Entire batches may be written off due to defects introduced by the subcontractor. To ensure they follow orders and comply with specifications, entire teams may need to jet off frequently to review what is going on and to bring the supplier back on track. Local representatives that are "on our side" and speak both languages may be recruited to undertake this vital role. Their salaries increase the overhead element on top of the purchase price. The company must aim to identify other factors that put the commercial viability at jeopardy. Risks to be mitigated include wage rises, lack of literate and skilled employees, language barriers, dishonest and unethical behavior, transport failure including train derailment, fire, ships sinking, new trade barriers, incoming border inspections, and administrative compliance issues that lead to refusal to admit the consignment.

A further factor that needs to be considered is the ability of the organization to respond to changes in volume demanded and sudden emergences of rival technologies and new competitor products. This can lead to significant discounting in order to sell the goods available, consignment recalls, and enforced upgrading activities. Lean aims to reduce the pipeline liability and obsolescence risk in the supply chain. If the goods are heavily discounted, revenue decreases. If they cannot be sold, their value must be paid for from profit and the goods are written off as obsolete. This can significantly reduce the viability of any business. To counter this, companies may mitigate the effects by producing a range of goods. Distance from market incurs logistics distribution time. Time-sensitive priced goods suffer from price erosion. It is necessary to ensure that goods are made, distributed, and sold as quickly as possible in order to minimize the stock holding cost associated with reducing prices. Companies like to reduce the time between placing orders with suppliers and receiving the goods. This is because the earlier they buy the parts, the higher the price that would have been paid for them. If purchase prices are high because orders were placed too early, and sale prices have dropped due to price erosion, then margins will be squeezed.

To reduce the price erosion, design teams should be included throughout the production life cycle in order to supply a constant stream of product upgrades. Each variant or iteration is only produced for a short period of time. All of the goods should be designed to be produced using the same production processes and 
assembly sequence. This avoids constant plant redesigns. An optimum sequence from supplier to customer should be identified in each plant. Designers should be instructed to design future iterations that fit that forward flow sequence from raw materials to finished goods. Group technology concepts including rank order clustering and to/from techniques can be used to identify the most efficient process sequence. Creating manufacturing cells can allow some backward flow without incurring overly long walks between the processes; (if we are walking, we aren't working). Minimizing the distances between processes eliminates the space beside each process to put work-in-process. One-piece flow can then be created where the material is walked from machine to machine. Some conveyor and robot movements may be permitted.

Plant location is a vital issue. Land cost, energy prices, average labor hour wages, and staff salaries, tax rates, transportation duration, and costs are vital pieces of the puzzle. Honda Corporation's motto can be summed up as "make where you sell, buy where you make" (adapted from [14]). In effect, it is necessary to identify major markets, make there, and buy from suppliers that are already there or can be encouraged to install themselves there as a global partner that sets up transplants alongside the producer.

Different locations have different ethical and responsible business practices. Emphasis may range from strict compliance through completely lacking on environmental protection, emissions control, pension contributions, healthcare schemes, employee training and education, and employee family education.

Ford Motor Company initially set up assembly plants in East London and Germany. These plants were supplied with kits from Detroit. It soon became apparent that it was more efficient to establish complete part and subassembly facilities to supply the final assembly plants. Ford's Dagenham plant had the largest brand dedicated iron and steel foundry in Europe. It was industrial disputes, repeated strike action, and union demands for higher equal pay for women that led to Dagenham's assembly plant being shut and production sent to Spain.

\section{Supply chain configurations}

Four basic supply chain configurations are possible. Using a two-by-two matrix, we can map long and short inbound supply chains and outbound logistics: (1) Long inbound, long outbound is mass production; (2) Short inbound, long outbound is just in time; (3) Long inbound, short outbound is just in time; (4) Short inbound and short outbound is just in time 3 .

Strategic financial commitment may be less than expected if most or all of the value-adding activities are undertaken in subcontractors. Empirical testing using a supply chain game [15] showed lower initial investment with JIT3, which reduces the volume required to breakeven. While salaries may be higher closer to the market, they should be few in number. Initial starting stock of $10 \%$ is achieved and maintained. Overall cost savings in terms of lower space, working capital, and cost of inventory offset the higher salaries. Profitability of a JIT3 operation is higher due to lower total costs and lower lost sales to competitors. Agile/mass production applied to the game using JIT3 enabled significantly increased capacity with the same number of people involved in JIT3, together with about $4 \%$ of the starting stock of mass production. Higher overall average revenue is achieved via more frequent product upgrade releases that maintain the sales price.

Many managers today believe it is cheaper to buy parts from low-labor-cost countries, import the goods, produce the finished product, and export these to the market that may be in high-labor-cost countries. Products with infinite inventory 
shelf lives could achieve a sustained sales price. However, overall sales volume per period may stagnate. Cost of holding the inventory may counter the savings from sourcing from low-labor-cost countries.

Figure 1 shows dyads from supplier to assembler and assembler to client. Many supply chain tiers can exist that can require many inbound and outbound kilometers. Mass production is induced by long inbound and distribution chains. To make long journeys, a viable option, large volumes are transported. Large loads deliver more volume than immediately required. Lean philosophies consider this to be a waste.

Lean supply chains can be setup in three configurations that enable inbound JIT, outbound JIT, or both. These correspond to JIT1, JIT2 and JIT3.

JIT1 is typified by Toyota City. This was developed following Toyota engineer's extensive study tours at Ford's Crystal Palace. Suppliers are encouraged to be "close by the plant" [16]. The issue Japan had, when they were the workshop of the world from the 1970s through the 1990s, was that they produced goods in a far-away country. Japan had to import much of the ore and energy required to produce basic engineering materials. Just-in-time deliveries were achieved from part producers, through module assemblers, and on to final assembly plants. They also required huge fleets of ships to transport their goods to markets, particularly in North America and Europe. In effect, only inbound just in time was used. Downstream distribution used large container ships full of finished goods. The key metric for distribution is not just in time. Instead the metric is just on time, where the just changes meaning to "only." Ships are expected at the docks neither too early, nor too late. If they are early, they have to wait until the current ship is off-loaded and new cargo is loaded. If they arrive too late, they use time reserved to service the next ship.

In a JIT2 scenario, the factory is close to the market, including locations with much passing trade and key account high-volume customers. McDonalds is a good

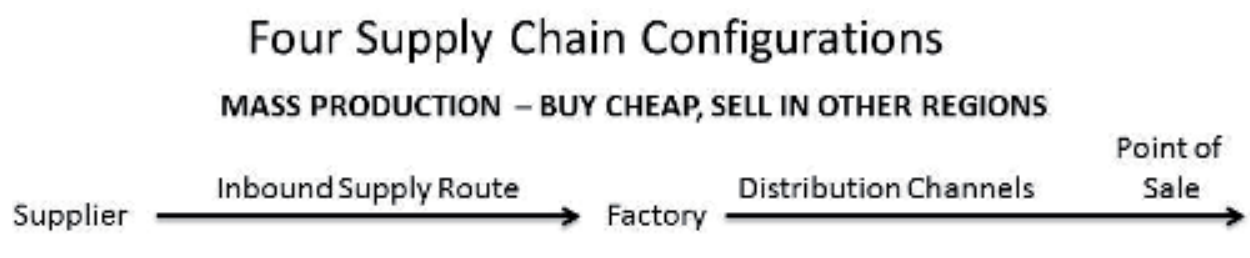

JUST IN TIME 1 - SUPPLIER IS 'CLOSE BY THE PLANT'

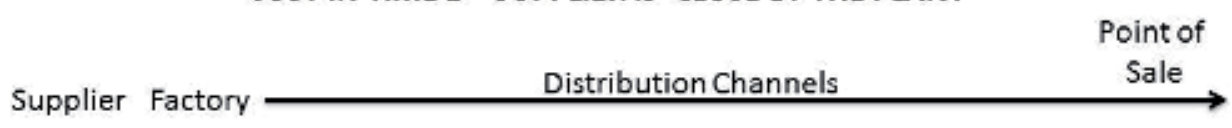

JUST IN TIME 2 - ‘CLOSE TO THE CUSTOMER’

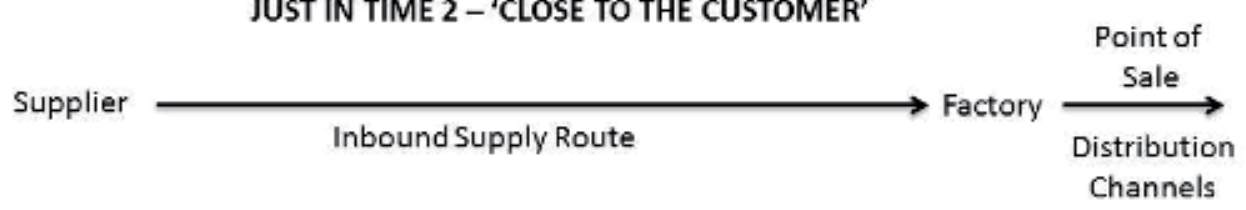

JUST IN TIME 3 - 'MAKE WHERE YOU SELL, BUY WHERE YOU MAKE

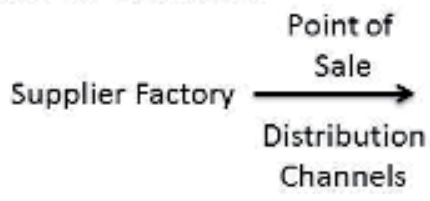

Figure 1.

Four general supply chain configurations. 
example of this strategy. Food must be fresh for people to eat it. Hence, the company cooks and assembles Big Mac's only a few meters from where they are bought. While in most cases, to reduce the purchase spend, suppliers may be faraway in low-labor-cost countries, but this is not the strategy taken by McDonalds. McDo' buy in UK and Ireland for that market. They buy in France/Belgium for that market, etc. Only two ingredients for the European market are imported in bulk. They are the sesame seeds on the buns from Mexico and the syrup for sodas that come from Atlanta.

JIT1 and JIT2 reduce pipeline stock and the number of people involved typically by half. However, this is not the $90 \%$, order of magnitude [17] reduction hoped for as a result of radical supply chain reengineering.

To achieve the $90 \%$ reduction in inventory espoused by just-in-time advocates, JIT3 is used. JIT3 is based on buying and making close to the point of sale. Many SMEs do this. A small-family-run bar or shop for example typically buys from cash and carry outlets. They may add value in their location and sell there.

\section{Pipeline liability trumps low labor cost}

This chapter proposes that a loaded supply chain is a risk to profit. This risk trumps low labor costs when demand for the product can be switched off rapidly. To sell remaining products, companies typically reduce the price. A key performance indicator is how much of total volumes ordered are sold at less than the full price. This represents over-ordering or late deliveries to points of sale. If we take Christmas trees as an example, it takes years to grow each unit. They start to have value at the beginning of October. Peak sales price is sought from November 1 through December 24. No one is buying on December 25. They have zero value from December 26. Any residual inventory in the pipeline is $100 \%$ obsolete.

Consumers may discard their tree in the street as trash. Remaining inventory must be paid for from the high margins made from goods sold. This reduces trader's overall contribution to profit. Traders may store long-term nonperishable goods in anticipation of demand build up during next season. However, they will have incurred holding costs and the older goods shall compete against the new inventory that may be sold with a higher margin.

Pipeline liability is the value of stock loaded into a supply chain. Orders placed with suppliers are translated into orders they then place on their suppliers. They in turn place orders with their suppliers. Despite this loading, in many cases, materials can be used for other orders and other clients. If this is not the case, the client will be liable for orders placed on their behalf up to a maximum level. The brand owner may buy materials directly and act as an agent to sell their materials to suppliers. They then buy back the finished units. They therefore can control supplier's material costs and can gauge the supplier's ability to efficiently transform materials into finished goods.

In just in time three (JIT3), suppliers are close to the factory and the factory is close to the market. The resulting reduction in pipeline inventory, and hence reduction in risk to profit, can support higher wages. German auto workers earn $\sim 37 € / \mathrm{hr}$., compared to equivalents in Poland on $7 € / \mathrm{hr}$. (Automotive News Europe). Making in Poland is "nearshoring." Goods made there could be transported to European sales regions within 1 or 2 days, with delivery on a regular basis. Other costs including plant costs, taxes, and indirect managerial overheads significantly may be more advantageous than German sites. Achieving apparently lower unit prices by outsourcing in relatively near lower labor cost countries can become a fallacy if delivery frequency is low. 


\section{Fast-moving consumer clothing case}

The example provided in Table 1 compares "as it is in Asia and Morocco" and a modified version of Moroccan initial conditions that result from supplier development and a changed ordering philosophy. The Asian purchase model uses the mass production supply chain configuration of long inbound supply pipelines and long outbound distribution. It requires suppliers to produce goods for 9 months with a single delivery date scheduled before the most significant seasonal sales period. The Moroccan supply chain initially takes the same delivery schedule as Asia. Modifying this to a short lead time and frequent delivery mode significantly reduces pipeline liability.

North Africa offers a relatively low-labor-cost alternative that logistically is near Europe. Moroccan workers in a clothing company were reported by a client to earn $3.80 € /$ hr., whereas Asian workers about $1.30 € /$ hr. Moroccan labor initially was $20 \%$ less efficient than Asian counterparts. Thus, more workers were required at a higher wage rate. This motivated the client to source from Asia, based on a single "headline" budget line. Various minor import and export duties apply to Asia and Morocco that negate these charges. Making goods in Morocco appears expensive by comparison. Making in Poland, with labor at around $7 € / \mathrm{hr}$. seems to double the cost compared to Morocco. Making in Germany at $37 € / \mathrm{hr}$. - hell is not that stupid? The simple answer to that, from a total cost perspective, is a counter intuitive No. Better training is required to improve workers' efficiency. That is half the issue. The other is pipeline liability and the consequent risk to profit.

This research found that using JIT3, companies could cover wages and costs up to $60 € / \mathrm{hr}$. and still make a profit, provided that productivity is equivalent to the best and providing pipeline liability dramatically is reduced. To achieve the labor productivity, benchmarking and activity training are required, together with known productivity targets.

Given a JIT3 supply chain structure, greater productivity can be achieved by better line balancing. This enables JIT3 to double productivity over mass production. Using JIT3 as a basic supply chain structure, modular product assembly to reduce hand time, sharing some assembly work with suppliers and some customer coproduction, and agile mass production, therefore, may double productivity again. This enables more revenue from more products being made and sold in less time. As a result, labor cost per unit is significantly reduced. Simultaneously, capacity per time period can be raised. Capacity utilization can be increased prior to major sale seasons. This approach avoids stockpiling finished goods that have been made months in advance, because capacity has not been created or is not available to respond to actual market demand.

Full cost analysis beyond pipeline liability, direct cost, and taxation should include other factors such as plant space costs, management overhead differential costs, legal administrative requirements and bureaucracy, healthcare and pension overheads, site security, and maintenance. These arguments are not well understood by operations managers, and even less so by managerial accountants/CFOs. This article aims to explain the logic of "making where you sell and buying where you make.” By contrast, KPMG [12] perspective is that near- and reshoring is to set up facilities near the corporate headquarters. They suggest "an 'in country for country" approach that encompasses not just manufacturing, but the location of product management and R\&D functions." That article is from the headquarters' perspective of where the market is. Based on research for this article, advice proposed is "produce within or close to both large and rapidly expanding markets." In summary, "buy, make, and sell locally." 
Sourcing and Manufacturing in the Market Region

DOI: http://dx.doi.org/10.5772/intechopen.87073

\begin{tabular}{|c|c|c|c|}
\hline & Asia pacific & Morocco & Morocco improved \\
\hline & & & weeks \\
\hline \multirow[t]{2}{*}{ Customer assembler order window (w) } & 40 & 15 & 1.6 \\
\hline & & & days \\
\hline Customer assembler order window (d) & 280 & 105 & 11.2 \\
\hline $\begin{array}{l}\text { Total number of stock pipeline liability } \\
\text { volume }\end{array}$ & $5,580,420$ & $2,092,657$ & 223,217 \\
\hline Number of work days/year & 286 & & \\
\hline Total number of days worked/year & 365 & & \\
\hline Working hours per day & 8 & & \\
\hline Number of work days/week & 5.5 & & \\
\hline Efficiency factor of Asia over EU & $0 \%$ & & \\
\hline Daily production volume & 19930 & & \\
\hline $\begin{array}{l}\text { Avg. human time needed to prepare } \\
\text { one unit }\end{array}$ & 31 & $\operatorname{mins}$ & \\
\hline Annual production demand & $5,700,000$ & units & \\
\hline Material BOM cost & $€ 4.02$ & $€ 4.38$ & $€ 4.38$ \\
\hline Transport cost percentage & $€ 0.10$ & $€ 0.06$ & $€ 0.06$ \\
\hline Transport cost unit & $€ 0.10$ & $€ 0.06$ & $€ 0.06$ \\
\hline Tax $\%$ & $10 \%$ & $0 \%$ & $0 \%$ \\
\hline Total material cost & $€ 22,433,286$ & $€ 9169,605$ & $€ 978,091$ \\
\hline Total transport cost & $€ 558,041$ & $€ 125,559$ & $€ 13,393$ \\
\hline Total tax & $€ 2,243,328$ & $€ 0.00$ & $€ 0.00$ \\
\hline Total mat cost + transport + tax & $€ 25,234657.34$ & $€ 9295165.38$ & $€ 991,484.31$ \\
\hline Number of employees & 1287 & 1545 & 1287 \\
\hline Mean cost per labor hour & $€ 1.29$ & $€ 3.86$ & $€ 3.86$ \\
\hline Total labor cost & $€ 3,786,428$ & $€ 13,634,845$ & $€ 11,359,285$ \\
\hline Working capital & $€ 26,777,757$ & $€ 22,930,011$ & $€ 12,350,770$ \\
\hline \multirow[t]{2}{*}{$\begin{array}{l}\text { Total margin (excluding any sales or } \\
\text { risk) }\end{array}$} & $€ 29,729,571$ & $€ 18,046,894$ & $€ 20,322,454$ \\
\hline & & $61 \%$ & $68 \%$ \\
\hline \multirow[t]{2}{*}{ Total margin clear of stock risk } & $€ 7,296,285$ & $€ 8,880,991$ & $€ 19,344,363$ \\
\hline & & $122 \%$ & $265 \%$ \\
\hline
\end{tabular}

Table 1.

Summary of mass to $\mathrm{JIT}_{3}$ financial comparisons for fast-moving consumer goods.

\section{Conclusions}

Buy locally, make locally, and sell locally—-the so-called "Glocal" strategy operates by making the goods tailored for local markets. The focus should be on where the markets are rather than on the headquarters. 
Mass production configuration supply chains are operated because it seems to be obvious. Buy cheap and sell expensive. However, pipeline liability from loaded inbound supply and outbound distribution chains creates increased end-to-end times. This reduces the flexibility to respond to market changes. If the good is stable in terms of technology and design specification, with high demand and unrestricted supply, the strategy may enable organizations to achieve viable cash flow. Taking an end-to-end perspective, working capital is excessive and represents a significant risk to profit if the sales window closes.

JIT1 and JIT2 reduce the amount of goods in the supply chain approximately halfway between mass production and JIT3. JIT1 can make use of low-cost material and labor to produce a finished good. Logistics infrastructure may be used to transport finished goods to other regions where premium sales prices justify the extra risk from a loaded distribution network. If the goods are made and supplied to other corporations as part of agreed volume contracts, the risk to profit is minimized.

JIT2 can use low-cost parts from low-cost countries. Using nearshoring for final assembly and offshoring for part production is a strategy noted near Monterrey, Mexico. Between the city center and the airport, the majority of the companies are Chinese owned. Parts are produced in China. Finished goods are assembled in Mexico from these parts. Since the majority of the value add is undertaken in NAFTA, duty among Mexico, the USA, and Canada is avoided.

Risk to profit needs to be minimized. This is achieved by sacrificing a loaded supply chain that is filled with millions of examples of cheap goods. Instead, emphasis is placed on productive labor that is comparatively cheap compared to home markets, but may be much more expensive compared to remote lowlabor-cost countries. In Europe, the highest salaries tend to be within the triangle Liverpool, Hamburg, and Paris. The further East and South the production site is located, the lower the general factory wage tends to be. A one-day distribution circumference can determine likely "nearshore" production locations. While total cost per unit may seem to increase, focusing on doubling the productivity and doubling it again should be primary design team and operations' objectives. This can be achieved by simplifying the product, reducing hand time to make them, worker training, supplier, and customer co-production.

A fast-moving consumer goods case supplying own-branded sport clothing outlets is presented. Reduced end-to-end pipeline times were achieved via adopting buy, make, and sell close to market point of sales. Now, redundant continental and regional distribution centers can be converted from cost centers to profit centers by undertaking "late configurability" value-adding activities. The products must be designed to permit this and must become part of the market offering. Premium prices may be commanded, for example, The Bear Factory.

The summary shown in Table 1 is an example of financial effects of JIT3 versus mass production provided in Section 9 "Pipeline liability trumps low labor cost." Financial analysis is shown highlighting critical factors that need to be managed that areforce multipliers for the supply chain configurations.

The analysis given in Table 1 shows the ability of the client to reallocate work to Morocco from Asia. They have understood the potential risk to profit from having a loaded supply chain, and significant discounting that was required to sell remaining goods after the end of the sales window. Total margin clear of stock risk is significantly higher for the baseline Morocco "near-production" scenario. The revised plan with more frequent deliveries doubles more than that. The client adopted JIT3 strategies, making closer to reduce pipeline inventory yet not too close that skyrocket labor wages. JIT3 can be enhanced with agile/mass customization approaches. This can enable the corporation to delay the point of variation and facilitate assemble-to-order strategies. 
Making in country, or trading region, primarily for sales, does not prohibit sales abroad, except where they are contractually bound to do so by intellectual property owners. Excess production beyond local market absorption may be exported to other market regions. This approach differs from make in low-cost countries exclusively for export to other, richer, markets.

Specification and legal compliance in sales regions imposes two options: comply with each market requirement separately or supersede requirements of both home and remote regions.

Mass production could yield higher margins; however, this strategy has higher potential risk of obsolescence that would yield the smallest total margin. The amount of profit free from pipeline obsolescence risk is significantly higher than JIT3 supply chain configurations. Mass production in remote low-labor-cost countries would suit "pile 'em high and sell 'em to everyone." This also suits undeveloped markets and monopoly technology scenarios. The results in the table indicate that nearshoring in inefficient plants yields the smallest total margin, while ensuring more than $20 \%$ higher minimum margin as a result of reduced pipeline liability. Optimizing nearshoring performance maximizes risk-free total margin, at least $250 \%$ more than the mass production model. The strategic choices must be re-evaluated as BOM cost approaches zero and as BOM costs become significantly more than total labor costs.

This model is static rather than stochastic. Static models are viable when distance to market, order-fulfilment lead time, delivery duration, and price and productivity are consistent.

\section{Author details}

David J. Newlands* and Fawaz Baddar Al Hussan

IÉSEG School of Management (LEM, CNRS 9221), Lille, France

*Address all correspondence to: d.newlands@ieseg.fr

IntechOpen

(C) 2019 The Author(s). Licensee IntechOpen. This chapter is distributed under the terms of the Creative Commons Attribution License (http://creativecommons.org/licenses/ by/3.0), which permits unrestricted use, distribution, and reproduction in any medium, provided the original work is properly cited. (cc) BY 


\section{References}

[1] Khan SAR. Introductory Chapter: Introduction of Green Supply Chain Management [Online First]. Rijeka: IntechOpen; 2018. DOI: 10.5772/ intechopen.81088. Available from: https://www.intechopen.com/onlinefirst/introductory-chapter-introductionof-green-supply-chain-management

[2] Khan SAR, Dong Q, Zhang Y, Khan SS. The impact of green supply chain on enterprise performance: In the perspective of China. Journal of Advanced Manufacturing Systems. 2017;16(3):263-273

[3] Khan SAR, Dong Q, Zhang Y. Role of $A B C$ analysis in the process of efficient order fulfilment: Case study. Advanced Engineering Forum. 2017;23(7):114-121

[4] Khan SAR, Zhang Y. Introductory Chapter: Purchasing and Supply Management [Online First]. Rijeka: IntechOpen; 2019. DOI: 10.5772/ intechopen.85380. Available from: https://www.intechopen.com/onlinefirst/introductory-chapter-purchasingand-supply-management

[5] Brad S, Bogdan M, Emilia B, Mircea F. Environmentally sustainable economic growth. Amfiteatru Economic Journal. 2016;18(42):446-460. The Bucharest University of Economic Studies, Bucharest. ISSN: 2247-9104

[6] Robert P. New Minimum Wage Too High, Business Owner Says; 12 August 2015. Available from: http://www. bbc.com/news/business-33885991 [Accessed: 12 August 2015]

[7] Lamming R. Beyond Partnership: Strategies for Innovation and Lean Supply. London: Prentice Hall International; 1993

[8] Andrew A. Companies increasingly turning to US cities for their outsourcing locations. 2015. Available from: http://www.supplymanagement. com/news/2015/companiesincreasingly-turning-to-us-cities-fortheir-outsourcing-locations [published 28 May, Site Accessed: 28 May 2015]

[9] Marino D. Keeping Manufacturing in the UK Even More Important than Reshoring'. 2015. Available from: http://www.supplymanagement.com/ news/2015/keeping-manufacturingin-the-uk-even-more-important-thanreshoring?utm_source=Adestra\&utm medium=email\&utm_term [published 16 May, Site Accessed: 18 May 2015]

[10] Friedman TL. The World Is Flat: The Globalized World in the Twenty-First Century Paperback. 2Rev ed. Penguin; 2007

[11] CCTV News. Trans-Eurasia Railway Connects China with Europe. 2013.

Available from: https://www.youtube. $\mathrm{com} /$ watch?v=5Z0kT8P6XDE

[12] KPMG. Production's Coming Home: What Companies Need to Know About Reshoring. 2014. Available from: http://www.kpmg.com/Global/en/ IssuesAndInsights/ArticlesPublications/ ConsumerCurrents/Pages/productionscoming-home.aspx

[13] Automotive News. Ford Opens Engine Plant in Russia to Reduce Dependency on Imports. 2015. Available from: http://europe.autonews.com/ article/20150904/ANE/150909931/ ford-opens-engine-plant-inrussia-to-reduce-dependency-onimports?cciid=email-ane-daily

[14] Nelson D, Mayo R, Moody P. Powered by Honda: Developing Excellence in the Global Enterprise. New York: John Wiley \& Sons; 1998

[15] Newlands D. Supply Chain Games, Operations Management, Vol 38, No. 4, Toyota Beefs up U.S build. August Purchasing, 15 December 1994. 2012 
Sourcing and Manufacturing in the Market Region

DOI: http://dx.doi.org/10.5772/intechopen.87073

[16] Treece J B. Nissan Purchasing Boss

Embraces Common Sense. Heresy!

Quoting Interview Text from Rebecca

Vest; North American Purchasing Head;

3 August 2011. Available from: http://

www.autonews.com/article/20110803/

BLOG06/308039990/1129

[17] Hammer M, Champy J.

Reengineering the Corporation: A

Manifesto for Business Revolution.

London: Nicholas Brealey Publishing

Ltd; 1993 



\title{
Supply Management of Rental Housing Facilities: Effect of Changes in the Quality of Housing Equipment in the Tokyo Housing Rental Market
}

\author{
Takeshi So and Chihiro Shimizu
}

\begin{abstract}
The Tokyo housing market is considered to be one of the fastest evolving markets in the world. In recent years, functions such as TV intercoms, bathroom dryers, system kitchens, and toilets with washlets, which are not often seen in European and US houses, have spread and become common in Japanese houses. Under such circumstances, the importance of various equipment ancillary to housing, together with the location and quality of the building, is increasingly a factor for determining the value of housing in Tokyo. This is because when a new product appears, the old product is ordered to be withdrawn from the market, or its commodity value is greatly depreciated. This study measured the economic value of improving the quality of housing with new equipment in the Tokyo rental housing market and clarified the extent of economic depreciation that is occurring due to obsolescence. According to the obtained results, new functions are being added sequentially to the Japanese rental housing according to the age of the building, and these functions are non-negligible in the determination of housing rent, even when compared with location and building structure. The effect of obsolescence due to the addition of new functions was roughly- $5 \%$.
\end{abstract}

Keywords: quality change, housing equipment, hedonic approach, depreciation, obsolescence, cohort effect

JEL classification: R31—housing supply and markets; R32—other spatial production and pricing analysis

\section{Introduction}

In the past, Japanese houses were ridiculed as being "rabbit hutches" as they were smaller in scale, lower in quality, and shorter in average service life than those of Western countries, and examples were often given illustrating Japan as having the worst residential environment among major advanced countries. However, after 
the period of high economic growth since the chaotic postwar period, this environment has already greatly improved. In recent years high-performance housing stock has accumulated, and housing with functions not found in other countries have become common.

Needless to say, when attempting an analysis of a housing market, it is necessary to fully understand the characteristics of the country. Below, we set out the reasons that have led to the false perception of Japanese housing still belonging to the era when they were ridiculed as rabbit hutches.

Although commonalities can be found in many parts of the Japanese housing market in comparison with the European and US housing markets, the following heterogeneity is conceivable as the postwar historical origin is different. It is possible that these are the cause of many misunderstandings.

In Japan, many houses were destroyed due to the large-scale air raids during the Second World War, not only in metropolitan areas but also in regional cities. In particular, a large number of houses were destroyed in the Tokyo metropolitan area, ${ }^{1}$ and very-low-quality houses were built in a disorganized manner to satisfy the urgent housing demand in the chaotic postwar period. In the so-called high economic growth period that began in the mid-1950s, such houses were rapidly upgraded as large numbers of apartment buildings came up throughout Japan. ${ }^{2}$ In addition, the drastic change in Japanese lifestyle through the rapid economic growth triggered the renewal of old housing stock by Westernizing the traditional housing style of Japan.

The private sector led construction to realize such a large-scale housing supply because the public sector was saddled with the large financial burden of postwar reconstruction. In particular, the government established a personal loan system to promote housing investment by households, and as a result, the ownership rate in postwar Japan significantly increased in comparison to before the war. Furthermore, as the supply of public housing was limited, a dedicated housing market for single-person renters formed in the rental housing market, which was rarely seen in Europe and the United States.

As a result of these short-term housing renewals, Japanese housing was brought into a state where their style, quality, and housing equipment were greatly different depending on the period of construction. In addition, due to natural disasters such as the Great Hanshin earthquake ${ }^{3}$ and the Great East Japan earthquake, ${ }^{4}$ housing earthquake resistance and other legal regulations have been successively

\footnotetext{
1 The Bombing of Tokyo was a series of firebombing air raids in Second World War. This was conducted on the night of 9-10 March 1945, 16 square miles $\left(41 \mathrm{~km}^{2}\right)$ of central Tokyo were destroyed, leaving an estimated 100,000 civilians dead and over 1 million homeless.

${ }^{2}$ Although the improvement of low-quality stock developed during the postwar reconstruction period has been carried out in many areas, some areas remain in which stock has not improved, referred to as "high density wooden structure areas." Since these areas are vulnerable to earthquake disasters and so on, improvement is urgently required.

3 The Great Hanshin earthquake, or Kobe earthquake, occurred on January 17, 1995 in the southern part of Hyōgo Prefecture, Japan, when combined with Osaka, known as Hanshin. Up to 6434 people lost their lives.

4 The Great East Japan Earthquake occurred on March 11, 2011. The report from the Japanese National Police Agency report in 2018 confirms 15,896 deaths, 6157 injured, and 2537 people missing across twenty prefectures.
} 
strengthened, thereby rapidly increasing the performance requirements of housing. ${ }^{5}$

This history is also closely related to the shortness of service life, which is a characteristic of the previously ridiculed Japanese houses. Several reasons can be envisaged to explain the short service life of Japanese houses, but the two most influential factors are considered to be the urgent task of promoting the renovation of low-quality housing stock that was built to temporarily compensate for the housing shortage after the war and the fact that the stock renewal was promoted by strengthening public regulations due to large-scale earthquakes and other disasters.

In addition, the high urban renewal rate can also be cited as a reason. In the rapid economic growth of postwar Japan, the main industrial structure shifted from primary to secondary industry in a single stroke, and urbanization was promoted throughout the country in the 1970s by developing highway and railway networks across the country, known as "Japanese archipelago remodeling." In the 1980s, a policy was developed to transform the industrial structure, which was centered on secondary industry to tertiary industry. The transformation of Tokyo into an international financial center was a symbolic policy, and against this background, redevelopment rapidly advanced in major cities. Under such circumstances, the conversion of building use of even physically usable housing into offices, commercial facilities, and so on was promoted through rebuilding, and the advancement of land use was promoted [1].

As a result, it can be said that the average service life of housing seen throughout the stock as a whole has been shortened over a long period.

In addition to these features, it should be noted that the speed of technological innovation in Japanese housing is fast. "Technological innovation" here refers not only to the improvement of productivity on the manufacturing side but also the significant improvement of household welfare levels through the release of new products developed by R\&D. In recent years, smart houses utilizing IOT and so on have become symbolic of advancing technology, but functions such as TV intercoms, bathroom dryers, system kitchens, and toilets with washlets, which are not often seen in European and American houses, have become common functions in Japanese houses and have greatly improved household living standards.

However, in a market where products with such new features arrive so quickly, the speed of obsolescence also increases. In these markets, when a new product appears, the old product is ordered to be withdrawn from the market, or its commodity value is greatly depreciated, that is, the service life of products is shortened.

This study aims to measure the economic value of the functions of housing with new quality in the rental housing market in Tokyo, where technological advancement has been the greatest, and to clarify how much economic depreciation is occurring due to obsolescence. In Section 2, we present the model and the framework for empirical analysis together with the data, and in Section 3, we present the estimated results. According to the obtained results, new functions are being added sequentially to Japanese rental housing according to the age of the building, and these functions are non-negligible in the determination of housing rent, even when compared with location (LC) and the building structure (ST). The effect of obsolescence due to the addition of new functions was roughly-5\%. In Section 4, we summarize the results by way of a conclusion.

\footnotetext{
${ }^{5}$ In response to major disasters, the Japanese Building Standards Law was revised. The first major revision of the Building Standards Law was in 1991, and the revision strengthened the earthquake resistance standards. After that, following the two great earthquakes, the standards strengthened.
} 


\section{Empirical analysis: data and estimation model}

\subsection{Literature review}

A technique known as the hedonic approach is effective to decompose prices of commodities corresponding to different qualities. Since the hedonic approach theoretically depicts the behavior of suppliers and consumers in a market with diverse quality and presents a framework for empirical analysis, it is possible to approximately measure the household limit shadow price for new functions and to identify economic deterioration accompanying obsolescence [2, 3].

Generally, the construction of household selection models in the residential market faces many difficulties compared to regular commodities and service markets. Not only is consumption expenditure high for housing, but consumers are also troubled by its highly nonuniform nature. Even when located in the same place, prices vary depending on the quality of housing, and even if the buildings are of the same quality, prices vary depending on the location. Furthermore, since housing has durability, depreciation has to be taken into consideration.

In such a market, the law of one price assumed by traditional pricing theory cannot be applied. Furthermore, the application of a model that deals with differentiated products as analyzed by Lancaster [4] is not effective both theoretically and in empirical analysis. Accordingly, Rosen [5] theoretically clarified the type of market mechanism that is generated when commodity price data are a bundle of such attributes. Specifically, the relationship between the offer function of the commodity supplier, the bid function of the commodity consumer, and the market price function established by the equilibrium of these is closely examined, and the market price is characterized from the behavior of consumers and producers [6].

However, when attempting to estimate the hedonic function, we face various difficulties. The first is the existence of unobservable variables, the so-called omitted variable bias problem [7]. In general, in the estimation of a hedonic function for the housing market, only the location and building attributes, which are easy to obtain, are taken into consideration. However, it is also easy to envisage that the actual market price of housing will change depending on the environment surrounding the house and the various kinds of performance of the building.

As for variable selection in the estimation of hedonic functions in Tokyo's rental housing market, Nishi et al. [8] have conducted an exhaustive survey of the previous research. Nishi et al. [8] pointed that the housing amenities used in hedonic analyses are categorized as "location or accessibility," "housing features," and "site advantages." This paper is focused on housing features, because they can be reflected in the rent due to the technological progress in the information systems and supply management.

Accessibility is defined as the "main accessibility related to commuting." Housing features are defined as "amenities that can be changed by landlords." Accessibility and housing features are the basic characteristics used as explanatory variables in hedonic models and are widely used in previous studies $[2,6,9,10]$.

Site advantages have also been researched recently using variables calculated using geographical information system or GIS [11, 12]. Shimizu [11] demonstrates that the environment surrounding housing is important in the case where house prices are determined by building use conditions and the characteristics of neighboring residents and suggests that in the case such variables are not taken into consideration and the estimated statistics of the hedonic function lack robustness. Nishi et al. [8] also show that there is a similar problem with estimated statistics when housing equipment is not taken into consideration. Fuerst and Shimizu [13] show that in the new condominium market in Tokyo, the offered value for highly novel 
functionality such as environmental performance differs greatly when taking the household's annual income into account.

As can be understood from these facts, attention must be given to the kind of variables that are used in estimating the hedonic function. According to Nelson [14], housing characteristics to be considered in function estimation are classified as follows.

Excluding characteristics related to traffic convenience, Nelson [14] considers it possible to categorize the positional characteristics of housing into housing equipment and location. Of these, "housing equipment" is variable and depends on the owner of the house, and "location" is an element that cannot be changed. Meanwhile, Chau and Chin [15] and Shimizu [11] add neighborhood characteristics.

In addition to location and building structure, this study classifies housing equipment into equipment ancillary to the room (room equipment (RE)) and to the building (building equipment (BE)) and also takes the conditions of the contract into account to estimate their marginal price effect by estimating the hedonic function and to estimate the extent of obsolescence caused by the appearance of products with new performance.

\subsection{Data}

Since the latter half of the 1990s, the use of the Internet for real estate advertising has expanded rapidly in Japan, and websites dealing with a large amount of rental advert data have been developed. This study uses the data on homes managed by LIFULL Co., Ltd. which is a major real estate portal site. ${ }^{6}$

Multiple real estate companies post concurrent advertisements for the same property on the real estate website, so we eliminated the duplicates from the data by grouping them by the criteria of address, property name, and room number. ${ }^{7}$ Furthermore, we independently assigned daytime railway travel time from Tokyo station to the nearest station to the property (minutes), which was not included in the data posted on the portal.

Since the aim of this study is to identify the effect due to the addition of new functions over time, we hypothesize that the price structure will change according to the period of construction. ${ }^{8}$ Data were segmented into the following three stocks:

- Old stock: built between 1968 and 1981

- Main stock: built between 1982 and 1999

- New stock: built between 2000 and 2018

\footnotetext{
${ }^{6}$ It should be noted that the data used are only for adverts appearing as of October 2018, and do not represent the situation of the entire housing stock.

7 Analytical data were prepared using the following conditions. (a) The average and standard deviation of the rent was calculated, and data of a value that is the average plus twice the standard deviation $(249,000$ yen $)$ were deleted. At the same time, data on rents of 30,000 yen or less that market participants recognize as the lower limit of market rent were deleted (this level is a value larger than the average minus twice the standard deviation). (b) Data on floor area less than $15 \mathrm{~m}^{2}$ (rental housing of floor area less than this is generally considered unsuitable for habitation) or over $100 \mathrm{~m}^{2}$ (generally housing of over $100 \mathrm{~m}^{2}$ is for the very wealthy) were deleted. (c) Data on housing exceeding 50 years of age (built before 1967), which were exceedingly few, were deleted.

${ }^{8}$ When the market structure changes, it is necessary to construct a model to absorb the change $[16,17]$. In addition, Karato et al. [18] propose an estimation method to discriminate between aging, period of construction, and time effects. In this research, we avoided these problems by using cross-sectional data and simply classified it into three period categories according to age.
} 
Earthquake resistance standards were greatly revised in 1981 according to the Building Standards Act, which stipulates building quality in Japan, and the earthquake resistance of buildings differs greatly according to whether they were built in or before 1981 or in or after 1982; buildings were therefore categorized using 1981 as a basis. There was also a major change in earthquake resistance standards in 2000, so this was also used as the standard for a category. In addition, the data used are for the 23 wards of Tokyo where a large volume of housing stocks was supplied due to a large population inflow.

As a result of this process, 53,550 data points were acquired as data for analysis. ${ }^{9}$

\subsection{Estimation model}

A general hedonic model can be expressed as

$$
y=\log p=\sum_{i} \beta_{i} x_{i}+\alpha \#
$$

where $y$ is the explanatory variable, $p$ is the housing rent, $x_{i}$ is the explanatory variable (housing characteristic), and $\beta_{i}$ and $\alpha$ are the estimation parameters.

In this study, in addition to the commonly used location and building structure, housing equipment was added to the estimation of the hedonic function for the housing market. Specifically, we classified housing equipment into equipment ancillary to the room (room equipment) and equipment ancillary to the building (building equipment) and took the conditions of contract (CC) into account to construct a hedonic function.

Eq. (1) can be rewritten as follows:

$$
\log p=\alpha+\sum_{j} \beta_{j}^{L C} L C_{j}+\sum_{k} \beta_{k}^{S T} S T_{k}+\sum_{l} \beta_{l}^{R E} R E+\sum_{m} \beta_{m}^{B E} B E_{m}+\sum_{n} \beta_{n}^{C C} C C_{n} \#
$$

Here, the actual estimation formula can be expressed as follows:

$$
\begin{aligned}
\# \log p_{i t}= & \beta_{0}+\beta_{1} \cdot A g e_{i t}+\sum_{j=1}^{3} \beta_{2 j} \cdot S T_{j i t}+\beta_{3} \cdot S_{i t}+\beta_{4} \cdot T S_{i t}+\beta_{5} \cdot D T_{i t} \\
& +\sum_{k=1}^{5} \beta_{6 k} \cdot S t r_{k i t}+\sum_{l=1}^{23} \beta_{7 l} \cdot W_{l i t}+\sum_{m=1}^{2} \beta_{8 m} \cdot T R_{m i t} \\
& +\sum_{n=1}^{20} \beta_{9 n} \cdot R E_{m i t}+\sum_{p=1}^{15} \beta_{10 p} \cdot B E_{p i t}+\sum_{q=1}^{9} \beta_{11 q} \cdot C C_{q i t}+\varepsilon_{i t}
\end{aligned}
$$

In Eq. (1), $\ln p_{i t}$ represents the log rent for $i$ property at time $t$ (October 2018). Age $_{i t}$ is the years since construction, $S T_{j i t}$ is the period of construction dummy (old/ main/new), $S_{i t}$ is the floor area, $T S_{i t}$ is the number of minutes on foot from the nearest station, $D T_{i t}$ is the number of minutes by train from Tokyo station, $S_{t} r_{j i t}$ is the structure dummy, $W_{\text {mit }}$ is the ward dummy, $T R_{h i t}$ is the high-rise condominium and ground floor room position dummy, $R E_{k i t}$ is the room equipment dummy, $B E_{k i t}$ is the building equipment dummy, $C C_{k i t}$ is the contract condition (CC) dummy, $\beta_{0}$ is a constant term, and $\varepsilon_{i t}$ is an error term.

\footnotetext{
9 The number of old stock data for 1968-1981 was relatively small at 4868, the number of properties built between 1992 and 1999 was 19,982, and the number of properties built between 2000 and 2018 was 28,700 .
} 
Supply Management of Rental Housing Facilities: Effect of Changes in the Quality of Housing... DOI: http://dx.doi.org/10.5772/intechopen.86163

\section{Verification analysis}

\subsection{Descriptive statistics for analysis data}

Before analysis, we calculated the descriptive statistics of the data to be analyzed (Table 1). From the descriptive statistics, there are several features as follows, depending on the period of construction:

\begin{tabular}{|c|c|c|c|c|c|}
\hline Variable & Type & Mean & Std. dev. & Min. & Max. \\
\hline Monthly rent & All & 94,779 & 34,873 & 30,000 & 249,000 \\
\hline \multirow[t]{4}{*}{ (JYE) } & Old stock & 84,968 & 30,631 & 30,000 & 240,000 \\
\hline & Main stock & 85,305 & 32,566 & 30,000 & 249,000 \\
\hline & New stock & 103,040 & 34,994 & 45,000 & 249,000 \\
\hline & New/old & $121.3 \%$ & $114.2 \%$ & $150.0 \%$ & $103.8 \%$ \\
\hline Floor space & All & 31.3 & 13.4 & 15.0 & 100.0 \\
\hline \multirow[t]{4}{*}{$\left(\mathrm{m}^{2}\right)$} & Old stock & 32.5 & 12.4 & 15.0 & 91.4 \\
\hline & Main stock & 32.0 & 15.3 & 15.0 & 100.0 \\
\hline & New stock & 30.6 & 12.1 & 15.0 & 99.5 \\
\hline & New/old & $94.3 \%$ & $97.7 \%$ & $100.0 \%$ & $108.9 \%$ \\
\hline Monthly rent $/ \mathrm{m}^{3}$ & All & 3192 & 806 & 988 & 8134 \\
\hline \multirow[t]{4}{*}{ (JYE) } & Old stock & 2717 & 668 & 1076 & 6528 \\
\hline & Main stock & 2864 & 701 & 988 & 7535 \\
\hline & New stock & 3501 & 766 & 1165 & 8134 \\
\hline & New/old & $128.9 \%$ & $114.8 \%$ & $108.3 \%$ & $124.6 \%$ \\
\hline Age of unit & All & 18.5 & 12.7 & 0.0 & 50.0 \\
\hline \multirow[t]{4}{*}{ (year) } & Old stock & 42.3 & 3.8 & 37.0 & 50.0 \\
\hline & Main stock & 27.4 & 4.4 & 19.0 & 36.0 \\
\hline & New stock & 8.3 & 5.5 & 0.0 & 18.0 \\
\hline & New/old & $19.7 \%$ & $144.0 \%$ & $0.0 \%$ & $36.0 \%$ \\
\hline Time to the nearest station & All & 7.7 & 4.6 & 0.6 & 41.0 \\
\hline \multirow[t]{4}{*}{ (minutes) } & Old stock & 7.4 & 4.4 & 1.0 & 41.0 \\
\hline & Main stock & 8.1 & 4.8 & 1.0 & 40.0 \\
\hline & New stock & 7.4 & 4.4 & 0.6 & 38.0 \\
\hline & New/old & $99.4 \%$ & $98.8 \%$ & $62.5 \%$ & $92.7 \%$ \\
\hline Time to Tokyo station & All & 27.2 & 8.6 & 1.0 & 48.0 \\
\hline \multirow[t]{4}{*}{ (minutes) } & Old stock & 26.5 & 8.3 & 4.0 & 48.0 \\
\hline & Main stock & 28.8 & 8.1 & 4.0 & 48.0 \\
\hline & New stock & 26.2 & 8.8 & 1.0 & 48.0 \\
\hline & New/old & $99.1 \%$ & $105.4 \%$ & $25.0 \%$ & $100.0 \%$ \\
\hline
\end{tabular}

Number of observations (all) $=53,550$

Table 1.

Descriptive statistics. 
- There is little difference between old and main stocks in average rent, but it is about $20 \%$ higher for new stock than the old stock.

- There is no significant difference in the average floor area, the number of minutes by foot from the nearest station, and the number of minutes by train from Tokyo station.

- Concerning the years since construction, the average of the total is 18.5 years and the standard deviation is 12.7 years, and the average value and standard deviation by construction date are consistent with the classification.

Based on these features, there is found to be little difference between the physical space distribution due to the period of construction and only the building quality changes.

\subsection{Distribution of analysis data by ward}

Next, we examined the distribution of old/main/new stock for each of the 23 wards (Table 2). The ratio of new stock ratio exceeds $70 \%$ in Chiyoda, Chuo, and Minato wards, which make up the center of Tokyo. As previously mentioned, the probability of large-scale redevelopment and so on being carried out increases for more urban areas, which may have caused this result due to active stock renewal. ${ }^{10}$

Outside the three wards of the city center, the ratio of new stock is over $70 \%$ in Taito and Sumida wards and over $60 \%$ in Koto and Shinagawa wards, but this may be due to the supply of large-scale high-rise condominiums due to the relaxation of regulations in the 1990s. The ratio of new stock in other wards is around 50\% (Table 3).

\subsection{Ancillary equipment rate by period of construction}

Table 4 shows the ancillary equipment rate by period of construction. Equipment was classified into that ancillary to the room, ancillary to the building, and conditions of contract. ${ }^{11}$

Housing equipment items are arranged in descending order of ancillary rate in all samples, and a comparison is made between old, main, and new stocks.

In terms of room equipment, the five items (i) air conditioning, (ii) hot water supply, (iii) indoor washing machine area, (iv) separate bath and toilet, and (v) flooring have a high ancillary rate of over $80 \%$. The equipments for which there is a large difference in ancillary rate between old and new stocks (ancillary rate increased) are bathroom dryer (+62.6\%), system kitchen $(+50.7 \%)$, toilet with washlet $(+43.4 \%)$, indoor washing machine area $(+38.0 \%)$, and separate washroom $(+36.0 \%)$.

In terms of building equipment, the ancillary rate is over $50 \%$ for the bicycle parking lot and fiber optic Internet. The equipment for which there is a large difference in ancillary rate between old and new stocks (ancillary rate increased) is automatic entrance door $(+65.0 \%)$, TV intercom $(+55.4 \%)$, delivery locker

10 This result is consistent with the results of Shimizu et al. [1].

11 Although it seems that the housing equipment ancillary to the room and building fluctuates somewhat due to renewal and so on, the equipment seems to be influenced by the construction date. Attention must be given to the fact that contract conditions may be changed regardless of the construction date because physical investment is unnecessary. 
Supply Management of Rental Housing Facilities: Effect of Changes in the Quality of Housing... DOI: http://dx.doi.org/10.5772/intechopen.86163

\begin{tabular}{|c|c|c|c|c|c|c|c|c|c|}
\hline \multirow[b]{2}{*}{ Item } & \multicolumn{4}{|c|}{ Number of observations } & \multicolumn{5}{|c|}{ Ratio } \\
\hline & Total & $\begin{array}{l}\text { Old } \\
\text { stock }\end{array}$ & $\begin{array}{l}\text { Main } \\
\text { stock }\end{array}$ & $\begin{array}{l}\text { New } \\
\text { stock }\end{array}$ & Total & $\begin{array}{l}\text { Old } \\
\text { stock }\end{array}$ & $\begin{array}{l}\text { Main } \\
\text { stock }\end{array}$ & $\begin{array}{l}\text { New } \\
\text { stock }\end{array}$ & New-old \\
\hline \multicolumn{10}{|l|}{ Room equipment } \\
\hline Air conditioning & 49.088 & 4029 & 17.883 & 27.176 & $91.7 \%$ & $82.8 \%$ & $89.5 \%$ & $94.7 \%$ & $11.9 \%$ \\
\hline Hot water supply & 44.841 & 3879 & 16.961 & 24.001 & $83.7 \%$ & $79.7 \%$ & $84.9 \%$ & $83.6 \%$ & $3.9 \%$ \\
\hline Indoor WM area & 43.954 & 2663 & 14.696 & 26.595 & $82.1 \%$ & $54.7 \%$ & $73.5 \%$ & $92.7 \%$ & $38.0 \%$ \\
\hline $\begin{array}{l}\text { Separate bath and } \\
\text { toilet }\end{array}$ & 43.943 & 3447 & 12.851 & 27.645 & $82.1 \%$ & $70.8 \%$ & $64.3 \%$ & $96.3 \%$ & $25.5 \%$ \\
\hline Flooring & 43.269 & 3364 & 14.915 & 24.990 & $80.8 \%$ & $69.1 \%$ & $74.6 \%$ & $87.1 \%$ & $18.0 \%$ \\
\hline Balcony & 40.851 & 3204 & 15.276 & 22.371 & $76.3 \%$ & $65.8 \%$ & $76.4 \%$ & $77.9 \%$ & $12.1 \%$ \\
\hline System kitchen & 27.758 & 1093 & 5666 & 20.999 & $51.8 \%$ & $22.5 \%$ & $28.4 \%$ & $73.2 \%$ & $50.7 \%$ \\
\hline $\begin{array}{l}\text { Separate } \\
\text { washroom }\end{array}$ & 26.292 & 1412 & 6221 & 18.659 & $49.1 \%$ & $29.0 \%$ & $31.1 \%$ & $65.0 \%$ & $36.0 \%$ \\
\hline 1 gas stove & 25.300 & 1416 & 6396 & 17.488 & $47.2 \%$ & $29.1 \%$ & $32.0 \%$ & $60.9 \%$ & $31.8 \%$ \\
\hline Washlet & 23.221 & 1089 & 3265 & 18.867 & $43.4 \%$ & $22.4 \%$ & $16.3 \%$ & $65.7 \%$ & $43.4 \%$ \\
\hline Bathroom dryer & 20.322 & 186 & 1077 & 19.059 & $37.9 \%$ & $3.8 \%$ & $5.4 \%$ & $66.4 \%$ & $62.6 \%$ \\
\hline 2 gas stoves & 18.632 & 1081 & 3304 & 14.247 & $34.8 \%$ & $22.2 \%$ & $16.5 \%$ & $49.6 \%$ & $27.4 \%$ \\
\hline Reheating bath & 15.127 & 1268 & 3459 & 10.400 & $28.2 \%$ & $26.0 \%$ & $17.3 \%$ & $36.2 \%$ & $10.2 \%$ \\
\hline $\begin{array}{l}\text { Washroom with } \\
\text { shower }\end{array}$ & 12.678 & 364 & 1764 & 10.550 & $23.7 \%$ & $7.5 \%$ & $8.8 \%$ & $36.8 \%$ & $29.3 \%$ \\
\hline Own house rental & 7187 & 497 & 1588 & 5102 & $13.4 \%$ & $10.2 \%$ & $7.9 \%$ & $17.8 \%$ & $7.6 \%$ \\
\hline IH stovetop & 6623 & 215 & 2653 & 3755 & $12.4 \%$ & $4.4 \%$ & $13.3 \%$ & $13.1 \%$ & $8.7 \%$ \\
\hline Walk-in closet & 3694 & 88 & 235 & 3371 & $6.9 \%$ & $1.8 \%$ & $1.2 \%$ & $11.7 \%$ & $9.9 \%$ \\
\hline Counter kitchen & 3409 & 70 & 516 & 2823 & $6.4 \%$ & $1.4 \%$ & $2.6 \%$ & $9.8 \%$ & $8.4 \%$ \\
\hline With loft & 2110 & 19 & 754 & 1337 & $3.9 \%$ & $0.4 \%$ & $3.8 \%$ & $4.7 \%$ & $4.3 \%$ \\
\hline Underfloor heating & 1147 & 8 & 87 & 1052 & $2.1 \%$ & $0.2 \%$ & $0.4 \%$ & $3.7 \%$ & $3.5 \%$ \\
\hline \multicolumn{10}{|l|}{$\begin{array}{l}\text { Building } \\
\text { equipment }\end{array}$} \\
\hline Bicycle parking lot & 33.795 & 2096 & 11.385 & 20.314 & $63.1 \%$ & $43.1 \%$ & $57.0 \%$ & $70.8 \%$ & $27.7 \%$ \\
\hline $\begin{array}{l}\text { Fiber optic } \\
\text { Internet }\end{array}$ & 27.307 & 2085 & 10.056 & 15.166 & $51.0 \%$ & $42.8 \%$ & $50.3 \%$ & $52.8 \%$ & $10.0 \%$ \\
\hline TV intercom & 26.689 & 953 & 4232 & 21.504 & $49.8 \%$ & $19.6 \%$ & $21.2 \%$ & $74.9 \%$ & $55.4 \%$ \\
\hline $\begin{array}{l}\text { Automatic } \\
\text { entrance door }\end{array}$ & 26.042 & 337 & 5062 & 20.643 & $48.6 \%$ & $6.9 \%$ & $25.3 \%$ & $71.9 \%$ & $65.0 \%$ \\
\hline Cable TV & 23.211 & 1316 & 8314 & 13.581 & $43.3 \%$ & $27.0 \%$ & $41.6 \%$ & $47.3 \%$ & $20.3 \%$ \\
\hline BS antenna & 20.013 & 472 & 4430 & 15.111 & $37.4 \%$ & $9.7 \%$ & $22.2 \%$ & $52.7 \%$ & $43.0 \%$ \\
\hline Elevator & 19.587 & 1189 & 5387 & 13.011 & $36.6 \%$ & $24.4 \%$ & $27.0 \%$ & $45.3 \%$ & $20.9 \%$ \\
\hline Tiling wall & 15.751 & 561 & 5265 & 9925 & $29.4 \%$ & $11.5 \%$ & $26.3 \%$ & $34.6 \%$ & $23.1 \%$ \\
\hline Delivery locker & 15.163 & 119 & 1550 & 13.494 & $28.3 \%$ & $2.4 \%$ & $7.8 \%$ & $47.0 \%$ & $44.6 \%$ \\
\hline Security camera & 12.694 & 302 & 1849 & 10.543 & $23.7 \%$ & $6.2 \%$ & $9.3 \%$ & $36.7 \%$ & $30.5 \%$ \\
\hline CS antenna & 11.888 & 304 & 1837 & 9747 & $22.2 \%$ & $6.2 \%$ & $9.2 \%$ & $34.0 \%$ & $27.7 \%$ \\
\hline $\begin{array}{l}\text { Garbage } 24 \mathrm{H} \\
\text { available }\end{array}$ & 6670 & 130 & 728 & 5812 & $12.5 \%$ & $2.7 \%$ & $3.6 \%$ & $20.3 \%$ & $17.6 \%$ \\
\hline Bike parking lot & 6335 & 354 & 1875 & 4106 & $11.8 \%$ & $7.3 \%$ & $9.4 \%$ & $14.3 \%$ & $7.0 \%$ \\
\hline
\end{tabular}




\begin{tabular}{|c|c|c|c|c|c|c|c|c|c|}
\hline \multirow[b]{2}{*}{ Item } & \multicolumn{4}{|c|}{ Number of observations } & \multicolumn{5}{|c|}{ Ratio } \\
\hline & Total & $\begin{array}{l}\text { Old } \\
\text { stock }\end{array}$ & $\begin{array}{l}\text { Main } \\
\text { stock }\end{array}$ & $\begin{array}{l}\text { New } \\
\text { stock }\end{array}$ & Total & $\begin{array}{l}\text { Old } \\
\text { stock }\end{array}$ & $\begin{array}{l}\text { Main } \\
\text { stock }\end{array}$ & $\begin{array}{l}\text { New } \\
\text { stock }\end{array}$ & New-old \\
\hline Design by artist & 4068 & 29 & 286 & 3753 & $7.6 \%$ & $0.6 \%$ & $1.4 \%$ & $13.1 \%$ & $12.5 \%$ \\
\hline Seismic structure & 3827 & 37 & 702 & 3088 & $7.1 \%$ & $0.8 \%$ & $3.5 \%$ & $10.8 \%$ & $10.0 \%$ \\
\hline \multicolumn{10}{|l|}{$\begin{array}{l}\text { Contract } \\
\text { conditions }\end{array}$} \\
\hline with NO guarantor & 20.257 & 1214 & 6274 & 12.769 & $37.8 \%$ & $24.9 \%$ & $31.4 \%$ & $44.5 \%$ & $19.6 \%$ \\
\hline No pets & 8417 & 733 & 3540 & 4144 & $15.7 \%$ & $15.1 \%$ & $17.7 \%$ & $14.4 \%$ & $-0.6 \%$ \\
\hline $\begin{array}{l}\text { NO musical } \\
\text { instrument }\end{array}$ & 6704 & 605 & 2702 & 3397 & $12.5 \%$ & $12.4 \%$ & $13.5 \%$ & $11.8 \%$ & $-0.6 \%$ \\
\hline NO office use & 5253 & 297 & 1731 & 3225 & $9.8 \%$ & $6.1 \%$ & $8.7 \%$ & $11.2 \%$ & $5.1 \%$ \\
\hline FREE Internet & 4682 & 100 & 616 & 3966 & $8.7 \%$ & $2.1 \%$ & $3.1 \%$ & $13.8 \%$ & $11.8 \%$ \\
\hline Pet consultation & 3906 & 210 & 801 & 2895 & $7.3 \%$ & $4.3 \%$ & $4.0 \%$ & $10.1 \%$ & $5.8 \%$ \\
\hline Pets allowed & 2189 & 150 & 437 & 1602 & $4.1 \%$ & $3.1 \%$ & $2.2 \%$ & $5.6 \%$ & $2.5 \%$ \\
\hline $\begin{array}{l}\text { Contract with } \\
\text { limited term }\end{array}$ & 1673 & 311 & 511 & 851 & $3.1 \%$ & $6.4 \%$ & $2.6 \%$ & $3.0 \%$ & $-3.4 \%$ \\
\hline Office use allowed & 1319 & 362 & 508 & 449 & $2.5 \%$ & $7.4 \%$ & $2.5 \%$ & $1.6 \%$ & $-5.9 \%$ \\
\hline \multicolumn{10}{|l|}{ Building structure } \\
\hline Wooden & 10.851 & 1285 & 4273 & 5293 & $20.3 \%$ & $26.4 \%$ & $21.4 \%$ & $18.4 \%$ & $-8.0 \%$ \\
\hline Steel frame & 13.796 & 891 & 6044 & 6861 & $25.8 \%$ & $18.3 \%$ & $30.2 \%$ & $23.9 \%$ & $5.6 \%$ \\
\hline $\mathrm{RC}$ & 23.654 & 2074 & 7635 & 13.945 & $44.2 \%$ & $42.6 \%$ & $38.2 \%$ & $48.6 \%$ & $6.0 \%$ \\
\hline SRC & 3644 & 599 & 1626 & 1419 & $6.8 \%$ & $12.3 \%$ & $8.1 \%$ & $4.9 \%$ & $-7.4 \%$ \\
\hline Others & 1605 & 19 & 404 & 1182 & $3.0 \%$ & $0.4 \%$ & $2.0 \%$ & $4.1 \%$ & $3.7 \%$ \\
\hline \multicolumn{10}{|l|}{ Others } \\
\hline $\begin{array}{l}\text { High-rise block } \\
\text { (16F over) }\end{array}$ & 387 & 3 & 54 & 330 & $0.7 \%$ & $0.1 \%$ & $0.3 \%$ & $1.1 \%$ & $1.1 \%$ \\
\hline $\begin{array}{l}\text { Room on the first } \\
\text { floor }\end{array}$ & 13.265 & 894 & 5217 & 7154 & $24.8 \%$ & $18.4 \%$ & $26.1 \%$ & $24.9 \%$ & $6.6 \%$ \\
\hline
\end{tabular}

Table 2.

Distribution of equipment in old stock, main stock, and new stock.

$(+44.6 \%)$, BS antenna $(+43.0 \%)$, and security camera $(+30.5 \%)$. In the conditions of contract, there are no items of note except for guarantor unnecessary, which is high at $37.8 \%$, and only guarantor unnecessary $(+19.6 \%)$ has a large difference in ancillary rate between old and new stocks (ancillary rate increased), but free Internet is also $+11.8 \% .^{12}$

Overall, the rise in security equipment is significant in building equipment, and the rise in the equipment that improves the living convenience is significant in room equipment. In addition, the ratio of building structures also shows changes,

\footnotetext{
12 Traditionally, when renting out a house in the Japanese rental housing market, it is necessary to have a guarantor to hedge the risk of nonpayment of rent. Since the guarantor is liable in the case of unpaid rent, relatives often become the guarantor, but as the size of families decreases, it is becoming difficult to find a guarantor. Under such circumstances, rent-guarantee companies have appeared, and systems that eliminate the need for a guarantor by paying a set insurance premium have been introduced.
} 
Supply Management of Rental Housing Facilities: Effect of Changes in the Quality of Housing... DOI: http://dx.doi.org/10.5772/intechopen.86163

\begin{tabular}{|c|c|c|c|c|c|c|c|}
\hline Ward & Old stock & Main stock & New stock & Total & Old stock & Main stock & New stock \\
\hline Chiyoda & 39 & 65 & 342 & 446 & $8.7 \%$ & $14.6 \%$ & $76.7 \%$ \\
\hline Chuo & 57 & 117 & 740 & 914 & $6.2 \%$ & $12.8 \%$ & $81.0 \%$ \\
\hline Minato & 137 & 182 & 927 & 1246 & $11.0 \%$ & $14.6 \%$ & $74.4 \%$ \\
\hline Shinjuku & 284 & 574 & 1264 & 2122 & $13.4 \%$ & $27.0 \%$ & $59.6 \%$ \\
\hline Bunkyo & 144 & 379 & 706 & 1229 & $11.7 \%$ & $30.8 \%$ & $57.4 \%$ \\
\hline Taito & 86 & 210 & 796 & 1092 & $7.9 \%$ & $19.2 \%$ & $72.9 \%$ \\
\hline Sumida & 103 & 348 & 1077 & 1528 & $6.7 \%$ & $22.8 \%$ & $70.5 \%$ \\
\hline Kouto & 134 & 454 & 1056 & 1644 & $8.2 \%$ & $27.6 \%$ & $64.2 \%$ \\
\hline Shinagawa & 190 & 650 & 1463 & 2303 & $8.3 \%$ & $28.2 \%$ & $63.5 \%$ \\
\hline Meguro & 134 & 537 & 789 & 1460 & $9.2 \%$ & $36.8 \%$ & $54.0 \%$ \\
\hline Ota & 458 & 2022 & 3054 & 5534 & $8.3 \%$ & $36.5 \%$ & $55.2 \%$ \\
\hline Setagaya & 494 & 2605 & 2450 & 5549 & $8.9 \%$ & $46.9 \%$ & $44.2 \%$ \\
\hline Shibuya & 188 & 425 & 908 & 1521 & $12.4 \%$ & $27.9 \%$ & $59.7 \%$ \\
\hline Nakano & 292 & 996 & 1367 & 2655 & $11.0 \%$ & $37.5 \%$ & $51.5 \%$ \\
\hline Suginami & 421 & 1915 & 1778 & 4114 & $10.2 \%$ & $46.5 \%$ & $43.2 \%$ \\
\hline Toshima & 189 & 687 & 1019 & 1895 & $10.0 \%$ & $36.3 \%$ & $53.8 \%$ \\
\hline Kita & 300 & 797 & 1061 & 2158 & $13.9 \%$ & $36.9 \%$ & $49.2 \%$ \\
\hline Arakawa & 100 & 339 & 582 & 1021 & $9.8 \%$ & $33.2 \%$ & $57.0 \%$ \\
\hline Itabashi & 291 & 1254 & 1441 & 2986 & $9.7 \%$ & $42.0 \%$ & $48.3 \%$ \\
\hline Nerima & 243 & 1639 & 1796 & 3678 & $6.6 \%$ & $44.6 \%$ & $48.8 \%$ \\
\hline Adachi & 182 & 1020 & 1518 & 2720 & $6.7 \%$ & $37.5 \%$ & $55.8 \%$ \\
\hline Katsushika & 177 & 926 & 1074 & 2177 & $8.1 \%$ & $42.5 \%$ & $49.3 \%$ \\
\hline Edogawa & 225 & 1841 & 1492 & 3558 & $6.3 \%$ & $51.7 \%$ & $41.9 \%$ \\
\hline Total & 4868 & 19,982 & 28,700 & 53,550 & $9.1 \%$ & $37.3 \%$ & $53.6 \%$ \\
\hline
\end{tabular}

Table 3.

Spatial distribution of rental housing.

such as wooden buildings decreasing by $8.0 \%$ and SRC by $7.4 \%$, while steel frames increase by $5.6 \%$ and RC by $6.0 \% .^{13}$

\subsection{Estimated results}

Table 5 shows the estimated results of the model. In addition, Figure 1 illustrates the dummy partial regression coefficients for the equipment.

Looking at the estimated results, as floor area increases, rent goes up, and as the number of minutes on foot from the station increases or the railway travel time from Tokyo station increases, the rent goes down. When taking a wooden structure as the baseline of the building structure, the rent will increase in the order of steel frame, RC, and SRC. The rent varies greatly depending on the ward in which the property is located; a high-rise condominium is a positive driver, and a $1 \mathrm{~F}$

${ }^{13}$ In addition, although the ratio of high-rise condominiums is rising, it is at about $1 \%$, and even the number of $1 \mathrm{~F}$ room positions is increasing. 


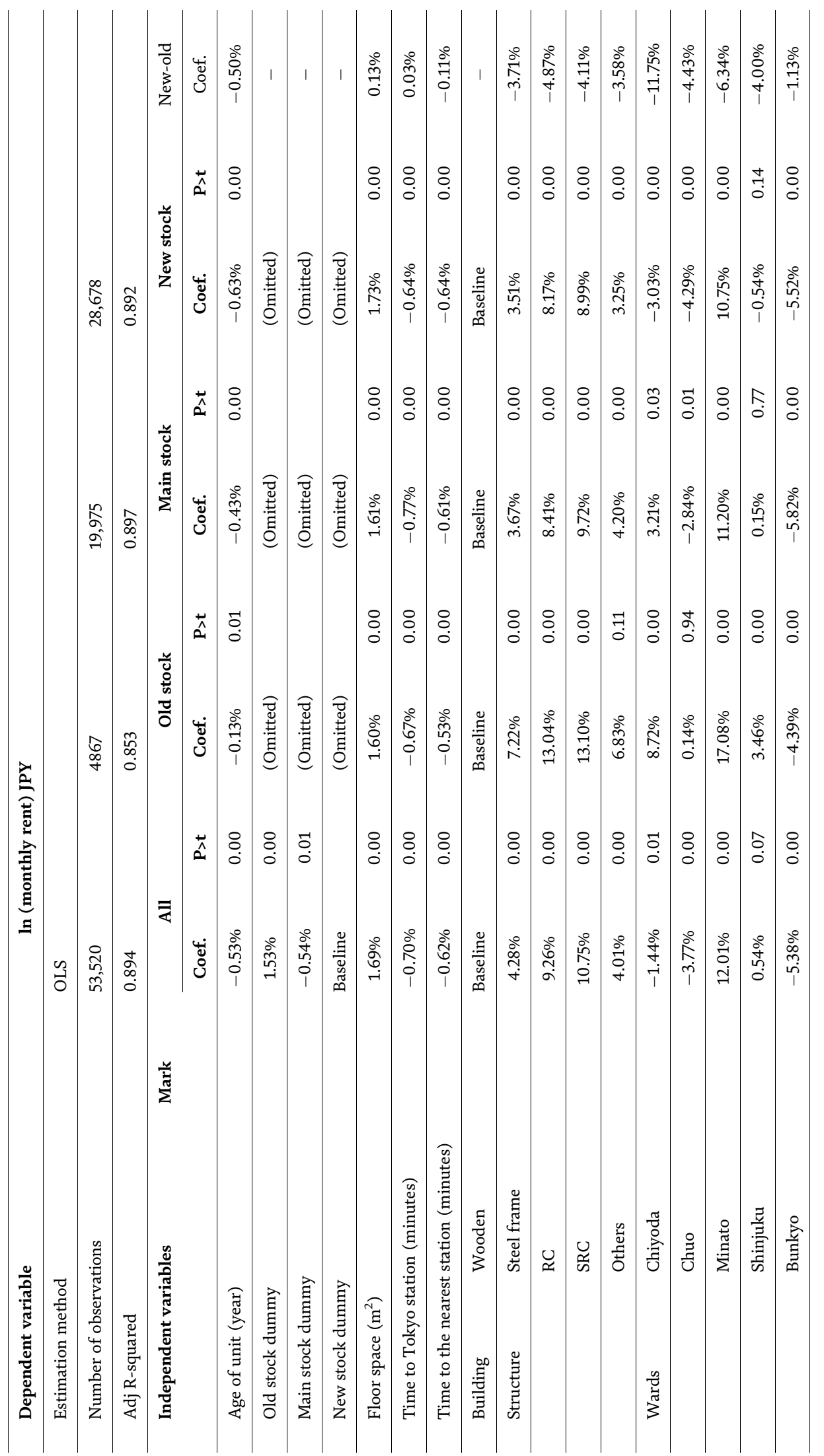




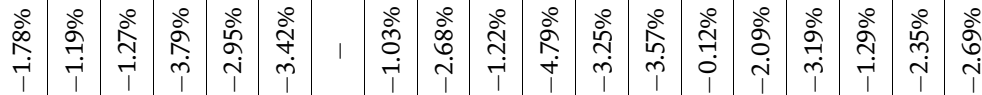

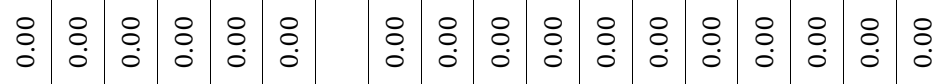

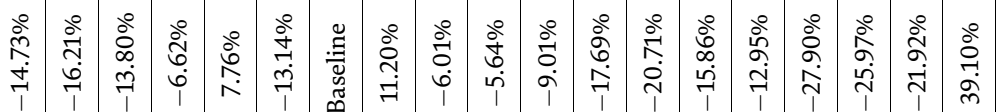

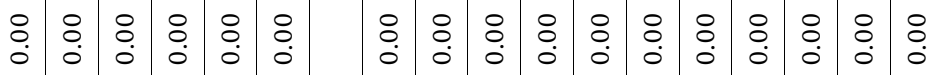

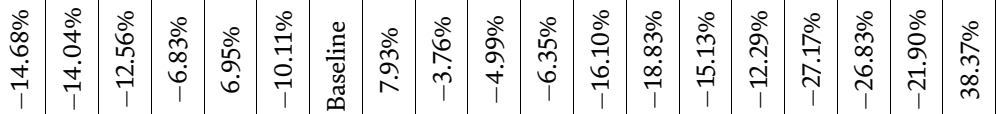

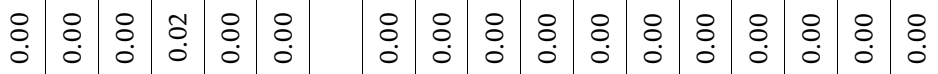

产

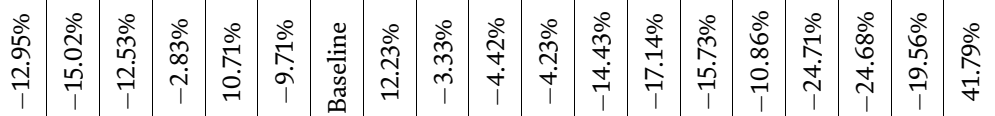

苞

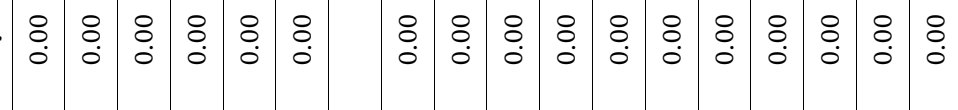

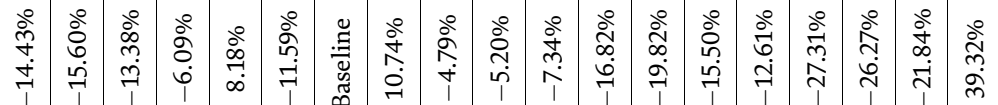

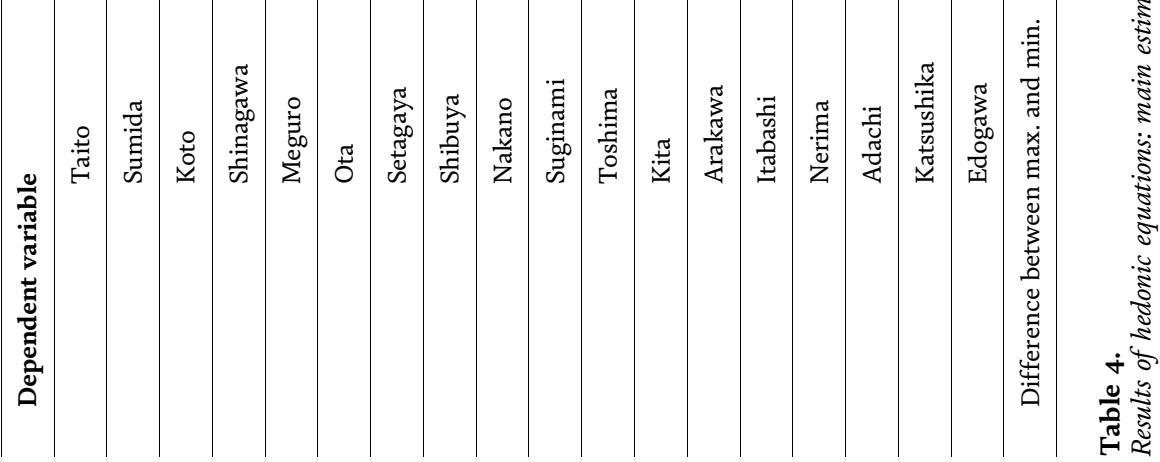


Modern Perspectives in Business Applications

\begin{tabular}{|c|c|c|c|c|c|c|c|c|c|c|c|}
\hline \multicolumn{3}{|c|}{ Independent variables } & \multicolumn{2}{|c|}{ All } & \multicolumn{2}{|c|}{ Old stock } & \multicolumn{2}{|c|}{ Main stock } & \multicolumn{2}{|c|}{ New stock } & \multirow{2}{*}{$\begin{array}{c}\begin{array}{c}\text { New- } \\
\text { old }\end{array} \\
\text { Coef. }\end{array}$} \\
\hline & & & Coef. & $P>t$ & Coef. & $P>t$ & Coef. & $P>t$ & Coef. & $P>t$ & \\
\hline \multicolumn{3}{|c|}{$\begin{array}{l}\text { High-rise block (16F } \\
\text { over) }\end{array}$} & $8.74 \%$ & 0.00 & $14.12 \%$ & 0.08 & $4.35 \%$ & 0.01 & $9.22 \%$ & 0.00 & $-4.89 \%$ \\
\hline \multicolumn{3}{|c|}{ Room on the first floor } & $-2.76 \%$ & 0.00 & $-0.55 \%$ & 0.28 & $-2.94 \%$ & 0.00 & $-3.00 \%$ & 0.00 & $-2.44 \%$ \\
\hline \multirow[t]{20}{*}{$\mathrm{RE}$} & $\begin{array}{l}\text { Air } \\
\text { conditioning }\end{array}$ & & $0.82 \%$ & 0.00 & $1.87 \%$ & 0.00 & $0.18 \%$ & 0.48 & $0.02 \%$ & 0.96 & $-1.86 \%$ \\
\hline & $\begin{array}{l}\text { Hot water } \\
\text { supply }\end{array}$ & & $-1.77 \%$ & 0.00 & $0.58 \%$ & 0.24 & $-1.03 \%$ & 0.00 & $-2.42 \%$ & 0.00 & $-3.01 \%$ \\
\hline & $\begin{array}{l}\text { Indoor WM } \\
\text { area }\end{array}$ & & $1.27 \%$ & 0.00 & $2.73 \%$ & 0.00 & $1.73 \%$ & 0.00 & $-0.77 \%$ & 0.00 & $-3.50 \%$ \\
\hline & Flooring & A & $0.16 \%$ & 0.22 & $3.35 \%$ & 0.00 & $0.50 \%$ & 0.01 & $-1.81 \%$ & 0.00 & $-5.17 \%$ \\
\hline & $\begin{array}{l}\text { Separate bath } \\
\text { and toilet }\end{array}$ & A & $5.07 \%$ & 0.00 & $5.58 \%$ & 0.00 & $6.46 \%$ & 0.00 & $1.55 \%$ & 0.00 & $-4.03 \%$ \\
\hline & balcony & A & $0.84 \%$ & 0.00 & $3.28 \%$ & 0.00 & $1.82 \%$ & 0.00 & $0.01 \%$ & 0.95 & $-3.27 \%$ \\
\hline & $\begin{array}{l}\text { System } \\
\text { kitchen }\end{array}$ & & $1.85 \%$ & 0.00 & $4.62 \%$ & 0.00 & $2.40 \%$ & 0.00 & $0.79 \%$ & 0.00 & $-3.83 \%$ \\
\hline & $\begin{array}{l}\text { Separate } \\
\text { washroom }\end{array}$ & & $2.11 \%$ & 0.00 & $2.18 \%$ & 0.00 & $2.35 \%$ & 0.00 & $2.16 \%$ & 0.00 & $-0.03 \%$ \\
\hline & 1 gas stove & & $-0.52 \%$ & 0.00 & $-1.09 \%$ & 0.04 & $0.13 \%$ & 0.52 & $-1.13 \%$ & 0.00 & $-0.05 \%$ \\
\hline & Washlet & A & $2.20 \%$ & 0.00 & $3.17 \%$ & 0.00 & $2.75 \%$ & 0.00 & $1.16 \%$ & 0.00 & $-2.01 \%$ \\
\hline & $\begin{array}{l}\text { Bathroom } \\
\text { dryer }\end{array}$ & A & $1.35 \%$ & 0.00 & $4.90 \%$ & 0.00 & $3.07 \%$ & 0.00 & $1.29 \%$ & 0.00 & $-3.61 \%$ \\
\hline & 2 gas stoves & & $-0.34 \%$ & 0.01 & $-0.03 \%$ & 0.95 & $1.17 \%$ & 0.00 & $-0.09 \%$ & 0.55 & $-0.05 \%$ \\
\hline & $\begin{array}{l}\text { Reheating } \\
\text { bath }\end{array}$ & C & $2.22 \%$ & 0.00 & $0.26 \%$ & 0.56 & $0.06 \%$ & 0.82 & $3.45 \%$ & 0.00 & $3.18 \%$ \\
\hline & $\begin{array}{l}\text { Washroom } \\
\text { with shower }\end{array}$ & & $-1.16 \%$ & 0.00 & $0.64 \%$ & 0.41 & $-0.18 \%$ & 0.55 & $-1.33 \%$ & 0.00 & $-1.97 \%$ \\
\hline & $\begin{array}{l}\text { Own house } \\
\text { rental }\end{array}$ & D & $-2.92 \%$ & 0.00 & $-0.54 \%$ & 0.45 & $-1.87 \%$ & 0.00 & $-3.42 \%$ & 0.00 & $-2.88 \%$ \\
\hline & IH stovetop & D & $-1.03 \%$ & 0.00 & $-0.65 \%$ & 0.49 & $-1.68 \%$ & 0.00 & $-1.62 \%$ & 0.00 & $-0.97 \%$ \\
\hline & $\begin{array}{l}\text { Walk-in } \\
\text { closet }\end{array}$ & B & $1.22 \%$ & 0.00 & $4.33 \%$ & 0.00 & $0.77 \%$ & 0.29 & $0.88 \%$ & 0.00 & $-3.45 \%$ \\
\hline & $\begin{array}{l}\text { Counter } \\
\text { kitchen }\end{array}$ & & $1.10 \%$ & 0.00 & $2.83 \%$ & 0.08 & $0.03 \%$ & 0.95 & $0.72 \%$ & 0.00 & $-2.11 \%$ \\
\hline & With loft & & $4.72 \%$ & 0.00 & $5.59 \%$ & 0.07 & $4.08 \%$ & 0.00 & $4.19 \%$ & 0.00 & $-1.40 \%$ \\
\hline & $\begin{array}{l}\text { Underfloor } \\
\text { heating }\end{array}$ & $\mathrm{C}$ & $5.19 \%$ & 0.00 & $-1.55 \%$ & 0.73 & $-1.09 \%$ & 0.36 & $4.97 \%$ & 0.00 & $6.52 \%$ \\
\hline \multirow[t]{5}{*}{$\mathrm{BE}$} & $\begin{array}{l}\text { Bicycle } \\
\text { parking lot }\end{array}$ & & $-0.94 \%$ & 0.00 & $-0.71 \%$ & 0.09 & $-0.70 \%$ & 0.00 & $-0.96 \%$ & 0.00 & $-0.25 \%$ \\
\hline & $\begin{array}{l}\text { Fiber optic } \\
\text { Internet }\end{array}$ & & $-1.04 \%$ & 0.00 & $-1.83 \%$ & 0.00 & $-0.93 \%$ & 0.00 & $-0.91 \%$ & 0.00 & $0.92 \%$ \\
\hline & TV intercom & A & $1.08 \%$ & 0.00 & $3.99 \%$ & 0.00 & $1.71 \%$ & 0.00 & $-0.15 \%$ & 0.34 & $-4.14 \%$ \\
\hline & $\begin{array}{l}\text { Automatic } \\
\text { entrance door }\end{array}$ & $\mathbf{A}$ & $1.74 \%$ & 0.00 & $4.47 \%$ & 0.00 & $2.72 \%$ & 0.00 & $1.63 \%$ & 0.00 & $-2.84 \%$ \\
\hline & Cable TV & & $-0.63 \%$ & 0.00 & $-1.61 \%$ & 0.00 & $-0.26 \%$ & 0.13 & $-0.51 \%$ & 0.00 & $1.10 \%$ \\
\hline
\end{tabular}


Supply Management of Rental Housing Facilities: Effect of Changes in the Quality of Housing... DOI: http://dx.doi.org/10.5772/intechopen.86163

\begin{tabular}{|c|c|c|c|c|c|c|c|c|c|c|c|}
\hline \multicolumn{3}{|c|}{ Independent variables } & \multicolumn{2}{|c|}{ All } & \multicolumn{2}{|c|}{ Old stock } & \multicolumn{2}{|c|}{ Main stock } & \multicolumn{2}{|c|}{ New stock } & \multirow{2}{*}{$\begin{array}{c}\begin{array}{c}\text { New- } \\
\text { old }\end{array} \\
\text { Coef. }\end{array}$} \\
\hline & & & Coef. & $\mathbf{P}>\mathbf{t}$ & Coef. & $\mathbf{P}>\mathbf{t}$ & Coef. & $P>t$ & Coef. & $P>t$ & \\
\hline \multicolumn{3}{|c|}{ BS antenna } & $-1.25 \%$ & 0.00 & $-2.58 \%$ & 0.01 & $-0.05 \%$ & 0.83 & $-1.45 \%$ & 0.00 & $1.13 \%$ \\
\hline \multicolumn{3}{|c|}{ Elevator } & $2.52 \%$ & 0.00 & $2.89 \%$ & 0.00 & $2.10 \%$ & 0.00 & $2.63 \%$ & 0.00 & $-0.26 \%$ \\
\hline \multicolumn{3}{|c|}{ Tiling wall } & $-1.44 \%$ & 0.00 & $-1.91 \%$ & 0.00 & $-1.21 \%$ & 0.00 & $-0.97 \%$ & 0.00 & $0.93 \%$ \\
\hline \multicolumn{2}{|r|}{$\begin{array}{l}\text { Delivery } \\
\text { locker }\end{array}$} & A & $2.03 \%$ & 0.00 & $4.55 \%$ & 0.00 & $1.42 \%$ & 0.00 & $2.68 \%$ & 0.00 & $-1.87 \%$ \\
\hline \multicolumn{2}{|r|}{$\begin{array}{l}\text { Security } \\
\text { camera }\end{array}$} & C & $1.33 \%$ & 0.00 & $0.62 \%$ & 0.45 & $1.06 \%$ & 0.00 & $1.61 \%$ & 0.00 & $0.99 \%$ \\
\hline \multicolumn{3}{|c|}{ CS antenna } & $0.60 \%$ & 0.00 & $1.76 \%$ & 0.15 & $-0.69 \%$ & 0.04 & $1.25 \%$ & 0.00 & $-0.51 \%$ \\
\hline \multicolumn{2}{|r|}{$\begin{array}{l}\text { Garbage } 24 \mathrm{H} \\
\text { available }\end{array}$} & $\mathrm{C}$ & $-0.13 \%$ & 0.49 & $-1.58 \%$ & 0.18 & $-0.84 \%$ & 0.06 & $0.98 \%$ & 0.00 & $2.56 \%$ \\
\hline \multicolumn{2}{|r|}{$\begin{array}{l}\text { Bike parking } \\
\text { lot }\end{array}$} & C & $0.75 \%$ & 0.00 & $-0.38 \%$ & 0.61 & $0.29 \%$ & 0.28 & $0.94 \%$ & 0.00 & $1.32 \%$ \\
\hline \multicolumn{3}{|c|}{$\begin{array}{l}\text { Design by } \\
\text { artist }\end{array}$} & $0.45 \%$ & 0.02 & $0.62 \%$ & 0.80 & $1.78 \%$ & 0.01 & $0.52 \%$ & 0.01 & $-0.09 \%$ \\
\hline \multicolumn{3}{|c|}{$\begin{array}{l}\text { Seismic } \\
\text { structure }\end{array}$} & $-2.25 \%$ & 0.00 & $-4.11 \%$ & 0.05 & $-1.95 \%$ & 0.00 & $-1.82 \%$ & 0.00 & $2.29 \%$ \\
\hline \multirow[t]{9}{*}{$\mathrm{CC}$} & $\begin{array}{l}\text { with NO } \\
\text { guarantor }\end{array}$ & D & $-0.82 \%$ & 0.00 & $-1.47 \%$ & 0.00 & $-1.07 \%$ & 0.00 & $-0.23 \%$ & 0.08 & $1.24 \%$ \\
\hline & No pets & & $0.06 \%$ & 0.77 & $-1.46 \%$ & 0.12 & $0.37 \%$ & 0.25 & $0.47 \%$ & 0.07 & $1.93 \%$ \\
\hline & $\begin{array}{l}\text { Pet } \\
\text { consultation }\end{array}$ & & $3.24 \%$ & 0.00 & $2.85 \%$ & 0.00 & $4.13 \%$ & 0.00 & $3.10 \%$ & 0.00 & $0.25 \%$ \\
\hline & Pets allowed & & $2.57 \%$ & 0.00 & $2.17 \%$ & 0.05 & $3.40 \%$ & 0.00 & $2.35 \%$ & 0.00 & $0.18 \%$ \\
\hline & $\begin{array}{l}\text { No musical } \\
\text { instrument }\end{array}$ & & $-0.32 \%$ & 0.15 & $1.61 \%$ & 0.11 & $0.22 \%$ & 0.54 & $-0.83 \%$ & 0.00 & $-2.44 \%$ \\
\hline & No office use & & $0.81 \%$ & 0.00 & $-1.18 \%$ & 0.18 & $0.01 \%$ & 0.97 & $1.13 \%$ & 0.00 & $2.31 \%$ \\
\hline & $\begin{array}{l}\text { Office use } \\
\text { allowed }\end{array}$ & C & $5.04 \%$ & 0.00 & $2.34 \%$ & 0.00 & $4.01 \%$ & 0.00 & $6.11 \%$ & 0.00 & $3.77 \%$ \\
\hline & Free Internet & B & $0.82 \%$ & 0.00 & $3.01 \%$ & 0.02 & $0.58 \%$ & 0.19 & $0.68 \%$ & 0.00 & $-2.33 \%$ \\
\hline & $\begin{array}{l}\text { Contract with } \\
\text { limited term }\end{array}$ & B & $-0.82 \%$ & 0.00 & $-2.80 \%$ & 0.00 & $-0.86 \%$ & 0.08 & $-0.30 \%$ & 0.39 & $2.50 \%$ \\
\hline _cons & & & $0.00 \%$ & 0.00 & $0.00 \%$ & 0.00 & $0.00 \%$ & 0.00 & $0.00 \%$ & 0.00 & - \\
\hline
\end{tabular}

Table 5 .

Estimated results of room equipment (RE), building equipment (BE), and contract conditions (CC).

apartment positions a negative driver for rent. These results are consistent with previous studies and the intuition of market participants.

The effect of the number of years since construction differs depending on the period of construction, and as a whole, there is a $-0.53 \%$ reduction in rent per year after construction. However, looking at the old $/ \mathrm{main} /$ new period of construction dummy, the speed of reduction is high for new stock and low for old stock. This shows that the effect of years since construction is nonlinear, indicating that the decline in rent will be considerably smaller after a certain number of years. Such nonlinearity is also consistent with a series of previous studies. 


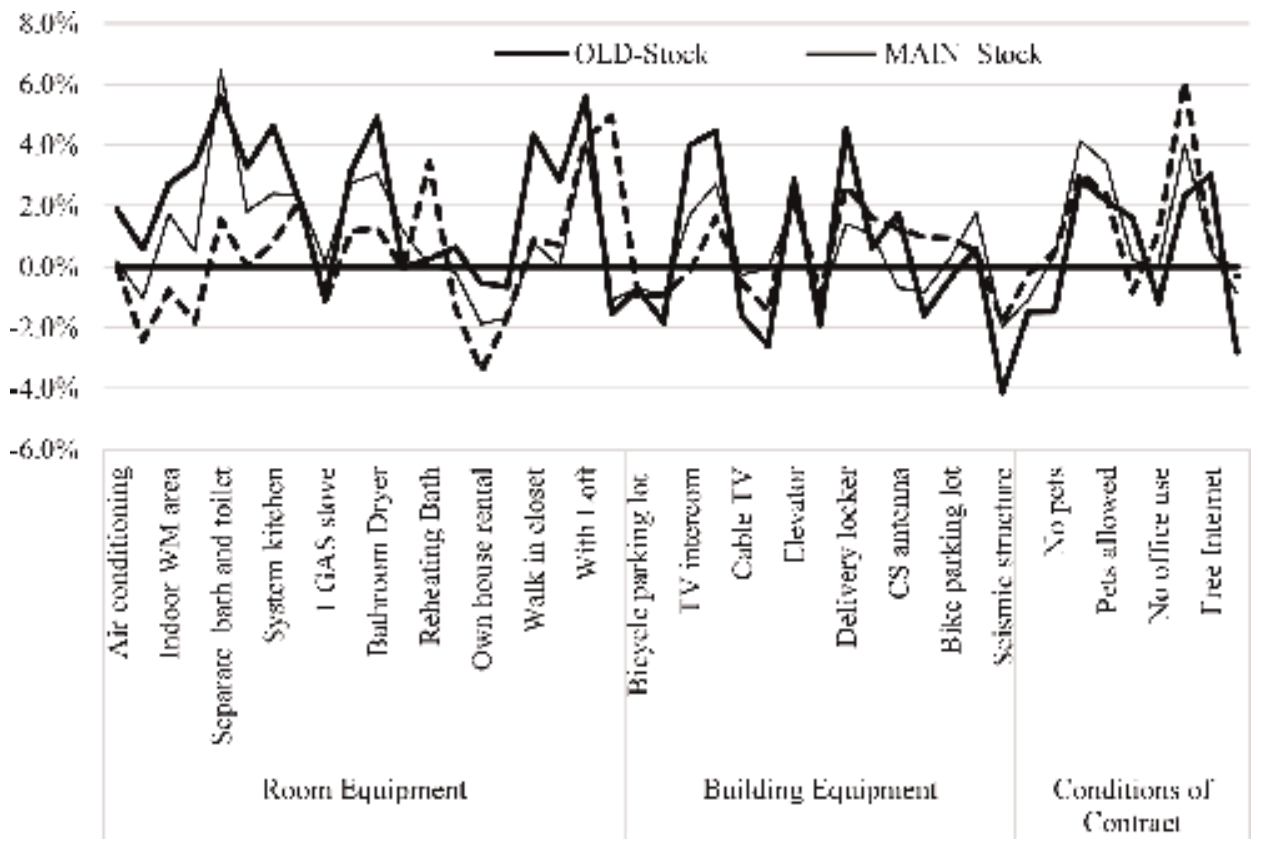

Figure 1.

Marginal price effect on $R E, B E$, and $C C$.

The influence of the ancillary equipment situation on the rent changes according to the period of construction (Figure 1). The change can be classified into the following four patterns. ${ }^{14}$

- Pattern A: Items considered to have lost value because of commonness

In Pattern $\mathrm{A}$, it is assumed that the equipment premium that was once a differentiating factor for price was lost because of the advancing commonness of equipment. This corresponds to room equipment (RE) such as flooring, separate bath and toilet, balcony, toilet with washlet, and bathroom dryer and building equipment (BE) such as TV intercom, automatic entrance door, delivery locker, and so on. In all cases, the ancillary rate has increased, so the superiority of the ancillary equipment falls, the influence on rent differs between old and new stocks, and such influence is generally small in new stock. Flooring and TV intercoms have a negative impact on new stock. This indicates that flooring and TV intercoms are no longer special equipment and do not offer price advantages.

- Pattern B: Items considered to have lost value because they satisfied limited needs

\footnotetext{
${ }^{14}$ Shimizu et al. [19] and Diewert and Shimizu [20-22] estimate a depreciation structure for the detached house and apartment market and the office market in Tokyo. The estimated results in this study show roughly the same form. As Diewert and Shimizu [23] covers the office market, durability is longer than for rental housing. Therefore, it has been reported that this will become a positive driver for rent at a stage exceeding 40 years after construction. The same tendency is observed in research targeting commercial real estate markets in Europe, the United States, and so on. The reason for this could be the influence of large costs for large-scale repairs and survivorship bias caused by higher-quality buildings having longer service life and only such buildings remaining. In this study, such bias is not observed, as it is limited to a certain period of time.
} 
In Pattern B, it is assumed that the price premium of the equipment was lost because the needs the equipment satisfied were limited in the first place and have been satisfied. The walk-in closet corresponds to this in room equipment (RE), nothing corresponds to this in building equipment (BE), and free Internet and contract with limited term correspond to this in contract conditions (CC). Contract with limited term has a negative impact on rent in new stock.

- Pattern C: Items for which demand is considered to be increasing but the ancillary rate is low, and value is increasing

Pattern $\mathrm{C}$ is such that although consumer demand is increasing over time, a price premium exists because of the low ancillary rate in the housing stock. Equipment such as a reheating bath and underfloor heating corresponds to this in room equipment (RE), and security cameras, garbage disposal available 24-hours a day, and bike parking correspond to this in building equipment (BE). Items such as use as an office correspond to this in contract conditions (CC). In particular, the reheating bath and use as an office have a significant influence of +3.45 and $+3.77 \%$, respectively.

- Pattern D: Items considered to be due to other individual factors

Items for which a price premium exists due to other factors correspond to ownerowned condominium for lease in room equipment (RE) and guarantor unnecessary in contract conditions (CC). Regarding condominium for lease, the effect of the increase in supply is considered to be caused by the change in the social situation, where the tendency for relatives to avoid guaranteeing rent obligations has strengthened.

\subsection{Influence of ancillary equipment situation on equipment depreciation rate}

Figure 2 shows the depreciation rate of all rents (All) and for the case where the ancillary equipment situation is poor (Poor). The equipment being poor indicates there is no (i) washlet, (ii) bathroom dryer, (iii) reheating bath, (iv) TV intercom, (iv) automatic entrance door, (iv) delivery locker, or (vii) security camera. These

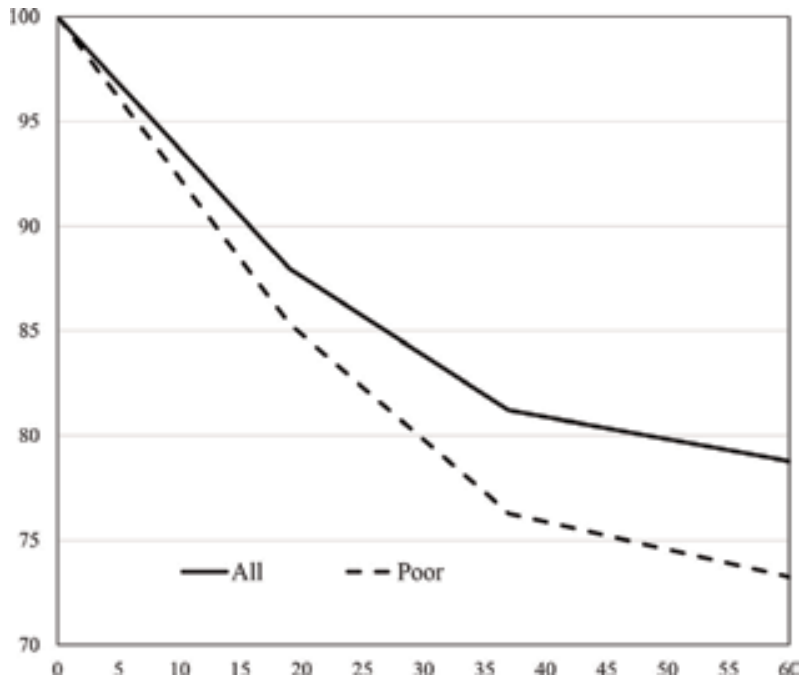

Figure 2.

Depreciation in rental housing. 
types of equipment have become more common in recent years and can be installed in existing buildings.

There were 13,033 properties with poor equipment; a regression analysis similar to the previous one was carried out with the logarithm of the rent as a target variable, and the regression coefficient of the years since construction was obtained. That is, as of October 2018, data points without the aforementioned equipment exist regardless of whether they are new, main, or old stock. This means that lowquality rental housing that does not have equipment that has become popular in recent years is still supplied. By extracting such data and comparing the depreciation of rental housing with new functions that benefited from technological progress and the depreciation of low-quality rental housing with no new functions, it is possible to extract the depreciation that accompanies obsolescence.

In Figure 2, the depreciation rate for each period is calculated with the rent at the time of construction as 100 to demonstrate the theoretical effect of the increasing number of years since construction on rent. When comparing the depreciation rate of all rents with that of rents of properties with a poor ancillary equipment situation, the depreciation rate increases in all cases (new, main, and old stocks). Roughly 60 years after construction, the difference was found to be $5.5 \%$.

In addition to the measurement of the magnitude of the age effect accompanying obsolescence, this result means that rent depreciation can be mitigated if appropriate ancillary equipment investment is made with respect to the demands for housing equipment that have increased with economic growth and changes in lifestyle. We believe that this will provide pointers for high-level policy with respect to Japan's rental housing market, where the aging of stock will advance in the future.

\section{Conclusion and future tasks}

Changes in prices over time are broken down into changes due to supply-demand relationships and those caused by quality changes. In particular, this means that in markets with rapid technological progress, the price rise accompanying quality change increases as new products are introduced successively, but at the same time, in markets where such new products are introduced, the speed of obsolescence is fast.

Compared with Western countries, new products are easy to create in the Japanese housing market. The background to this is there are many housing providers and a comparatively large number of companies that do business throughout Japan and overseas. Such companies possess, for example, think tanks to develop new products, and are developing integrated business from large-scale procurement of raw materials to design, construction, sales, and management.

In this study, we focused on the period in which the housing was supplied and clarified the types of functions and equipment supplied to the market in each period and the extent of the marginal price effect in 2018. In addition, we measured the magnitude of obsolescence that accompanies the addition of a new function.

The conclusion can be summarized as follows.

- Rent is strongly influenced by the floor area, years since construction, building structure, number of minutes on foot from the nearest station, railway travel time from Tokyo station, location, and so on. This confirms conclusions provided by previous studies.

- The ancillary conditions of housing equipment vary greatly depending on the construction year. This suggests that the Japanese rental housing market is strongly influenced by regulations such as the Building Standards Act and the improvement of living standards by economic growth. 
- Some ancillary conditions have a large influence on rent, but if the ancillary rate increases, the influence becomes smaller due to commonness, and housing equipment responding to new needs have a positive influence on rent.

- Even if the number of years since construction is large, depreciation of the rent can be reduced if additional investment in appropriate housing equipment is carried out.

These evaluations are for the present time, and they are expected to change in the future as housing equipment ancillary rates change and social conditions, lifestyles, and resident demands evolve. The conclusion of this study shows the possibility of increasing profitability by responding to resident demands and raising rent through adding ancillary equipment, even in countries in Europe and in the United States, where housing building restrictions are strict.

However, several tasks remain. First, it is possible to add new functionality even to housing classified as old stock through large-scale renovation investment. In this sense, this study has not been able to measure the effect of investment in renovation. Moreover, in order to generalize the study result, it is necessary to identify appropriate housing equipment according to changes in lifestyle and social conditions, in addition to the influence of housing equipment on rent. Even if the scope is restricted to Japan, it is also necessary to consider points such as the type of differences that arise depending on the scale of the city and the standard of living and climate in different regions, as well as whether the necessary housing equipment differs according to the age, gender, family composition, income, and so on of the residents.

We would like to clarify these questions as future research tasks.

\section{Acknowledgements}

The second author gratefully acknowledges the financial support of the Nomura Foundation.

\section{Author details}

Takeshi So ${ }^{1,2}$ and Chihiro Shimizu ${ }^{2 *}$

1 Institute of Future Design in Housing Market, Daito Trust Construction Co. Ltd., Tokyo, Japan

2 Center for Spatial Information Science, The University of Tokyo, Tokyo, Japan

*Address all correspondence to: cshimizu@csis.u-tokyo.ac.jp

\section{IntechOpen}

(C) 2019 The Author(s). Licensee IntechOpen. This chapter is distributed under the terms of the Creative Commons Attribution License (http://creativecommons.org/licenses/ by/3.0), which permits unrestricted use, distribution, and reproduction in any medium, provided the original work is properly cited. (cc) BY 


\section{References}

[1] Shimizu C, Karato K, Asami Y. Estimation of redevelopment probability using panel data-asset bubble burst and office market in Tokyo. Journal of Property Investment and Finance. 2010;28(4):285-300

[2] Sirmans GS, David A, Emily N. The composition of hedonic pricing models. Journal of Real Estate Literature. 2005; 13(1):1-44

[3] Yoo S, Im J, Wagner JE. Variable selection for hedonic model using machine learning approaches: A case study in Onondaga County, NY. Landscape and Urban Planning. 2012; 107(3):293-306

[4] Lancaster K. A new approach to consumer theory. Journal of Political Economy. 1966;74(2):132-157

[5] Rosen S. Hedonic prices and implicit markets: Product differentiation in pure competition. Journal of Political Economy. 1974;82(1):34-55

[6] Shimizu C, Karato K. Property price index theory and estimation: A survey. CSIS Discussion Paper Series. The University of Tokyo; 2018. Available from: http://www.csis.u-tokyo.ac.jp/ wp-content/uploads/2018/11/156.pdf

[7] Ekeland I, Heckman J, Nesheim L. Identification and estimation of hedonic models. Journal of Political Economy. 2004;112(S1):S60-S109

[8] Nishi H, Asami Y, Shimizu C. Housing features and rent: Estimating the microstructures of rental housing. International Journal of Housing Market and Analysis. 2018. forthcoming. DOI: 10.1108/IJHMA-09-2018-0067

[9] Billings SB. Hedonic amenity valuation and housing renovations. Real Estate Economics. 2015;43(3):652-682
[10] McMillen DP, Thorsnes P. Housing renovations and the quantile repeat sales price index. Real Estate Economics. 2006;34(4):567-584

[11] Shimizu C. Estimation of hedonic single-family house price function considering neighborhood effect variables. Sustainability (Switzerland). 2014;6(5):2946-2960

[12] Gao X, Asami Y. The external effects of local attributes on living environment in detached residential blocks in Tokyo. Urban Studies. 2001; 38(3):487-505

[13] Fuerst F, Shimizu C. The rise of ecolabels in the Japanese housing market. Journal of Japanese and International Economy. 2016;39:108-122

[14] Nelson RH. Housing facilities, site advantages and rent. Journal of Regional Science. 1972;12(2):249-259

[15] Chau KW, Chin TL. A critical review of literature on the hedonic price model. International Journal for Housing Science and Its Applications. 2003;2(27):145-165

[16] Shimizu C, Nishimura K, Watanabe T. Housing prices in Tokyo: A comparison of hedonic and repeat sales measures. Journal of Economics and Statistics. 2010b;230:792-813

[17] Shimizu C, Takatsuji H, Ono H, Nishimura KG. Structural and temporal changes in the housing market and hedonic housing price indices. International Journal of Housing Markets and Analysis. 2010c;3(4): 351-368

[18] Karato K, Movshuk O, Shimizu C. Semiparametric estimation of time, age and cohort effects in an hedonic model 
Supply Management of Rental Housing Facilities: Effect of Changes in the Quality of Housing... DOI: http://dx.doi.org/10.5772/intechopen.86163

of house prices. Asian Economic Journal. 2015;29(4):325-345

[19] Shimizu C, Nishimura KG, Karato K. Nonlinearity of housing price structure-Secondhand condominium market in Tokyo Metropolitan Area. International Journal of Housing Markets and Analysis. 2014;7(3): 459-488

[20] Diewert WE, Shimizu C. Residential property price indexes for Tokyo. Macroeconomic Dynamics. 2015;19(8): 1659-1714

[21] Diewert WE, Shimizu C. Hedonic regression models for Tokyo condominium sales. Regional Science and Urban Economics. 2016;60:300-315

[22] Diewert WE, Shimizu C. Alternative approaches to commercial property price indexes for Tokyo. Review of Income and Wealth. 2017;63(3):492-519

[23] Diewert WE, Shimizu C. Alternative land price indexes for commercial properties in Tokyo. In: Discussion Paper 17-07. Vancouver School of Economics: University of British Columbia; 2017 

Section 3

\section{Sales Management in the New Age}





\title{
Prologue: Marketing in the Modern Age
}

\author{
Selay Ilgaz Sümer
}

\section{Introduction}

The most important way of businesses to succeed in their activities is to follow their environment carefully and try to integrate innovations in their bodies. In short, businesses must adopt the latest developments to maintain their existence under fierce competitive environment.

Marketing is one of the business functions that must keep up with these developments. In recent years, significant improvements have been made in the marketing efforts of the businesses. They have started to plan their marketing activities within the framework of different perspectives and techniques.

In recent years, the concept of value began to take place in the center of the marketing activities. Today, value is important almost for all businesses. There are different ways of creating value in marketing. In other words, the value that will be offered to consumers as a business can be evaluated in a wide range starting from the presale stages of the product to the after-sale periods. Therefore, the way of creating value can include using technology, empowering employees, etc. However, it is a fact that the basic condition of providing value in marketing is to make strategic marketing planning value-oriented.

Digital age and its implications also influenced the firms' marketing activities. The transition to the digital age has made it necessary to make significant changes in many aspects from the design stage of the products to the sales stage and even after-sale services. Consumers of the digital age have started to act consciously and have information about products as well as sales forces. With the introduction of digitalization, physical stores are gradually being replaced by virtual organizations. Electronic commerce has been adopted by many businesses as an effective way of marketing their goods and services.

The transition to the digital age also had an impact on the sales management activities. In other words, the presence of the digital environment has both created a variety of challenges for businesses and sales forces and also has facilitated sales forces activities. Especially in recent years sales forces, who strive to operate in a more value-oriented manner, have further increased their consulting roles. It is understood that the main task of the sales forces is not only to sell but also to provide information on various topics such as product and price comparisons to the consumers. This necessitates more careful selection and orientation of sales forces. It should be also noted that sales visits are now more effective by means of technological tools. In short, thanks to technological tools, the visual presentation of products is made more effectively than before. This facilitates the persuasion of consumers in the selling stage. 


\section{Sales management in modern marketing}

One of the prerequisites for success in an intense competitive environment is the effective planning of sales management activities. In this context, sales management activities should be planned considering the micro- and macro-environment of the businesses.

In recent years various changes and developments have significantly affected marketing activities of the businesses. Forces affecting sales management can be grouped as behavioral, technological, and managerial forces. Behavioral forces are related with the dynamism of consumer behavior. Technological forces cover the effects of technological innovations on sales management. Managerial forces include managerial efforts to increase the effectiveness of sales management-related activities [1]. These forces have made it necessary to consider certain points in the planning of sales management activities. Some of them can be listed as follows [2]:

- Powerful customers

- Global customers

- Variety in marketing channels

- Increased importance of services

As a result of the changes in sales management activities, the role of sales forces has started to change. Sales forces that were previously only the people who take the order of the customers have now become the relationship manager of the businesses [3]. As a result, the responsibilities and duties undertaken by the sales forces within the organization have increased.

\section{Process of sales management}

Sales management can be defined as "all activities, processes, and decisions involved in managing the sales function in an organization" [4]. Sales management-related activities play an important role in the successful implementation of the strategies developed by the businesses [5]. The activities related to the sales management process consist of three major stages which are formulating the sales program, implementing the sales program, and evaluation and control. Sales management process is given in Figure 1.

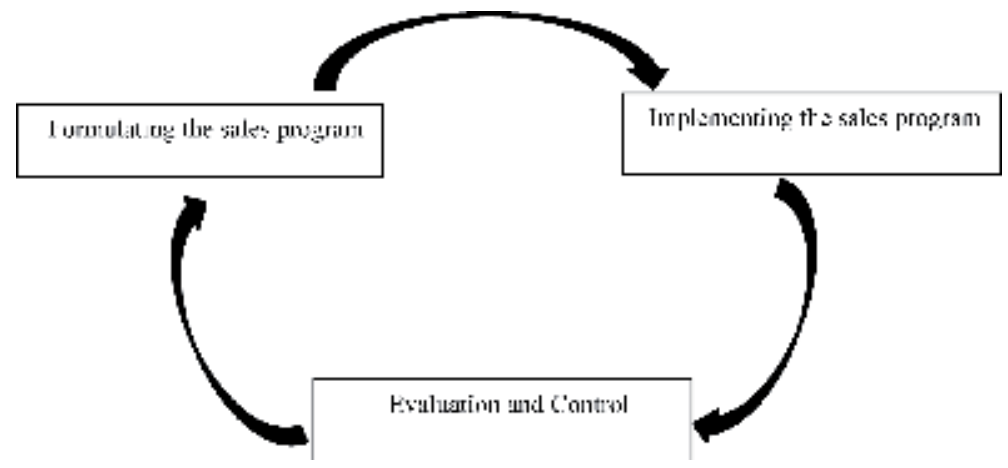

Figure 1.

Process of sales management [4]. 
The first stage of the sales management is formulating the sales program activities. At this stage, it is necessary to make plans in terms of business environment, potential customers, demand and quota estimation, and determination of sales territories. The second stage covers the activities related with the implementation of the sales program. Stage 2 involves the motivation of sales forces to actualize the sales program. At this stage, issues such as role perceptions, aptitude, skill level, and motivation gain importance. In the third stage, an overall evaluation and control of the sales program and sales forces is performed. According to the results to be obtained at this stage, various changes can be made in the sales program of the business [4].

\section{Author details}

Selay Ilgaz Sümer

Department of Management, Faculty of Economics and Administrative Sciences, Baskent University, Ankara, Turkey

*Address all correspondence to: silgaz@baskent.edu.tr

\section{IntechOpen}

(C) 2019 The Author(s). Licensee IntechOpen. This chapter is distributed under the terms of the Creative Commons Attribution License (http://creativecommons.org/licenses/ by/3.0), which permits unrestricted use, distribution, and reproduction in any medium, provided the original work is properly cited. (cc) BY 


\section{References}

[1] Anderson RE. Personal selling and sales management in the new millennium. Journal of Personal Selling \& Sales Management. 1996;16(4):17-32

[2] Colletti JA, Fiss MS. The ultimately accountable job: Leading today's sales organization. Harvard Business Review. 2006;84(7-8):124-131

[3] Storbacka K, Ryals L, Davies IA, Nenonen S. The changing role of sales: Viewing sales as a strategic, crossfunctional process. European Journal of Marketing. 2009;43(7/8):890-906

[4] Churchill GA, Ford NM, Walker OC, Johnston MW, Marshall GW. Sales Force Management. 9th ed. Boston: McGrawHill; 2009

[5] Ural T. The impact of sales management practices on job satisfaction of salespeople. Innovative Marketing. 2008;4(3):28-36 


\title{
Insight-Driven Sales Management
}

\author{
Hesham O. Dinana
}

\begin{abstract}
In the new VUCA (Volatile, Uncertain, Complex and Ambiguous) world that we live in, there are new rules that will reshape many of the components of sales management, from prospecting, to lead qualification, to closing and relationship management. This chapter will explore the impact of technology, data proliferation, and omni-channel customer touch points on how organizations will manage their sales process and the sales teams in the integrated online and offline worlds $(\mathrm{O} 2 \mathrm{O}$ sales). The digital-age consumer and the digital-age sales team will have different communication needs and tools that need to be addressed by sales leaders to ensure their organizations' success and competitiveness in this new landscape. Customer insights is the new name of the game and it needs to be developed using techniques such as content management, user experience management, performance analytics, machine learning, and artificial intelligence. Effectively and efficiently managing the sales process and the sales practices in the digital age will be the new challenge that organizations need to face as some types of sales jobs might disappear (order takers) and new jobs will need to be developed (sales analysts and data scientists). Todays sales managers need to put science into the art of selling.
\end{abstract}

Keywords: data, analytics, sales management, insights, digital, new-age consumers, O2O, AWATAD

\section{Introduction}

Most companies have heard about the VUCA world that we live in today, but few have developed actionable strategies to thrive in this business environment that is entangled in volatility, uncertainty, complexity, and ambiguity (VUCA).

Insight-driven sales management is one of those powerful systems that can help companies thrive not only survive in this new business world.

To understand this novel approach to sales management, a review of academic literature and practitioner reports was conducted to explore this shift in the business environment and how it will impact the sales process and how we manage it. This chapter will review the impact of data and advanced technologies such as Artificial Intelligence and machine learning on sales decisions and the characteristics of the digital-age sales teams, consumers, and business buyers. It will also discuss the future of the sales process (planning, coordinating, controlling, and motivating) and the sales management practices.

Companies need to embrace the VUCA world and proactively manage it to capitalize on the many opportunities it represents and reduce the negative impact of threats that might arise. Sales organizations are the frontline forces that can help manage this new business world. 
Sales management teams need to use agility to manage volatility, information to manage uncertainty, restructuring to manage complexity, and experimentation to manage ambiguity as follows:

- Agility is the way to manage volatility; resources should be allocated to build flexibility in the company ability to take advantage of the windows of opportunities presented by the rapidly changing business environment.

- Information is the way to manage uncertainty; companies should learn to integrate and understand relationships and patterns to develop insights to support decision-making. Sales organizations are a great source of valuable information that can support this uncertainty management.

- Restructuring is the way to manage complexity; companies should learn to develop high-performing organization designs that align internal company capabilities with the external complexities in the most efficient and effective manner. Sales organizations represent a big part of the companies' human capital and need to continually evolve and innovate to support complexity management.

\begin{tabular}{|c|c|c|c|}
\hline & What it is & An example & How to effectively address it \\
\hline Complexity & $\begin{array}{l}\text { A diverse but interrelated set } \\
\text { of information, processes, and } \\
\text { procedures that require deep } \\
\text { integrated analysis to be usable }\end{array}$ & $\begin{array}{l}\text { International market } \\
\text { penetration involves } \\
\text { managing a very complex } \\
\text { set of relationships, laws, } \\
\text { regulations, financing } \\
\text { options, and logistics issues }\end{array}$ & $\begin{array}{l}\text { Internal standard operating } \\
\text { procedures (SOPs) need to } \\
\text { embrace the external environment } \\
\text { perspective. Operations need to } \\
\text { analyze the market information } \\
\text { and integrate it in its practices } \\
\text { through effective and efficient } \\
\text { restructuring }\end{array}$ \\
\hline Ambiguity & $\begin{array}{l}\text { Lack of knowledge and } \\
\text { inability to link antecedents } \\
\text { and consequences of critical } \\
\text { issues with limited ability to } \\
\text { use lessons learnt to make } \\
\text { future predictions }\end{array}$ & $\begin{array}{l}\text { The impact of new digital } \\
\text { platforms on traditional } \\
\text { media channels (TV, radio, } \\
\text { and newspapers) has caused } \\
\text { many shifts in consumer } \\
\text { behavior that is impacting } \\
\text { many industries such as } \\
\text { media, telecomm, and } \\
\text { entertainment }\end{array}$ & $\begin{array}{l}\text { Experimentation is the way } \\
\text { to manage ambiguity. The } \\
\text { management should develop an } \\
\text { effective system for anticipation } \\
\text { and deployment of strategies that } \\
\text { can handle the unknowns based } \\
\text { on the integration of new trends } \\
\text { and best practices }\end{array}$ \\
\hline Volatility & $\begin{array}{l}\text { Instability that comes from } \\
\text { frequent and unpredictable } \\
\text { changes in the business } \\
\text { environment }\end{array}$ & $\begin{array}{l}\text { Raw material prices can } \\
\text { be affected by many issues } \\
\text { (such as political tensions, } \\
\text { transportation costs, } \\
\text { regulations, environmental } \\
\text { issue, etc.) that cause it to be } \\
\text { very volatile }\end{array}$ & $\begin{array}{l}\text { Agility is the best way to handle } \\
\text { volatility. Companies should focus } \\
\text { on building controlled and well- } \\
\text { planned slacks to allow for future } \\
\text { flexibility and manage volatility }\end{array}$ \\
\hline Uncertainty & $\begin{array}{l}\text { Situations are understood; } \\
\text { antecedents and consequences } \\
\text { can be correlated, but past } \\
\text { experiences cannot be used to } \\
\text { assess the ramifications and } \\
\text { magnitude of the changes }\end{array}$ & $\begin{array}{l}\text { The war on terrorism } \\
\text { generally suffers from } \\
\text { uncertainty; we understand } \\
\text { the root causes of terrorism, } \\
\text { but not exactly when and } \\
\text { how it will hit next }\end{array}$ & $\begin{array}{l}\text { Information based on new } \\
\text { sources of data (both online and } \\
\text { offline) coupled with insights are } \\
\text { critical to managing uncertainty. } \\
\text { Organizations need to embrace a } \\
\text { new perspective on information } \\
\text { use in business }\end{array}$ \\
\hline
\end{tabular}

Table 1.

Managing the VUCA world [1]. 
- Experimentation is the way to manage ambiguity; learning to put your ideas to the test and to leverage the lessons learnt is the best way to reduce the business ambiguity and to engage the teams and reduce anxiety about the changes.

Those are the new rules for effective sales management in the future. Table 1 defines the dimensions of the VUCA world and provides examples to demonstrate it and explain how to effectively address it.

\section{The data-driven sales world}

We are living in a world where DATA is considered the new oil. Companies that will learn how to manage its internal and external customer data to develop insights to drive its sales process and its decision-making are those that will lead the way for the future sales management models.

IDC indicates in their study about "Worldwide Embedded and Intelligent Systems" that by 2020 the world will have more than 4 billion connected people, with $\$ 4$ trillion in revenue opportunities, more than 25 million mobile applications, and more than 25 million embedded intelligent systems. All this will generate 50 trillion GB of data [2].

We are now moving toward the Internet of things (IoT), where the physical and virtual worlds are integrated. We are already seeing many devices and applications that are gradually coming part of our life such as smart homes, driverless cars, smart personal assistants, and industrial robotics. At the same time, many companies are working on commercializing the Internet of everything (IoET). This is where people, applications, devices, sensors, and data are seamlessly integrated and used to generate revenue and create value.

This explosion of connectivity and data will require a different type of sales management approach that can turn this data into valuable information that is used to create organizational knowledge that can be leveraged using new tools such as Artificial Intelligence (AI) and data science into customer insights.

Syam and Sharma indicated that part of the fourth industrial revolution is the integration of Artificial Intelligence (AI) and machine learning (ML) into the sales functions. They labeled this movement as the "Sales Renaissance." They indicated that the impact will not be uniform across all sales situations, such that the higher the complexity of the sales process, the lower the impact of AI and ML on the salesperson. In such cases technology will augment the salesperson role but will not replace him/her. In such cases the salesperson is a knowledge broker. On the other hand, simple sales situations are good target for AI and ML to minimize the role of the salesperson or even replace him. They proposed that AI and ML can play a significant role in improving the efficiency and effectiveness of all the steps of the sales process including prospecting, pre-approach and approach, presentation, overcoming objections in closing stage, and follow-up [3].

Sales teams will never relinquish its reliance in traditional salesmanship and relationship skills but will need to complement this with an intelligent use of the data and the insights that can be drawn out of it to bring the sales team efficiency and effectiveness to new heights that matches the new challenges presented by the VUCA world we live in.

The following Figure 1 clearly indicates that the world has passed the information age and the knowledge economy and is now moving toward insight-driven business models as the foundation of future competitive advantage. But the figure also shows that data is the foundation of this progression and evolution.

William C. Moncrief in his paper titled "Are sales as we know it dying... or merely transforming?" argued that many galvanizing environmental factors have 


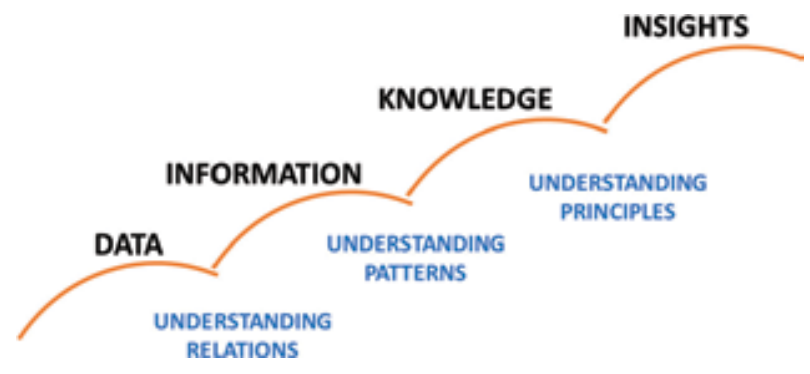

Figure 1.

From data to insights.

changed sales over the years (such as globalization, changing consumer habits, and automation), but the impact of social media effects on sales will present a leapfrog in sales transformation. The social media environment will be affected by and will affect all aspects of the sales organization [4]. With the information SM provides the analytic tools available (such as Facebook analytics, Socialbakers, etc.); sales teams have a very powerful new tool to support their sales efforts and in customer relationship building.

In a case study developed by Bocconcelli et al. in 2017, they confirmed that small and medium enterprises (SMEs) can use different types of social media (SM) platforms (such as Facebook, YouTube, and LinkedIn) to manage the sales relationships with its distributors, customers, and business partners. SM as a valuable resource reduced constraints of time and space, enhanced communication, and provided more planned and proactive sales approach. Finally, SM effectiveness as sales resource depends on its integration with other SME sales resources [5].

The future of sales management is to be insight driven and to be built on a solid foundation of data, information, and knowledge. This provides better understanding of relations, patterns, and principles to manage all of the process stakeholdersboth the digital-age sales team and the digital-age consumers.

\section{The digital-age sales team}

The digital-age sales team has seven key attributes needed to remain at the top of the future sales management system. These attributes hold true regardless of the size or shape of sales operation [6].

1. Modern sales teams are data driven: they use data along the full sales cycle from prospecting to lead qualification to closure and after-sales relationship management or upselling and cross-selling opportunities.

2. Modern sales teams are religious about sales forecast accuracy: the VUCA world that sales teams need to manage requires accuracy in forecasting to avoid resources misallocation and to increase their efficiency and effectiveness. Both underperforming and overachieving on sales forecasts should be looked at as areas for improvement.

3. Modern sales teams focus on sales performance management: beyond sales targets achievement, the digital-age sales teams must incorporate in their system a total sales performance management (SPM) system that integrates data from four sources: 
a. The Customer Relationship Management (CRM) system: data such as Pipeline Analytics, commission forecasting, and sales effectiveness measures

b. The enterprise resources planning (ERP) system: data such as demand planning, pricing optimization, and contract management

c. The human resources information system (HRIS): data such as onboarding, coaching, and certification

d.The industry data such as territory optimization, route optimization, and underserved market segments

4. Modern sales teams deliver constant real-time coaching: coaching should be an on-going process that is integrated in sales management and not as an add-on or ad hoc practice. It should also be based on information about sales performance management and targeted to achieve specific KPIs.

5. Modern sales teams manage using leading KPIs: traditional lagging KPIs such as sales target achievement and deal profitability are not enough to effectively manage the digital-age sales teams. Leading KPIs such as number of calls made, number of visits, average duration of sales calls, etc. are forward-facing indicators that give a picture of the health of our sales process efficiency and effectiveness.

6. Modern sales teams continually monitor and tune their sales process: as sales teams continuously face new types of customers and new markets with challenging new needs, the sales process must be continually monitored and tweaked to match the evolving sales situations and requirements. Sales process elements such as inputs, non-value-adding steps, decision points, and control points need to be assessed and improved.

7. Modern sales teams encourage performance through motivational initiatives: compensation plans and commission schemes motivate basic sales performance, but high-level sales performance requires creative motivational initiatives such as sales contests that motivate the winners as well as the whole team.

\section{The digital-age consumers}

Our sales teams need to face today's digital-age consumers. Those consumers are more complex and better equipped to deal with sales people. They are characterized by the following seven dimensions:

1. They are more knowledgeable: thanks to internet accessibility, user-generated content, and social media, consumer today have access to many sources of information to learn about companies, products, and services from different sources and perspectives.

2. They are more demanding: consumers today have new definition of VALUE that goes way beyond features and benefits. Sales teams need to focus on value propositions that can satisfy consumer demand. 
3. They are more empowered: connected consumers have more options that allow them to compare and contrast different offerings to choose the best. They have more channels to access information, products, services, and companies.

4. They are more collaborative: consumers today help each other and provide information, opinions, advice, and support that were traditionally provided by the sales person.

5. They are more diverse: thanks to the globalization of markets and consumerization of technology, consumers today share different experiences from different backgrounds and perspectives to enrich each other's purchase experience and make it more challenging for the sales team and the sales process adaptation to manage this diversity.

6. They are more interactive: the prefiltration of user-generated content (UGC) represents a whole new input to the company-customer communication process. This many-to-many communication requires continuous monitoring and evaluation by the sales team.

7. They are more on the move: sales teams need to learn how to manage this new Any-Where, Any-Time, Any-Device (AWATAD) shopping behavior of consumers that are constantly on the move.

All those dimensions are driven by the inherent characteristics of the digital world we live in. this new consumer needs a new breed of sales people, tools, and processes to meet his needs, expectations, and higher levels of power.

This new level of consumer power in the digital age is based on four sources: two individual-based power sources (demand- and information-based power) due to higher level of accessibility and information availability and two dynamic and complex network-based power sources (network- and crowdbased power) due to higher levels of connectivity and interactions on social media platforms [7].

Demand-based power is viewed as democratic voting power exercised by the consumer in different actions online, such as Facebook likes, YouTube views, Google searches, and Amazon purchases. Information-based power is related both to the consumer content consumption and content creation.

Network-based power comes from the consumer ability to add value beyond the original content through content dissemination, content completion, or content modifications. Finally, crowd-based power comes from pooled, mobilized, and structured resources that the individual consumer and the groups he belongs to can benefit.

This escalating level of consumer power needs to be managed across the different areas of customer touch points and interactions both in the physical and digital worlds. That led to the redefinition of when and where the customer and the sales team connect.

Sales management is about efficiently and effectively managing the customer moments of truth. Traditionally, companies use different sales and marketing stimuli to create the first moment of truth during the sales process at the store (in-store promotions, merchandizing techniques, etc.) then the second moment of truth as the customer experiences the product/service (product design, after-sales service, updates/upgrades, etc.). Figure 2 shows the traditional three-step mental model of sales/marketing [8].

As per Google, in the digital age, sales management needs to add a zero moment of truth (ZMOT), where the sales process starts in a pre-shopping stage that can happen 
online or at home or in store. This means that modern sales teams need to change their engagement model and definition of customer touch points (see Figure 3 below).

In a survey of 5000 customers, Google found that online comparison shopping comes (54\%) immediately after talking with the sales person (57\%) as the main influencer in their buying decision (see Figure 4 for the comparison shopping online and searching online (50\%) rank among the top influences on the shoppers' ultimate decision) [9].

Savvy consumers are becoming increasingly fastidious and expect a tailored, personal shopping experience. Modern day consumers expect to be able to shop anywhere (home, in-store, at work, on the road), at any time $(24 \times 7)$, and from any device (computer, mobile phone, e-kiosk, etc.). They want the right product and the right price delivered at the right time. Consumer-focused retailers are working hard to meet these stringent demands across the different channels the consumer is using. This integrated customer shopping experience is formed by the new environment known as the omni-channel retailing.

The future in retailing is in the tight and seamless integration of online and offline business practices into a new business model that cater to the new emerging consumer needs. Traditional brick-and-mortar outlets, pure e-tailer sites/applications, and brick-and-click (bricks-and-mortars that also have an online presence) players need to develop new omni-channel-based strategies. That is why traditional retailers are looking to go online and why e-tailers are looking at various options to establish a physical presence (lately AMAZON acquired a supermarket chain called

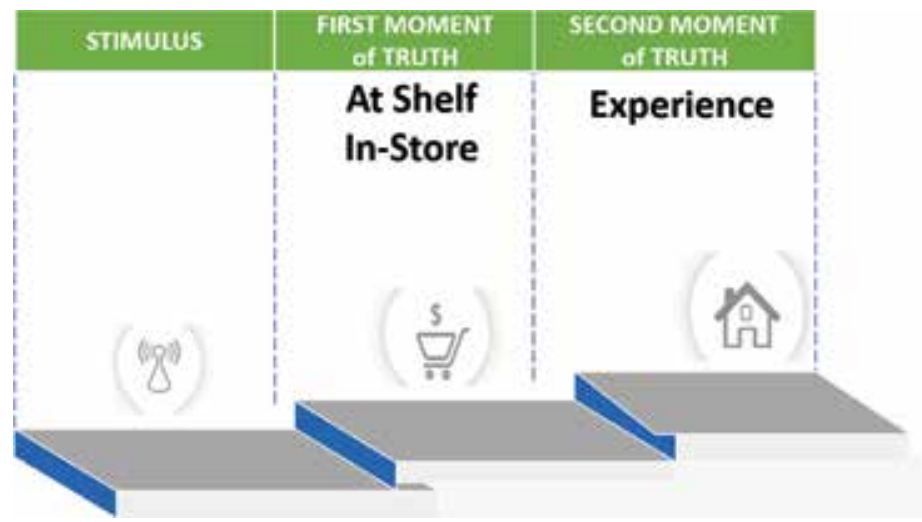

Figure 2.

Traditional sales/marketing mental model [8].

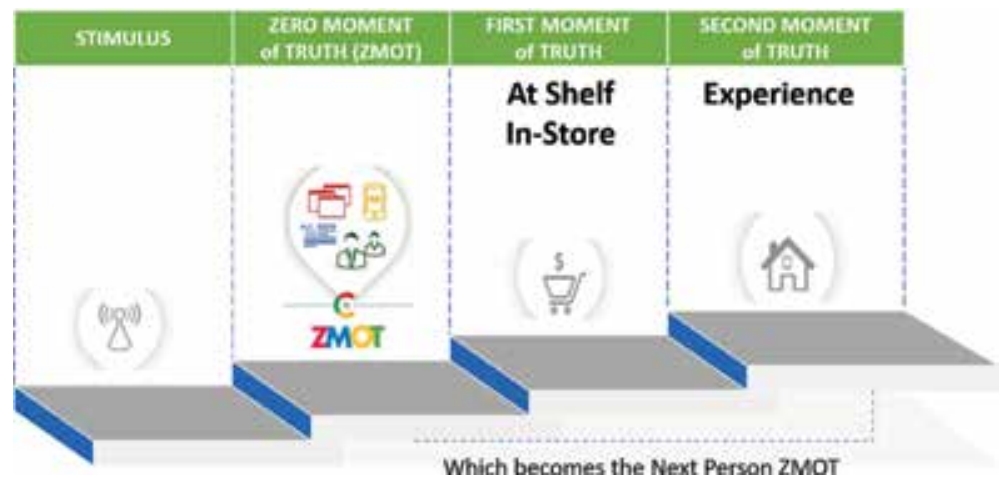

Figure 3.

New-age sales/marketing mental model [8]. 


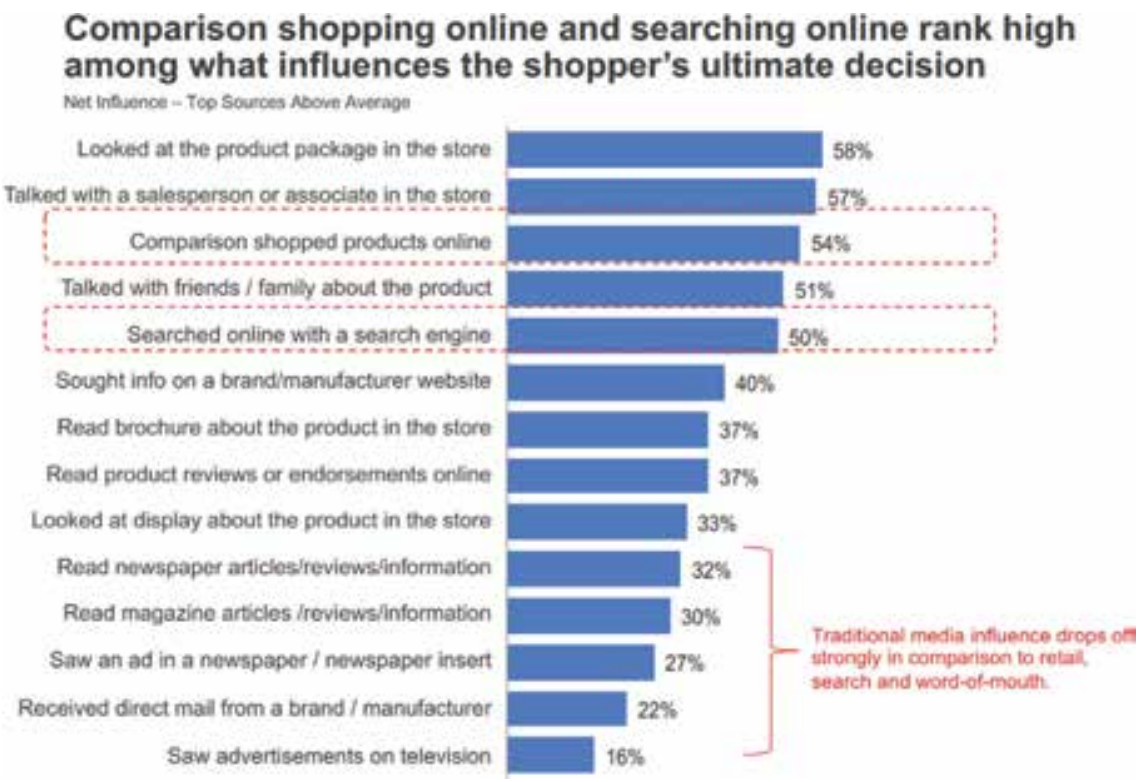

Figure 4.

What influences the shopper's ultimate decision [9].

WHOLE FOODS and established pilots for physical stores called AMAZON GO). The challenge is to find a seamless solution for both the customer experience and internal sales management processes.

The omni-channel sales environment integrates both online and offline sales outlets including elements such as (1) online catalogs, (2) point of sale (POS) and payment systems, (3) mobile applications, (4) social media, (5) websites, (6) physical store, (7) near-filed communication (NFC) devices, (8) touch screen and tablets, and (9) digital screens. Those nine elements might see more options added to them in the future, so what we consider as complex sales environment today will be more and more complex in the future. That brings both opportunities and threats that sales management teams need to be aware of and ready for. This can be managed by adopting an integrated online to offline and offline to online $(\mathrm{O} 2 \mathrm{O})$ that meets the expectations and needs of the digital-age consumer [10].

Cummins et al. define omni-channel marketing in a sales context as the synergetic integration of customer touch points and communication opportunities for the purpose of creating a unified brand experience regardless of channel, platform, or stage in the selling process. They developed a framework for the impact of omnichannel marketing on six sales dimensions [11]:

- Sales contexts (B2C vs. B2B)

- Impact of technology

- Stages in the sales process

- Impact on relationships

- Impact on firm performance

- The role of communication tools and platforms 


\section{The digital-age $B 2 B$ buyers}

Compared with buyers in the business-to-consumer (B2C) sector, businessto-business (B2B) buyers have been largely predictable in how they make buying decisions. But increasingly, that is no longer the case. Today, B2B buyers are behaving like consumers. They use online resources to collect information about the products, different suppliers, other buyers, and many more. This behavior reshapes the business buyers purchasing process, roles, and decision-making. This "consumerization" of B2B buying has made business customers more and more powerful. To maintain their balance of power in the process, sales professionals need to change their approach and become as digital as their customers [12].

One major driver is the dramatic increase in the level of competition and disruption in the marketplace. The advent of more transparent marketplaces and the proliferation of online content and digital communities, combined with social media, allow buyers to increasingly self-educate and to process their purchases directly without dealing with a salesperson. According to the International Data Corporation (IDC), the majority of buying decisions (between 50 and 80\%) are made prior to the engagement of the salesperson. Also $90 \%$ of B2B buying, decision-makers never respond to cold sales calls.

A recent study by Mckinsey \& Company reported that the type of buying situation will have a big impact on the how B2B buyers value the involvement of the sales professional. In new-B=buy situations (where the buyer is researching a new product or service), $76 \%$ reported that it is helpful to engage with a salesperson. In the case of modified re-buy, the figure dropped to $52 \%$. Finally, in the case of straight re-buy of the same product/service, only $15 \%$ of buyers saw value of dealing with the salesperson [13].

The above reviewed studies clearly indicate that traditional sales organizations face the risk of obsolescence as buyers become more self-sufficient and more digital savvy. Basic sales interactions can be easily handled using online resources/portals such as Alibaba. Sales organizations need to focus more on managing complex purchasing situations where their value can be appreciated.

Managing the digital-age B2B buyers requires the adaption of digital selling approach that integrates new skills, tools, and processes. Companies like SAP and XEROX adopted a methodology that called for the establishment of a digital sales center of excellence ( $\mathrm{CoE}$ ) that provides leadership, best practices, skills, processes, technologies, and other kinds of support to their sales teams.

The digital sales CoE develops the following six competencies [12]:

1. Digital performance management links sales activities tracking and content management to financial outcomes.

2. Digital sales confidence integrates digital skills and capabilities into sales activities and understand customer's agenda to position the offered solutions.

3. Cross-channel coverage management delivers consistent, seamless experiences to maximize revenue potential and cost efficiency across channels.

4. Social networking enables sales to identify leads and the right decision-makers.

5. Relationship intelligence automation leverages internal data and external data to understand relationships and relationship strength. 
6. High-value marketing content engages with content aligned to the customers' agenda, while reinforcing company brand and key marketing messages.

With a digital selling CoE in place, a company's sales operations can become much more efficient and effective and substantially improve the return sales delivered to the enterprise, while meeting the expectations and needs of the digitalage B2B buyers. The digital selling CoE uses sales enablement process and tools to deliver on its promise.

\section{Putting modern sales enablement to work}

There is no question that technology in the digital age has rapidly advanced the way we approach, negotiate, and close new opportunities. Sales enablement which is the process of providing the sales organization with the information, content, and tools that help sales people sell more effectively and successfully engage the buyer throughout the buying process is a great example of the impact of digitization. Once there is an information technology (IT) solution for better content management and basic performance feedback, sales enablement is now central to how business gets done at companies of all sizes and varieties.

Emerging technologies have made it possible to see what, when, and how the sales process, sales/marketing content, and customer interactions/feedback are working. This provides a solid foundation for digital sales transformation.

Analytics are at the core of sales enablement tools and are key to sales teams' performance improvement. When the sales leaders use analytical insights, they can link what the marketing team is pushing (e.g., content) out and what the sales team is pulling in (e.g., conversions/sales).

Digital sales organizations need to develop an effective content strategy that is based on solid understanding on how the offered content is being used both by the sales team members and the customers. Tracking and analyzing what content is being accessed, how often, at what time, and at what stage in the sales process can provide the needed insights for sales management.

Following are the major advantages that the sales enablement tools offer and the importance of analytics to each [14]:

1. Content management: Sales teams deal with different customer segments that need different types of content; hence, offering dynamic, flexible ways to organize content that is enriched by performance data, and best practices are of great value to todays' digital sales organization.

2. User experience (UX): Sales teams need to focus their time and efforts on customer engagement and not on navigating complex software menus and clicking on endless number of buttons. Providing a user experience that integrates with the way sales teams work is a must for adaption.

3. Machine learning: Using data collected on searches, content recommendations, and sales enablement tools performance, machine learning can provide smart, efficient, and customized use of tips to the sales team members to get the best out of the tool.

4. Customer engagement: Delivering the right content at the right time through the right channel for each customer ensures higher levels of engagement and ultimately better conversion rates. 
5.Performance analytics: Advanced analytics for content utilization and customer engagement can support the development of best practices.

6. Modification tracking: As sales people modify the content to customize their customers' interactions, it is important to track those changes to be able to continuously improve the content quality.

7. Technology integration: It is important to integrate the sales enablement tools with existing enterprise resources planning (ERP) and Customer Relationship Management (CRM) systems or other advanced tools such as business intelligence (BI) software to ensure data exchange and integrity in the developed insights.

8. Onboarding and training: Using the insights drawn from the analytics, sales teams can shorten onboarding time for new salespeople and improve overall sales team efficiency and effectiveness.

9. Usage Rates: Managers can monitor the sales enablement tool usage for the whole team or for individual salespeople to provide feedback to improve performance and highlight accomplishments.

10. Proven ROI: Sales enablement tools has proven track record in achieving higher levels of customer conversion. This is the real objective that sales teams have for the use of the tools.

\section{Sales management in the digital age}

Sales management is at the forefront of management systems development due to its direct link to the customer - the ultimate prize of sales. As new business models evolve, sales management needs to add new dimensions to the sales process and needs to embrace new ways to manage its traditional ones. So sales management has to work in a broader and newer environment, in coexistence with the traditional lines.

Traditionally, there are four basic elements of sales management [15]. All of them can be enhanced when augmented by digitization as indicated below:

1.Planning: Sales plans must be based on extensive market research, and the facts must be verified at every stage. The plan should also be subject to continued review. The details of the plan should be discussed, with the different stakeholders to gain alignment and commitment. The ease of access to market information and availability of analytical tools can help the sales teams develop better plans to guide their efforts.

2. Coordination: Coordination is all pervasive and permeates every step of the sales management process. It should be done both at the interdepartmental and interpersonnel levels. Utilization of digital sales management tools can ensure free flow of information that is selective to the objectives of the business.

3. Controlling: Sales managers need to check regularly that the sales activities are moving in the right direction. The management system should capture the lessons learnt (based on the analytics and insights) and take corrective actions while instilling new ways to prevent future deviations. The management needs to make sure that targets, budgets, and schedules are achieved or followed in letter and spirit. 
But gaining control over the sales team is not a simple task. Studies have shown that sales force has opportunism tendencies to gain short-term personal advantages over the long-term firm or team gains. This opportunism takes two main forms: shirking and influence activities. In their article on regaining control of the sales force, Kim and Jung studied 304 Korean automobile dealers and found that outcome controls and behavioral controls have different effects depending on the type of sales opportunism.

Output controls (preset goals to reward or penalize the sales force) mitigate sales control loss when it is matched with shirking behavior (evasion of obligation and withholding efforts), while it aggravates control loss when matched with salespeople influence activities (intentional acts to persuade the employer to take actions that that will be in their own advantage). On the other hand, behavior control (rules and procedures to reward and penalize sales force) mitigates control loss when matched with salesperson's influence activities and aggravates control loss when matched with shirking activities [16].

4. Motivating: Only motivated salespeople can achieve company's strategic sales goals (not only sales targets). Hence, motivating the sales teams is crucial for the long-term sustainability of results. It is a complex process that involves many tools and techniques since different people are motivated by different things. Hence, sales managers need to pay a lot of attention to this element of the sales management process.

In 2017, Reid et al. studied the use of 68 sales management practices (SMPs) such as forecasting, training, incentive pay, evaluations, etc.-covering seven key managerial areas building on the seminal work done by Dubinsky and Barry in 1982. Those sales management areas are (1) sales planning, (2) organization and selection, (3) training, (4) sales compensation, (5) supervision and evaluation, (6) control of sales force performance, and (7) sales technology. They identified a list of 21 challenges that sales managers face today and concluded that the low level of technology use by sales organizations amplifies the impact of those challenges [17].

Technology today is being used in the field by sales people for data collection and automation of sales tasks but is not as prevalent when it comes to managing and supporting the sales management practices (SMPs).

Hence, there is need for higher level of adoption to meet the need of the new breed of digital-age sales managers that is emerging. They are data hungry and technology savvy. This new breed also behaves more like a modern-day sports coach, craving sales performance insight. Digital-age sales managers live by a new mantra: motivate, engage, and coach.

With the integration of people and technology, sales managers need to continually develop their skills, process, and tools to achieve results in the VUCA world. This can be can only be achieved when they develop systems that fully integrate the seven sales management areas and not to deal with them as discrete or sequential steps. For example, this means using the control system (KPIs) to motivate the team and the coordination system to optimize the planning process.

In 2018, Panagopoulos et al. discussed the importance of boosting sales force morale in highly dynamic complex markets. They used the job demand-resource (JD-R) theory as the basis for their model. They studied the impact of market demands (customer purchase complexity and market dynamism) on sales force morale that drives key outcomes (sales force turnover and sales force productivity). Three job resources (sales capabilities training, firms product portfolio depth, and sales units' cross-functional cooperation) were used as moderating variables for the relationship between market demands and sales force morale [18]. 
In the longitudinal study they conducted over 2 years, they found that an increase of morale by one point on a five-point scale improves sales force productivity by $€ 226,834$ of operating revenues per salesperson, while it lowers turnover rate by $5 \%$.

Finally, since the driver of any sales management process and the target is the efficient and effective sales team, the following section will demonstrate how can we encourage, engage, and coach the digital-age sales team [19].

ENCOURAGE: Sales people are target driven. Achieving the annual revenue target is of course vital but not enough to provide the needed encouragement for the sales team. It is the approach to achieving the set of targets that needs to be redefined in today's VUCA sales environment.

The problem with the sales revenue metric is that it is rearview facing. It is often referred to as a "lagging metric." Digital sales managers need to use an integrated set of metrics that combines lagging and "leading metrics" to manage not only the sales results/outcomes but the sales process inputs and steps. This will allow sales managers to improve the process control as well as timely actions to ensure the desired results achievement. This provides a real proactive approach to sales teams' encouragement.

For example, this can be achieved by having the sales teams:

- Qualify leads within 24 hours of creation

- Create a certain number of pre-pipe opportunities each week

- Meet a target of “meaningful” sales calls each week

- Book more meetings or demos with the right level of contact each week

- Build a regular monthly or quarterly cadence of deal closure

These leading sales metrics need to be combined into a regular cadence of daily, weekly, monthly, or even quarterly targets. This would allow the sales manager to drive the sales behaviors right across the sales process that delivers sustained success.

Sales metrics also need to follow different time intervals. This allows for balancing the short-term and long-term monitoring of the performance. This approach is called metrics pacing. There are four pacing methods:

1. Constant-equal split of the target value across the whole time period

2. Front loaded — starts with a high percentage of the target value then reduce it gradually over the time period

3. Back loaded—starts with a low percentage of the target value then increase it gradually over the time period

4. Late push-accelerated rate of target achievement toward the end of the time period

This pacing approach for sales target setting allows for the flexibility in adapting the targets for different sales teams' capabilities and different client buying situations. This customized approach to target setting provides a more personalized approach that is more fit with today's sales people mentality that does not approach the one-size-fits-all traditional approach.

Building on the need to use a combination of leading and lagging metrics, calculating the Salesperson Future Value (SFV) to the firm can add a whole new dimension 
that supports today's sales managers challenging task of encouraging their teams while managing their investment in the team members to maximize the sales team performance and the firm return. Kumar, Sunder, and Leone proposed a system to measure the Salesperson Future Value and its drivers. They defined SFV as the net present value (NPV) of future cash flows from the salesperson's customers after accounting for appropriate costs associated with the salesperson. The study identified the drivers of SFV as training interventions (both for growth-related and task-related key skill areas) and incentives (both monetary and non-monetary). They used the salesperson tenure, region, market size, and competition level as control variables. They found that using current revenue generated by the sales person can lead to the wrong decision about the SFV in $27 \%$ of the cases and that the correlation between revenue generated and SFV is only 0.64. Effective management of the drivers of SFV for different segments of salespeople based on this leading indicator can help the organization optimize its resources and achieve its strategic sales objectives [20].

Finally, encouragement is reinforced with celebrating success. The digital-age sales manager knows that publicly recognizing achievement will not only encourage the winners to do more to stay at the top but will motivate the rest of the team to join the winner ranks.

The traditional once-a-year sales competitions that uses only sales target achievement (lagging indicator) does provide the foundation to develop a culture of continuous improvement. Hence using multiple year-round competitions using leading indicators is a better tool to maintain a highly motivated sales team.

ENGAGE: Most studies on salespeople behavior indicate that they are independent and individualistic personalities that did not follow instructions easily and value their freedom, unlike production workers or accountants. Engaging sales team to strictly follow the sales process developed by the organization is a challenging task for the management.

One of the approaches used to improve salespeople compliance with the sales process is to incorporate a set of "sales behaviors" metrics (leading indicators) as part of the sales management dashboard. This addition of key behavioral indicators (KBIs) to the traditional business oriented key performance indicators (KPIs) such as revenues and linking them to have a new definition of winners and losers is a critical part of the digital-age sales management approach.

The correlation between achievement of behavioral targets and revenue targets generates four profiles/segments of sales performers that not only focus on target achievements but in sustainability of delivering results while balancing the shortterm and long-term outcomes.

Winners: The group that overachieved on both the "sales behavior" target and revenue target. These are the top performers that should be closely monitored in order to learn from their best practices.

Growers: This group overachieved on their "sales behavior" target but did not meet their revenue target. They need coaching to improve their performance on specific parts of the sales process such as handling customer objections and closing. If we used only the traditional revenue targets as the metric for success, those sales people would be treated as Strugglers.

Strugglers: The sales people that did not achieved neither their "sales behavior" nor their revenue target. This group needs to receive sales training with active coaching or need to leave the sales organization.

Mavericks: The sales people that achieve the revenue target, but not the "sales behavior" target. They most probably do not follow the sales process and potentially close unhealthy deals that can hurt the organization down the road. If we used only the traditional revenue targets as the metric for success, those sales people would be treated as inners. 
This approach of tailored support to sales team will provide higher levels of engagement and more user adoption of the sales management tools. Digital-age sales managers transform the Customer Relationship Management (CRM) system from a passive data repository that is otherwise easily mistaken for a management reporting tool. They turn the CRM system into a real-time sales engagement tool.

COACH: Proactive, deal-specific coaching to the sales team is the real driver for future success. The active use of the Digital Sales Management System (DSMS) by the sales managers ensures that achieving results today while coaching the team build the capabilities for tomorrow.

The data savvy sales manager knows they can utilize the achievement of leading sales behaviors mapped against a deal to determine its true health. Utilizing machine learning, they drive the Digital Sales Management System to provide a real-time deal health prediction for every single deal.

Finally, coaching to improve sales force performance beyond deal closing can be achieved by incorporating innovation implementation into the sales organization. Wang and Miao proved that sales force creativity impact on performance is fully mediated by innovation implementation. The relationship between creativity and innovation is moderated by innovative organization culture and behavior-based supervision. This is where proactive coaching that is guided by real-time data and analytics can lead to higher levels of sales force performance. The coaching should focus on market orientation (MO) (customer orientation, competitor orientation, and inter-functional coordination) to spur sales force creativity [21].

\section{Conclusion}

The VUCA world is dramatically changing the face of sales management. The digital-age consumer and B2B buyers need digital-age sales managers and organizations that continuously and actively map out and manage their sales process. Sales management today needs to be insight-driven, agile, experimentation based, and flexible.

New tools that collect, integrate, and analyze customer data from internal and external sources provide the foundation for the insight-driven sales management. This includes technologies such as analytics (Web, social, and mobile), Artificial Intelligence, machine learning, dynamic content management, and user experience (UX).

Those tools might represent a risk for some basic sales jobs that is focused on order taking for simple products but represent a great opportunity to augment salespeople that manage complex and high-margin sales to improve their efficiency and effectiveness.

New sales management practices need to manage the omni-channel approach to customer touch points because customers today expect to engage with the company sales team Any-Where, Any-Time, Any-Device (AWATAD). They continuously move between the online and offline worlds $(\mathrm{O} 2 \mathrm{O})$ during the buying decisionmaking process. This represents a major opportunity for data collection to develop real-time insights beyond the traditional consumer market research studies.

The modern-day sales managers need to use leading indicators (not only traditional sales revenue lagging indicators) to measure progress along the sales process end-to-end path, to make these steps transparent to the whole team and motivate them to overachieve. They make success transparent and build a culture of winning based on creativity and innovation. They use the data insights and technology to provide intelligent coaching in real time.

The digital-age sales manager thinks and behaves like a modern sports coach and brings science into the art of selling. 


\section{Author details}

Hesham O. Dinana

American University in Cairo, Cairo, Egypt

*Address all correspondence to: hdinana@aucegypt.edu

\section{IntechOpen}

(C) 2019 The Author(s). Licensee IntechOpen. This chapter is distributed under the terms of the Creative Commons Attribution License (http://creativecommons.org/licenses/ by/3.0), which permits unrestricted use, distribution, and reproduction in any medium, provided the original work is properly cited. (cc) BY 


\section{References}

[1] Bennet N, Lemoine JG. What a difference a word makes:

Understanding threats to performance in a VUCA world. Business Horizons. 2014;57(3):311-317

[2] IDC: Worldwide Embedded and Intelligent Systems 2015-2020 Market Forecast. Framingham, MA, USA: IDC; 2015

[3] Syam N, Sharma A. Waiting for a sales renaissance in the fourth industrial revolution: Machine learning and artificial intelligence in sales research and practice. Industrial Marketing Management. 2018;69:135-146

[4] Moncrief W. Are sales as we know it dying... or merely transforming? Journal of Personal Selling \& Sales Management. 2017;37(4):271-279

[5] Bocconcelli R, Cioppi M, Pagano A. Social media as a resource in SMEs' sales process. Journal of Business \& Industrial Marketing. 2017;32(5):693-709

[6] Cloudapps. 7 Attributes of a Modern Sales Team. Available from: https://info. cloudapps.com/modern-sales-teamattributes [Accessed: 22 September 2018]

[7] Labrecque L, vor dem Esche J, Mathwick C, Novak TP, Hofacker CF. Consumer power: Evolution in the digital age. Journal of Interactive Marketing. 2013;27(2013):257-269

[8] Łysik Ł, Kutera R, Machura P. Zero moment of truth: A new marketing challenge in mobile consumer communities. In: Proceedings of the European Conference on Social Media: ECSM. Brighton, UK; 2014. pp. 294-304

[9] Google/Shopper Sciences.

Zero Moment of Macro Study. April 2011. Available from: https:// www.thinkwithgoogle.com/ marketing-resources/micromoments/2011-winning-zmot-ebook/ [Accessed: 21 September 2017]

[10] Omni-Channel Marketing for Customer-Driven Interaction. Available from: https://www.kentico. com/product/resources/whitepapers/ omni-channel-marketing-forcustomer-driven-interac [Accessed: 14 July 2017]

[11] Cummins S, Peltier JW, Dixon A. Omni-channel research framework in the context of personal selling and sales management: A review and research extensions. Journal of Research in Interactive Marketing. 2016;10(1):2-16

[12] Digital selling: reinventing sales to stay relevant to changing B2B buyers. Available from: https://assets.ey.com/ content/dam/ey-sites/ey-com/global/ topics/advisory/ey-reinventing-salesto-stay-relevant-to-b2b-buyers.pdf [Accessed: 22 September 2018]

[13] Colter T, Guan M, Mahdavian M, Razzaq S, Schneider JD. What the Future Science of B2B Sales Growth Looks like. McKinsey; 2018. Available from: https://www.mckinsey.com/ business-functions/marketing-andsales/our-insights/what-thefuturescience-of-b2b-sales-growth-looks-like [Accessed: 27 December 2018]

[14] Sales Enablement in the Digital Age. 2016. Posted by Rachel Davidson. Available from: https://salespop.net/salesprofessionals/sales-enablement-digitalage/ [Accessed: 23 September 2018]

[15] Sales Management: An Overview. Posted by Kundu S, Bishnoi VK. Available from: www.ddegjust.ac.in/ studymaterial $/ \mathrm{mba} / \mathrm{mm}-308 . p d f$. 6-8

[16] Kim SK, Jung YS. Regaining control of sales force. Industrial Marketing Management. 2018;73:84-98 
[17] Reid DA, Plank RE, Peterson RM, Rich GA. Examining the use of sales force management practices. Journal of Business \& Industrial Marketing. 2017;32(7):974-986

[18] Panagopoulos NG, Hochstein B, Baker TL, Pimentel MA. Boosting sales force morale in highly dynamic, complex markets: The role of job resources. Industrial Marketing Management. 2018;74:237-253

[19] Sales Management in the Digital Age: Motivate, Engage \& Coach, The 3 Key Aspects of Modern Sales Management. Available from: https://www.cloudapps.com/salesmanagement-digital-age/ [Accessed: 23 September 2018]

[20] Kumar V, Sunder S, Leone RP. Measuring and managing a salesperson's future value to the firm. Journal of Marketing Research. 2014;51(5):591-608

[21] Wang G, Miao CF. Effects of sales force market orientation on creativity, innovation implementation, and sales performance. Journal of Business

Research. 2015;68:2374-2382 


\title{
Organizational Capabilities, Value Cocreation, and Marketing Innovation: How Well Are We Prepared to Face Future Challenges?
}

\section{Leslier Valenzuela-Fernández and Natacha Peñaloza-Briones}

\begin{abstract}
The purpose of this chapter is to discuss the importance of management and strategic development, as well as network management and market orientation, in the results of innovation in marketing and collaboration of companies. In addition, the authors analyze how collaboration with other agents of interest is fundamental for the change of projects to have strategic impact, that is, for there to be a relationship between the development efforts of the area and the results of the business. Hence, the relevance of business models and the existence of dynamic capabilities to create value to the organization, the client, and society are analyzed. Coupled with the authors' empirical examination of the degree of collaboration that Chilean industrial companies have achieved, the main contributions of this chapter are (1) an explanatory study that provides a systematic analysis of literature regarding innovation organizational capabilities; (2) identification of three aspects of structure of a company's network, market orientation, and strategic development, which are relevant to consider when establishing superior performance; and (3) generation of empirical evidence through a study applied to companies of the business-to-business sector in Chile using a self-administered survey method and presentation of results at the variable level.
\end{abstract}

Keywords: organizational capability, marketing innovation, collaboration, market orientation, value cocreation

\section{Introduction}

Consensus agrees that the term known as "marketing” first appeared between the years 1906 and 1911 in the United States. Although its origin is linked to the act of sales and distribution by the period's small-time merchants, Kotler believes that, instead, it was born alongside the arrival of humanity [1].

The American Marketing Association (AMA) introduced the first formal definition of this discipline as "the conducting of business activities that direct to the flow of goods and services from the producer to the consumer or users" ([2], pp. 191). This definition was widely accepted by the international scientific community and is still in use today. 
In retrospect, marketing has experienced substantial change in its conceptualization since it first appeared. One such case is the introduction of a strategic component to the discipline during the 1980s, where a proactive vision of environmental control was created in alignment to a new idea of marketing that is capable of generating change and expanding its influence in the field [3]. In this regard, Sheath et al. [4] classified marketing into 12 different schools of thought, organizing the common denominators and components into the general theory of marketing.

Considering the aforementioned, it is Kotler and Keller [5] whom proposed the new concept of marketing that best adapts to the current world. According to the authors, and from the perspective of companies, marketing is "the process of planning and executing the conception, pricing, promotion and distribution of ideas, goods and services to create exchanges that satisfy the specific objectives and organizations. Marketing management is the art and science of selecting target markets and to attract and retain customers through the generation, delivery and communication of superior value" ([5], pp. 816).

In addition, the theories and domains of marketing have increased in number since the very start of the discipline [6]. Hence, the current approach of marketing now defines that it must not only be beneficial for all the relevant actors and people involved in the business but must also bring positive benefits to society as a whole [3]. These numerous changes have increased interest in marketing from various groups in society [7]. It is in this context that the relationship between marketing and innovation has been highlighted $[8,9]$, bringing an understanding that innovation in marketing serves to utilize and generate significant change in design, packaging, positioning, promotions, relationships, brand, and product or service pricing, all with the aim of increasing sales [3].

In this regard, innovation in marketing mainly tackles client needs beyond the general scope of the product [8]. Hence being part of a corporate competitivity nurturing process that contributes to the economic development of companies and society $[10,11]$. In addition, innovation in marketing can bring to (1) the rise of a new idea, such as developments or radical innovation, and (2) incremental innovation, which is incremental modification of an existing concept, thus improving it [12]. Regarding radical innovation, this includes new products or business models [12] , as well as generating value over an already existing product by means of improvements [12].

Regardless that the literature originally considered innovation in marketing as an effect of competitivity, modern context highlights the importance of the relationship as an indicator that measures a company's competitive level $[13,14]$. This considers the fact that resource-advantage theory recognizes competitive advantage as a function of marketing, identifying a company's capability of innovating in marketing as a true measure that demonstrates a firm's true abilities [15-18].

The resource-advantage theory shows that the firm is determinant of profitability and not only the industry. This theory is based on the view that superior performance and a sustainable competitive position depend primarily on the resources of the firm $[16,18]$. The key challenge is to transform imitable and substitutable resources into core competencies, which form the foundation of superior competitive positions in specific market segments $[16,17]$. By doing this, these resources are developed and embedded as core competencies within the firm, not acquired, and improve with use, making them a source of sustainable competitive advantage [18].

The interest in resources and capabilities highlights the role of the management and strategic development. That means the firm's ability to make decisions regarding the resources to be allocated for the main actions to take place, where the effectiveness will be influenced by such decisions and their objectives [19]. Hence, the process of innovation transforms existing markets by creating new markets 
and opportunities. Furthermore, innovation encourages financial growth and is an important element in the search of sustainable competitive advantages that can ensure the survival and growth of companies [20-25].

\section{Marketing innovation and value cocreation}

Innovation in marketing is a key factor for company survivability, growth, job creation, improved productivity, and corporate competitiveness [9, 26, 27]. To benefit from it, pioneering firms must develop organizational models that can align to the business context, client needs, and company situation [28]. Traditional business models focus mainly on creating and retaining corporate value. In retrospect, the new economic environment requires business models to ask additional questions pertaining client value and structural reconfigurations for companies in the field [29]. Such reconfigurations demand firms to develop competitive capability through innovation and collaboration with providers, clients, government agencies, and other organizations [30].

In this regard, organizational capability is a work method that represents a collective problem-solving system due to its "dynamic" aspect. This dynamism is possible from its tendency to evolve in time through learning processes, which is distinctive and superior in the role of combining and assigning resources [31, 32].

When an organization possesses a specific ability, it means "the organization (or the parts that compose it) can perform an activity in a trustworthy, and at least in a minimally satisfactory manner" ([33], pp. 1244). "Minimally satisfactory" is defined as that the result of an activity complies with the minimum requirements of the organization. The use of organizational capability is linked to an action and performance. An organization possesses capability when it does something that is valued in an effective manner when compared to others. However, a case of isolated effective performance does not imply that the organization possesses the capability to solve the problem, as this would require the existence of recurring (problemsolving) patterns in time [34].

Based on this logic, a strong (dynamic) capability in organizational innovation in marketing would mean superior capability (in regard to the competition) to integrate, construct, and reconfigure internal competences to tackle or achieve changes in the corporate environment and diverse marketing situations [35]. Hence, understanding the determinants of innovation capability in performance is of great importance to companies, particularly when faced with markets that have different factors and competitive intensity [36].

The new models of competitivity in organizations highlight the existence of strong capabilities as sustainable competitive advantages. This is due to companies having learned how to copy various systems of costs, technology, distribution, service chains, manufacturing processes, and product features [37]. This makes it important to create business models that allow for the development of dynamic organizational capabilities related to innovation and proactive response to the needs of clients, consumers, and society as a whole [35]. Thus, business model sustainability is the result of creation and transformation of organizational capability [35].

In this regard, in the context of resource-based vision (RBV), a company builds a sustainable competitive advantage due to its resources and capabilities, which can be rare, valuable, inimitable, and nonsubstitutable in the market [38]. The capabilities (or competences) allow companies to use resources to achieve a desired result [39]. Thus, integrating resources and complementary capabilities encourage a generation of innovation and increase positive innovation influence, improving corporate performance $[40,41]$. 
Henceforth, managing a marketing innovation project in today's world has deeper significance than simply planning and developing a series of sequential and interrelated activities. It now requires taking actions from before the official "project development phase" by helping encourage an enabling environment [42]. This increase in complexity also requires greater coordination and collaboration efforts [43]. The latter, where knowledge and resources are exchanged, allow companies to benefit from the advantages that come from specialization, knowledge integration, and post-innovation performance [44].

Collaboration is defined as a type of cross-organizational integration with high levels of transparency, responsiveness, and synergy [45]. Collaboration refers to the capability of two or more actors/groups to communicate, coordinate activities, and share a team goal [22]. Concerning the aforementioned, various studies show the role of cooperation networks in the generation of innovation $[46,47]$. The most common arguments presented for collaboration involve the beneficial combination of sharing risks, resources, and competences [48, 49], gaining access to new markets and technologies [50], accelerating the launch of products to the market and combining complementary skills $[51,52]$, encouraging joint solutions of problems $[53,54]$, and facilitating the generation of cocreation of value and conservation of clients [55].

Thus, the choice to collaborate depends on balancing the risk versus the returns. Companies collaborate to acquire resources and abilities that they cannot internally produce but only when the risks of cooperation can be controlled at a tolerable level [56]. After all, there are always risks and limitations that are important to consider when collaborating $[57,58]$. Based on the intangible nature of the assets in play, the probability of experiencing opportunistic behaviors and knowledge disclosure increases, hence also increasing the transactional costs required to prevent such behaviors $[48,51]$. Furthermore, organizations might have difficulty in evaluating the value of a partner due to information asymmetry and the secret nature of collaboration itself [59]. In addition, each additional collaborator increases the costs of monitoring, coordination, and transactions [59].

It is important not only to collaborate between companies [60], as the involvement of other agents in marketing innovation can bring positive effects to future quality of service [61]. In this respect, project changes have strategic impact when the relationship between development efforts of an area and the business results are achieved through collaboration with the agents of interest [62-64]. Agents can be other companies, trade associations, universities, and even public institutions depending on the economic sectors and objectives that are sought [65-67]. Therefore, innovation is a collective process that involves multiple actors [65].

With the corporate cooperation for innovation is reflected in cocreation value, which emphasizes stakeholder participation in the various innovation processes [68]. Since "value is always co-created" and "all social and economic actors are resource integrators," value creation is increasingly interconnected and collaborative by nature [55]. As value is "always uniquely and phenomenologically determined by the beneficiary" ([55], pp. 9), value cocreation processes can include multiple actors; thus value as an outcome is subjectively determined.

Perks et al. [69] define cocreation as "the joint creation of value by the company and its network of diverse entities (clients, providers, and distributors). Hence innovation is the result of the interaction and behaviour between individuals and organizations" ([69], pp. 935). Therefore innovation is the valuable potential result of interactions and meetings with the involved actors in the process of cocreation [70, 71].

Several researchers have studied cocreation value and coinnovation, highlighting the importance of commitment, teamwork, and generation of convincing experiences in the creation of value [68]. Based on the works of Sheath and Uslay [72], 
Vargo and Lusch [55], Frow and Payne [70], and Frow et al. [73], 12 specific different forms of cocreation can be identified: (1) coconception of ideas (i.e., solutions of public origin), (2) joint design (i.e., product personalization), (3) coproduction (i.e., working collaboratively with producer), (4) copromotion (i.e., brand community), (5) shared prices (i.e., political events), (6) joint distribution (i.e., direct and indirect distribution channels), (7) coconsumption (i.e., digital platforms), (8) joint maintenance (i.e., army), (9) cooutsourcing (external customer support and service), (10) codisposition (i.e., recycling initiatives from tech companies), (11) joint experiences (i.e., adventure-based vacations), and (12) creation of shared meanings (i.e., organizational culture).

Regardless that the list covers a substantial number of possible ways of cocreation, Frow and Payne [70] recognize that in the future, new ways can rise. These authors also point to the fact that one form of cocreation can jointly exist with others. Thus, in a cocreation framework value is created for all actors through a win-win perspective [74]. In this regard, the inclusion of various agents that can form part of the cocreation value process becomes the very reason that the output can be so attractive $[75,76]$.

Cocreation allows companies to use the creative thought of other agents in the innovation process [77]. The sum of results in each process produces an increase in collective cocreation performance $[78,79]$. Considering that cocreation generates benefits to the interested parties, it also brings forth new challenges due to the characteristics, interests, and diverse objectives that exist among the different involved actors [80].

The participation of various actors (such as clients, providers, and partners) makes the cocreation value process to be complex by nature. Hence, it needs the development of new frameworks to analyze the creation of value because of numerous relationships between all involved actors, instead of only focusing on the relationship between providers and clients [74]. Based on previous research, a firm can establish collaborative activities in marketing innovation with a wide range of agents. These can be categorized as (1) those belonging to the value chain, providers and customers, with those who seek to optimize existing skills; (2) those with which new knowledge is generated, universities and research centers; and (3) those with which both ends can be sought, governments, competitors, and others $[62,63]$. Thus, understanding the determinants of innovation capability in performance is of great importance to companies, particularly when faced with markets that have different factors and competitive intensity [36].

\section{Determinants of innovation capability}

\subsection{Management and strategic development}

Strategy is defined as the logical combination of actors, factors, and actions selected among other combination alternatives to achieve a specific objective in a specific context [81]. It is the ability (of the organization) to make decisions regarding the resources to be allocated for the main actions to take place [19]. The effectiveness of project strategy management is influenced by the decisions and the objectives set during the process.

The operation of a firm is focused on achieving the objectives, facing difficulties, and facing opportunities in the context in which the company carries out its activities with the capabilities and resources it possesses. Hence, in seeking to achieve its objectives, a firm will intend to ensure the development of these activities in the most appropriate manner while generating value [82]. 
In this regard, Brand et al. [83] affirm that governance consists of setting control mechanisms, incentives, rules, and penalties and coordinating the actions of network players, which the authors define as collective structuring [84]. These elements of governance are the mechanisms used by managers and network players to ensure better control over the formal and informal aspects of the network [83]. Concerning network management, Roth et al. [85] state that management is responsible for positively influencing the members' competitiveness and for reaching the goals proposed by the organization. The authors also list some of the roles of interorganizational network management such as member selection, planning and communication, assessment, integration, providing services to members, coordination, incentives, and controls.

Hence, innovation management is an intentional systematic process where the level of affinity that the company has with its environment plays an important role [86]. A firm can choose to apply different innovation strategies to achieve its objectives or improve its competitive advantages [87]. Thus, innovation stops being a single act that applies novel ideas, instead becoming a manageable and susceptible process that is both measured and systematically controlled [88]. In this regard, the structuralization of innovation processes becomes the starting point of great interest for companies [86].

The structuralization of innovation is managed through the stabilization of processes and the setting of conditions, restrictions, behaviors, and expected results [89]. Hence, the management of the innovation process must consider the framework, criteria, and tools for identifying, elaborating, and systemizing each of the involved activities. Under these conditions, each organization will be able to control, improve the different aspects of innovation, and thus integrate them into the total processes of the company.

The literature has addressed a series of aspects related to management structure and control such as the rules, penalties, formal agreements, and control mechanisms that include leadership and coordination, which are relevant to sustain innovation initiatives [84].

Organizations must take into account the relevant guidelines to build, implement, and evaluate innovation strategies adopted by the company. Innovation strategy must (a) recognize the importance of the client in the process, (b) develop strong ties with providers, (c) integrate different phases and actors in the constructive process, (d) improve the flow of information, (e) transmit knowledge of one project to another, and (f) encourage the use of rules based on the results, which are not pre-established [90]. This is important because in any collaboration process, there are risks and limitations that are considered [48,57]. Based on the intangible nature of the assets at play, the probability of experiencing opportunistic behaviors and knowledge disclosure increases, hence also raising the transactional costs required to prevent such behaviors [51]. Furthermore, organizations might have difficulty in evaluating the value of a partner due to information asymmetry and the secret nature of collaboration itself [59]. In addition, each additional collaborator increases the costs of monitoring, coordination, and transactions [59, 91, 92].

Therefore, collaboration is evaluated with a largely strategic focus [48]. The option to collaborate must depend on balancing the risks versus the returns, where companies collaborate to acquire resources and skills that they cannot internally produce, if the cooperation is maintained at a tolerable level [56].

\subsection{Relations and network management}

As humans are social beings, the creation of networks and relationships are phenomena that span since the very start of society [93]. The social network theory 
states that various agents of a society find themselves connected to each other, forming communication and influence channels [94]. In this regard, networks are among the most common tools for diffusing and acquiring knowledge. A (social) network is a means for communication, bonding, advice, and support that exists between the members of a social system [95]. The features and structure of relationship networks, created by an organization, are crucial to determine the flow of idea diffusion, innovation, and sharing of experiences [94, 95].

An interorganizational cooperation network stands itself on the management of relationships between its members [84, 96-98], which are composed of individual and collective interests [99-101]. The former brings new members to take part in the network to chase common goals, thus obtaining individual and collective benefits [84].

Management efficiency in the relationship with agents of interest is the main source of income and opportunity that increases profitability of a business [102]. It is the ability to collaborate interorganizationally; share risks, resources, and competences; unify skills; and foster joint solutions; among others [55, 103]. Superior performance comes from market detection capability, better reception of ideas, use of information, and bonding [104]. Thus, a relationship is the repetition and maintenance of solid interactions between parties due to the existence of economic or social links between them to achieve mutual benefits [102]. The exchange based on relationships corresponds to a larger number of complex exchanges of resources and information [55].

In the case of innovation, cooperation can be a dilemma due to the existence of the transfer of knowledge, abilities, and resources, which can make members distrust in participating [36]. Some of the preoccupations in the innovation process that can be considered as deterrents for collaboration can be found in the form of profit splitting of a new tech, research and development decisions, and fearing that a member can benefit more than another, among others [47, 97, 105, 106].

Thus, the concept of networks highlights two key observations: (1) intra- and interorganizational collaboration is not simply a means to compensate for the lack of internal skills; and (2) collaboration is not a series of discrete transactions. The value and capability of a company as a collaborator are based on its internal assets, but simultaneously, the activity of collaboration will develop and strengthen those internal competences. This means that companies deepen their capability to collaborate by not only managing relations in a dyadic way but also by instantiating and refining routines for synergistic association [107].

\subsection{Market orientation}

In the literature, innovation is shown in two ways: as a structural approach and as a process-oriented approach [108]. The structural approach is tradition-based by nature, where by structuralizing certain parameters with innovation, companies bring value to the users and final consumers [109]. The process-oriented approach views innovation as a complex process that follows a defined design through the interaction of various social groups at an internal and external form from the organizations [110]. Both cases understand innovation as an iteration of decisions and implementation of new ideas by people who communicate with other people [108]. In this regard, the competitive environment in which a company operates affects the benefits and costs of collaboration [111]. Disclosure costs are higher for companies in highly competitive markets, where information leaks quickly translate into loss of market share, making collaboration riskier [112-114].

Strategic marketing literature assumes that the key to the success of organizational processes lies in the belief that market orientation provides the capability to detect the market, have a proactive attitude toward customer satisfaction, obtain greater use of information, possess a better reception of ideas, and have a degree 
of connection that leads to superior organizational performance [104]. This puts the concept of market orientation as an organizational cultural approach or as an integral part of the mission, vision, and values of a company [115]. It is important to note that the perspective from the conception of generation of intelligence identifies a series of specific actions around information [116].

These different approaches are considered as interrelated perspectives [117]. Strategic orientation will reflect a company's philosophy on how to conduct business through a set of deeply held values and beliefs that guide the company's attempt to achieve superior performance [118]. In addition, these values and beliefs define the resources to be used, transcend individual capabilities, and unify resources and capabilities into a cohesive whole [119].

Considering the concept of market orientation, there is a broad general consensus that it is a combination of three critical dimensions [116]: (1) generation of intelligence on all the elements of the market (customers, competitors, and the environment), (2) dissemination or establishment of internal common knowledge of the said intelligence, and (3) development and implementation of a response action that involves the effective satisfaction of the established target audience [115].

The results of this chapter should be the obtainment of improved capabilities to adapt to changes in the business environment or to obtain a proactive decisionmaking ability to produce competitive advantages [120-122]. Hence, a company learns to acquire and develop new relevant knowledge and skills that will help it remain competitive in the market $[115,116,123,124]$.

\section{Empirical case}

\subsection{Methodology}

The methodology employed is exploratory by nature. This research uses the IBM SPSS version 14.0 statistical software, with a self-administered survey through $Q$ ualtrics platform. The survey considered three sub-scales that represent each of the three variables previously mentioned. The authors used a structured questionnaire, with closed questions on an 11-point Likert scale and questions regarding business characteristics. The scale considers that the most favorable response receives the highest score, while the least favorable response the lowest score.

The authors sent the survey to 580 potential participants, obtaining a response rate of $41.7 \%$. Thus, the sample is composed of 242 executives in relevant positions in the decision-making process of industrial companies with offices in Chile. This last inclusion criterion used by the authors has the objective of ensuring that the respondents have experience within the industry. Most of the respondents had positions of management and corporate levels (56.2\%) and professions related to engineering (64\%). The main industrial sectors represented are the iron and steel industry (15.7\%), distribution (15.3\%), mining (14.9\%), financial (14\%), and agroindustry (12.8\%). Most of the companies have clients from the national market as their main buyers $(80.2 \%)$, with most of the surveyed respondents being mainly established in the central region of Chile (71.9\%).

\section{Results}

A confirmatory and exploratory analysis using AMOS was done to have access to the properties of latent variables. The relation of variables can be observed 
with a $99 \%$ of confidence, KMO over 0.6 , goodness of fit of data $\left(\chi^{2}=735,673\right.$, $\mathrm{p}<0.001, \mathrm{IFI}=0.83, \mathrm{CFI}=0.823, \mathrm{NFI}=0.8, \mathrm{TLI}=0.8, \mathrm{PNFI}=0.670)$, reliability $(\mathrm{AVE}=0.613 ; \mathrm{IVE}=0.980)$, and discriminant validity with a $95 \%$ of reliability.

Table 1 shows the general results declared by the responses in the different items.

Based on the empirical data, the degree of progress in each of the analyzed variables (see Table 1) of the different sectors of the sample has been calculated. At a general level, the study shows an evaluation value of approximately 6 points ("Often"), which turns out to be regular with respect to the maximum of 11 . The level of development is $54.5 \%$, with respect to the potential of each variable according to the perception of the respondents. The relations and network management are the least perfected capability, while management and strategy development is the most developed.

According to the results of this study (Table 1), the mining sector is the one that presents the best overall evaluation due to the sector placing great importance in considering long-term strategic planning. This in part is due to the "virtuous, inclusive and sustainable mining by 2035" plan. Nonetheless, there is still a long way to go in terms of collaboration. Regarding this point, the management of relations and networks is the factor in which the mining sector shows less development and in which the managers should emphasize their future strategies. This would allow them to increase the value proposition and get a more stable level of profitability in the long run.

The agroindustrial sector is worrisome regarding their relations and network management and market orientation. The companies of this sector require a greater focus on the external analysis of clients and competitors that would help them guide their plans toward innovation in marketing. This would allow them to increase their efficiency and effectiveness of their projects in those areas. In addition, data shows that the financial sector must work with special emphasis on management and strategic development in terms of collaboration. One of the lowest values obtained in this variable is on the establishment of collaboration as a source of competitiveness.

At the variable level, the study shows that strategic focus makes possible improvement on organizational innovation capabilities. Without strategic value, the efforts and resources devoted to it will always be scarce. Hence, even though they possess the capabilities to develop initiatives successfully, in practice, this will not necessarily be true. It can be observed that the companies point out that the activities they do the most are to consider the costs in their planning, to encourage the

\begin{tabular}{lccc}
\hline Industrial & $\begin{array}{c}\text { Management and strategic } \\
\text { development }\end{array}$ & $\begin{array}{c}\text { Relations and network } \\
\text { management }\end{array}$ & $\begin{array}{c}\text { Market } \\
\text { orientation }\end{array}$ \\
\cline { 2 - 4 } & $\begin{array}{c}\boldsymbol{\alpha}: \mathbf{0 . 9 2 0} \\
\boldsymbol{\sigma}: \mathbf{0 . 4 8} \\
\boldsymbol{k}: \mathbf{0 . 9 6 8}\end{array}$ & $\begin{array}{c}\boldsymbol{\alpha}: \mathbf{0 . 8 4 3} \\
\boldsymbol{\sigma}: \mathbf{0 . 4 6} \\
\boldsymbol{k}: \mathbf{0 . 6 1 1}\end{array}$ & $\begin{array}{c}\boldsymbol{\alpha}: \mathbf{0 . 8 6 9} \\
\boldsymbol{\sigma}: \mathbf{0 . 6 3} \\
\boldsymbol{k}: \mathbf{0 . 9 5 0}\end{array}$ \\
\hline Mining & 6.9 & 6.1 & 7.0 \\
\hline Iron and steel & 6.5 & 5.8 & 6.9 \\
\hline Distribution & 6.5 & 5.5 & 6.5 \\
\hline Financial & 5.6 & 6.3 & 6.2 \\
\hline Agroindustry & 6.7 & 5.0 & 5.3 \\
\hline Others & 6.9 & 5.9 & 6.7 \\
\hline Average & 6.5 & 5.8 & 6.4 \\
\hline Self-elaboration $; \alpha$, Cronbach's alpha $\boldsymbol{\sigma}$, standard deviation; $k$, standardized coefficient. & \\
\hline
\end{tabular}

Table 1.

Empirical results. 
participation of different functional areas of the company in the development of a project, and to consider innovation in long-term strategic planning.

For its part, relations and network management were the worst evaluated variable according to the sample. It is interesting to note how companies have better results in the network items with clients than with other agents. This shows that companies are willing to cooperate with their clients with a short-term view oriented to sales but do not find it relevant to establish promises with other agents in the long term, which would allow them to establish continuous innovation projects over time. This short-term focus on products may impair the viability of long-term business relationships, where other factors such as networking and collaborative actions have a significant impact on results.

In terms of market orientation, the results show that the lowest scores come from companies investigating close to nothing on what their competitors do. Based on these results, it is possible to deduce that companies have a research process more focused to their own projects or problems than to surveillance mechanisms on what competitors do. For instance, agroindustrial sector, which was the worst ranked in this dimension. In addition, their values are significantly lower than the other sectors in the study.

\section{Conclusions}

The chapter reveals that innovation in marketing is conceived as a process oriented to the market and the use of knowledge, which is modeled by the characteristics of the organizational culture, through a management that controls and assumes risks in its projects, often developing relevant activities collaborative in the process. The role of the degree of market orientation, collaboration, and strategic project management is highlighted as incident characteristics of the company's capacity to reconfigure its assets and compete in current, emerging, or mature businesses.

Currently, society is constantly evolving, so innovating is no longer a "nice to have," but it has become a necessity in companies. In this context, innovation must be considered activity in the company strategic axis, where its magnitude and focus should be supported in the organizational plan. Innovating should not be just having a brilliant idea; it is generating something that creates value for the market, the organization, and/or the other agents of interest. The company must be able to identify, anticipate, and characterize its own potential to formulate the best strategy for innovation in the future. A methodology must be established to innovate and how to structure strategically innovative processes.

Managers should question possible gaps in the positioning map of the sector, decide to cover them, and make them grow. To develop an innovative strategy, you must question the business in which our organization is located, how we develop our processes, and what we know about the market. Reflect on our client (current and potential); analyze our availability of resources, skills, and our ability to develop new, as well as how we relate to other agents of interest.

As a result, new businesses will not be discovered if they do not leave the security offered by the current ones. Innovation implies a need to be market oriented. When an organization makes the decision to innovate, it must have the ability to question how it does business and rethink it. Managers should look at new sources of their own ideas but also monitor innovation processes in their industries or in other industries, national or foreign. The key to success is not only in playing better than the competition, but in how an organization can effectively change the rules of the game.

However, having a look at strategic innovation and market orientation does not ensure success. The different mechanisms, networks, and relationships that 
facilitate the organization to carry out these processes must be taken into account. In this line, it is important to develop the capacity and corporate culture in the company to take risks, boost the commitment of employees, and empower them to propose ideas to innovate.

For the above to be possible, it is important to promote the sharing of information between the different lines of business. But this collaboration is not just about encouraging conversations but generating structured processes that allow interacting and giving support to each of the areas on relevant issues of the process, where the contribution of the top managers is essential. To link collaborative initiatives to larger business objectives, the manager must create a comprehensive and measurable strategy that responds to the complexities of the extended enterprise. It is therefore important to adopt a methodical and detailed approach to collaboration and innovation. Collaborative initiatives should be linked to high-level business objectives, with careful attention to risk profiles and tolerance levels throughout the company.

However, collaboration must also extend beyond the company. The organization is in constant interaction with other organizations and agents that have their own knowledge of the industry and, therefore, turn out to be components that can and should influence the strategic direction of innovation processes. There is no generic list of possible collaborating agents, not even from the same sector. Each organization must identify and prioritize all those groups that can contribute to innovate, understanding that these can change over time. The prioritization criteria are ponderable, adaptable, and unique. However, a proposal of criteria could include analyzing the following strategic variables: (1) capacity of influence or dependence (current and future), (2) interest in the commitment and willingness to participate, (3) knowledge of the organization and industry, (4) geographical dimensions, and (5) social context (organizational culture, legal restrictions, etc.). Finally, the company must define the collaboration model to be developed. There are different existing tools to facilitate a model of integration of the relationship with stakeholders with different management levels that can be modulated according to the different strategic variables already raised.

In conclusion, the strategic innovation depends on the sector where the organization competes, the real needs of the client, and the competitive position of the same, bearing in mind all the support of resources that the organization has, because without the operation and efficiency of these is difficult to ensure its success. Managers are required to be in a constant state of contemplation of their company, from an internal and external point of view with a long-term focus. This approach makes possible the strategic management of innovation, which becomes increasingly essential in the company.

Then, this study opens new lines of research and helps establish guidelines in which managers in innovation or marketing could manage their relationships with stakeholders in a proactive and efficient manner. This chapter shows a better understanding of the opportunities and challenges of organizational capability in marketing innovation, and cocreation value is achieved, allowing the identification of specific issues that need to be developed at the company and country level. For instance, long-term competitiveness for any company will depend on its ability to comprehend the environment, integrate knowledge about competitors and consumers' needs, develop improvements, and manage the buying behavior of its customers. Furthermore, this business intelligence could be useful as a guide for businesspersons, politicians, managers, and researches, among others. 


\section{Author details}

Leslier Valenzuela-Fernández* and Natacha Peñaloza-Briones

Department of Business Administration, School of Economics and Business, University of Chile, Santiago, Chile

*Address all correspondence to: lvalenzuela@unegocios.cl

\section{IntechOpen}

(C) 2019 The Author(s). Licensee IntechOpen. This chapter is distributed under the terms of the Creative Commons Attribution License (http://creativecommons.org/licenses/ by/3.0), which permits unrestricted use, distribution, and reproduction in any medium, provided the original work is properly cited. (cc) BY 


\section{References}

[1] Kotler P. A generic concept of marketing. Journal of Marketing. 1972;36:46-54

[2] AMA. AMA Educators' Proceedings: Enhancing Knowledge Development in Marketing. Chicago, IL: American Marketing Association; 2007. pp. 191-198

[3] García JS. El marketing y su origen a la orientación social: Desde la perspectiva económica a la social. Los aspectos de organización y comunicación. Em Questão. 2011;16(1):61-77

[4] Sheth JN, Gardner DN, Garrett DE. Marketing Theory: Evolution and Evaluation. New York: John Wiley \& Sons; 1988. p. 16

[5] Kotler P, Keller K. Marketing Management. Pearson: Prentice Hall; 2006. p. 816

[6] Achrol RS, Kotler P. Frontiers of the marketing paradigm in the third millennium. Journal of the Academy of Marketing Science. 2012;40(1):35-52

[7] Martínez-López FJ, Merigó JM, Valenzuela-Fernández L, Nicolás C. Fifty years of the European Journal of Marketing: A bibliometric analysis. European Journal of Marketing. 2018;52(1/2):439-468

[8] Holmlund M, Kowalkowski C, Biggemann S. Organizational behavior in innovation, marketing, and purchasing in business service contexts-An agenda for academic inquiry. Journal of Business Research. 2016;69(7):2457-2462

[9] Pino C, Felzensztein C, ZwergVillegas AM, Arias-Bolzmann L. Nontechnological innovations: Market performance of exporting firms in South America. Journal of Business Research. 2016;69(10):4385-4393
[10] Lundvall B, Maskell P. In: Clark G, Nahapiet J, Gertler M, editors. The Oxford Handbook of Economic GeographyNation states and economic development: From national systems of production to national systems of knowledge creation and learning. Oxford: Oxford University Press; 2000. pp. 353-372

[11] Weerawardena J. Exploring the role of market learning capability in competitive strategy. European Journal of Marketing. 2003;37(3/4):407

[12] Lin CYY, Chen MYC. Does innovation lead to performance? An empirical study of SMEs in Taiwan. Management Research News. 2007;30(2):115-132

[13] Pappas LO, Kourouthanassis PE, Giannakos MN, Chrissikopoulos V. Explaining online shopping behavior with fsQCA: The role of cognitive and affective perceptions. Journal of Business Research. 2016;69(2):794-803

[14] Woodside AG. Embrace perform model: Complexity theory, contrarian case analysis, and multiple realities. Journal of Business Research. 2014;67(12):2495-2503

[15] Ernst H, Kahle HN, Dubiel A, Prabhu J, Subramaniam M. The antecedents and consequences of affordable value innovations for emerging markets. Journal of Product Innovation Management. 2015;32(1):65-79

[16] Hunt SD, Morgan RM. The comparative advantage theory of competition. The Journal of Marketing. 1995;59(2):1-15

[17] Hunt SD, Morgan RM. The resourceadvantage theory of competition: Dynamics, path dependencies, and evolutionary dimensions. The Journal of Marketing. 1996;60:107-114 
[18] Srivastava RK, Fahey L, Christensen HK. The resource-based view and marketing: The role of marketbased assets in gaining competitive advantage. Journal of Management. 2001;27(6):777-802

[19] Reid SE, Brentani U. The fuzzy front end of new product development for discontinuous innovations: A theoretical model. The Journal of Product Innovation Management. 2004;21:170-184

[20] Augusto M, Coelho F. Market orientation and new-to-the-world products: Exploring the moderating effects of innovativeness, competitive strength, and environmental forces. Industrial Marketing Management. 2009;38(1):94-108

[21] Fløysand A, Jakobsen S-E. The complexity of innovation: A relational turn. Progress in Human Geography. 2010;35(3):328-344

[22] Hult GTM, Ferrell OC. A tribute to forty years of top-level marketing research. Journal of the Academy of Marketing Science. 2012;40(1):1-7

[23] Schmidt J, Sarangee K, Montoya M. Exploring new product development project review practices. Journal of Product Innovation Management. 2009;26(5):520-535

[24] Von Hippel E, Susumu O, Jong J. The age of the consumer-innovator. MIT Sloan Management Review. 2011;53(1):27-36

[25] Zhou KZ, Yim CK, Tse DK. The effects of strategic orientations in technology- and market-based breakthrough innovation. Journal of Marketing. 2005;69(2):42-60

[26] Petrakis P, Kostis P, Valsamis D. Innovation and competitiveness: Culture as a long-term strategic instrument during the European great recession. Journal of Business Research. 2015;68(7):1436-1438

[27] Ribeiro D, Huarng K-H. Innovation and entrepreneurship in knowledge industries. Journal of Business Research. 2013;66(10):1964-1969

[28] Teece DJ. Business models, business strategy and innovation. Long Range Planning. 2010;43(2-3):172-194

[29] Spieth P, Schneckenberg D, Ricart JE. Business model innovationState of the art and future challenges for the field. R\&D Management. 2014;44(3):237-247

[30] Brenes ER, Camacho AR, Ciravegna L, Pichardo CA. Strategy and innovation in emerging economies after the end of the commodity boom-Insights from Latin America. Journal of Business Research. 2016;69(10):4363-4367

[31] Helfat CE, Peteraf MA. The dynamic resource-based view: Capability lifecycles. Strategic Management Journal. 2003;24(10):997-1010

[32] Schreyögg G, Kliesch-Eberl M. How dynamic can organizational capabilities be? Towards a dual-process model of capability dynamization. Strategic Management Journal. 2007;28(9):913-933

[33] Helfat CE, Winter SG. Untangling dynamic and operational capabilities: Strategy for the $(\mathrm{N})$ ever-changing world. Strategic Management Journal. 2011;32(11):1243-1250

[34] Winter SG. Capabilities: Their origins and ancestry. Journal of Management Studies. 2012;49(8):1402-1406

[35] Teece DJ. Business models and dynamic capabilities. Long Range Planning. 2017;51(1):40-49 
[36] Tsai K-H, Yang S-L. Firm innovativeness and business performance: The joint moderating effects of market turbulence and competition. Industrial Marketing Management. 2013;42(8):1279-1294

[37] Lichtenthaler U, Lichtenthaler E. A capability-based framework for open innovation: Complementing absorptive capacity. Journal of Management Studies. 2009;46(8):1315-1338

[38] Barney J. Firm resources and sustained competitive advantage. Journal of Management. 1991;17(1): 99-120

[39] Eisenhardt K, Martin J. Dynamic capabilities: What are they? Strategic Management Journal. 2000;21(10/11):1105-1121

[40] Christmann P. Effects of "best practices" of environmental management on cost advantage: The role of complementary assets. Academy of Management Journal. 2000;43(4):663-680

[41] Damanpour F, Walker R, Avellaneda C. Combinative effects of innovation types and organizational performance: A longitudinal study in service organizations. Journal of Management Studies. 2009;46(4):650-675

[42] Koen P, Ajamian G, Burkart R, Clamen A. Providing clarity and a common language to the "fuzzy front end". Research and Technology Management. 2001;44(2):46-55

[43] Wiersema F. The B2B Agenda: The current state of $\mathrm{B} 2 \mathrm{~B}$ marketing and a look ahead. Industrial Marketing Management. 2013;42:470-488

[44] Ritala P, Olander H, Michailova S, Husted K. Knowledge sharing, knowledge leaking and relative innovation performance: An empirical study. Technovation. 2015;35:22-31

[45] Emden Z, Calantone RJ, Droge C. Collaborating for new product development: Selecting the partner with maximum potential to create value. Journal of Product Innovation Management. 2006;23(4):330-341

[46] Breschi S, Malerba F. Clusters, Networks and Innovation. England: Oxford University Press; 2005

[47] Funk RJ. Making the most of where you are: Geography, networks, and innovation in organizations. Academy of Management Journal. 2014;57(1):193-222

[48] Biemans W. Managing Innovation Within Networks. London: Routledge; 2018

[49] Dyer JH, Nobeoka K. Creating and managing a high-performance knowledge-sharing network: The Toyota case. Strategic Management Journal. 2000;21(3):345-367

[50] Hislop D, Bosua R, Helms R. Knowledge Management in Organizations: A Critical Introduction. England: Oxford University Press; 2018

[51] Caloghirou Y, Ioannides S, Vonortas NS. Research joint ventures. Journal of Economic Surveys. 2003;17(4):541-570

[52] Chuang SH, Lin HN. Co-creating e-service innovations: Theory, practice, and impact on firm performance. International Journal of Information Management. 2015;35(3):277-291

[53] Ahuja G. Collaboration networks, structural holes, and innovation: A longitudinal study. Administrative Science Quarterly. 2000;45(3):425-455 
[54] Martin G, Gözübüyük R, Becerra M. Interlocks and firm performance: The role of uncertainty in the directorate interlock-performance relationship. Strategic Management Journal. 2015;36(2):235-253

[55] Vargo S, Lusch RF. Servicedominant logic: What it is, what it is not, what it might be. In: Lusch R, Vargo S, editors. The Service-Dominant Logic of Marketing: Dialog, Debate and Directions. Armonk, NY: M. E. Sharpe; 2006. pp. 43-56

[56] Teece DJ. Profiting from technological innovation: Implications for integration, collaboration, licensing and public policy. Research Policy. 1986;15(6):285-305

[57] Kumar K, Van Dissel HG. Sustainable collaboration: Managing conflict and cooperation in interorganizational systems. MIS Quarterly. 1996:279-300

[58] Li G, Fan H, Lee PK, Cheng TCE. Joint supply chain risk management: An agency and collaboration perspective. International Journal of Production Economics. 2015;164:83-94

[59] Hottenrott H, Lopes-Bento C. R\&D partnerships and innovation performance: Can there be too much of a good thing? Journal of Product Innovation Management. 2016;33(6):773-794

[60] Kindström D, Kowalkowski C, Sandberg E. Enabling service innovation: A dynamic capabilities approach. Journal of Business Research. 2013;66:1063-1073

[61] Ngo LV, O’Cass A. Innovation and business success: The mediating role of customer participation. Journal of Business Research. 2013;66:1134-1142

[62] Binder J. Global Project Management: Communication,
Collaboration and Management across Borders. London: Routledge; 2016

[63] Faems D, Van Looy B, Debackere K. Interorganizational collaboration and innovation: Toward a portfolio approach. Journal of Product Innovation Management. 2005;22(3):238-250

[64] Tripsas M. Unraveling the process of creative destruction: Complementary assets and incumbent survival in the typesetter industry. Strategic Management Journal. 1997;18(6):119-142

[65] Cantù C, Corsaro D, Tunisini A. Editorial—Organizing for innovation networks. Journal of Business \& Industrial Marketing. 2015;30(3/4)

[66] Dagnino GB, Levanti G, Minà A, Picone PM. Interorganizational network and innovation: A bibliometric study and proposed research agenda. Journal of Business \& Industrial Marketing. 2015;30(3/4):354-377

[67] Hall B, Rosenberg N. Introduction to handbook. In: Hall B, Rosenberg N, editors. The Handbook of Economics of Innovation. Vol. 1. Amsterdam: Elsevier, North-Holland Publications; 2010. pp. 3-9

[68] Lee HHM, Van Dolen W. Creative participation: Collective sentiment in online co-creation communities. Information \& Management. 2015;52(8):951-964

[69] Perks H, Gruber T, Edvardsson B. Co-creation in radical service innovation: A systematic analysis of microlevel processes. Journal of Product Innovation Management. 2012;29(6):935-951

[70] Frow P, Payne A. Co-creation: A typology and framework. In: Working Paper, Discipline of Marketing. University of Sydney; 2013 
[71] Galvagno M, Dalli D. Theory of value co-creation: A systematic literature review. Managing Service Quality: An International Journal. 2014;24(6):643-683

[72] Sheth J, Uslay C. Implications of the revised definition of marketing: From exchange to value creation. Journal of Public Policy and Marketing. 2007; 26:302-307

[73] Frow P, Nenonen S, Payne A, Storbacka K. Managing co-creation design: A strategic approach to innovation. British Journal of Management. 2015;26(3):463-483

[74] Polese F, Mele C, Gummesson E. Value co-creation as a complex adaptive process. Journal of Service Theory and Practice. 2017;27(5):926-929. DOI: 10.1108/jstp-07-2017-0111

[75] Arnould EJ, Thompson CJ. Consumer culture theory (CCT): Twenty years of research. Journal of Consumer Research. 2005;31(4): 868-882

[76] Bonsu SK, Darmody A. Co-creating second life: Firm-consumer co-operation in contemporary economy. Journal of Macromarketing. 2008;28(3):355-368

[77] García N, Álvarez B, Santos M. Aplicación de la lógica dominante del servicio (LDS) en el sector turístico: El marketing interno como antecedente de la cultura de co-creación de innovaciones con clientes y empleados. Cuadernos de Gestión. 2011;11(2):53-75

[78] Lee SM, Olson D, Trimi S. Co-innovation: Convergenomics, collaboration, and co-creation for organizational values. Management Decision. 2012;50(5):817-831

[79] Lee SM, Hwang T, Choi D. Open innovation in the public sector of leading countries. Management

Decision. 2012;50(1):147-162

[80] Kazadi K, Lievens A, Mahr D. Stakeholder co-creation during the innovation process: Identifying capabilities for knowledge creation among multiple stakeholders. Journal of Business Research. 2016;69(2):525-540

[81] Borges-Andrade JEE, Palomino MD, Saldaña J, Silva RS. Planificación estratégica en la administración de la investigación agropecuaria. Capacitación en Planificación, Seguimiento y Evaluación Para la Administración de la Investigación. 1995; (2)

[82] Amat JM. El Control de Gestión: Una Perspectiva de Dirección.

Barcelona: Ed. Gestión; 1996. p. 2000

[83] Brand FC, Rigoni EH, Verschoore JR. Governance interorganizacional: Um estudo do relacionamento entre agentes econômicos do setor de flores. Desenvolve Revista de Gestão do Unilasalle. 2014;3(1):99-111

[84] Câmara SF, de Lima BB, da Gama Mota TLN, e Silva AL, Padilha P. The management of innovation networks: Possibilities of collaboration in light of game theory. Business and Management Studies. 2018;4(2):24-34

[85] Roth AL, Wegner D, Junior JAVA, Padula AD. Diferenças e inter-relações dos conceitos de governança e gestão de redes horizontais de empresas: Contribuições para o campo de estudos. Revista de Administração. 2012;47(1):112-123

[86] Correa CL, Yepes V, Pellicer E. Determinant issues and proposals for the management of innovation in construction companies. Revista Ingeniería de Construcción. 2007;22(1):05-14 
[87] Cheng C-F, Lai M-K, Wu W-Y. Exploring the impact of innovation strategy on R\&D employees' job satisfaction: A mathematical model and empirical research. Technovation. 2010;30(8):459-470

[88] Pellicer E, Yepes V, Correa CL, Alarcón LF. The dilemma of innovation in the construction company: A decade of lessons learned. In: Project Management and Engineering Research. Cham: Springer; 2017. pp. 21-33

[89] Kondo Y. Innovation versus standardization. The TQM Magazine. 2000;12(1):6-10

[90] Blayse AM, Manley K. Key influences on construction innovation. Construction Innovation. 2004;4(3):143-154

[91] Deeds DL, Rothaermel FT. Honeymoons and liabilities: The relationship between age and performance in research and development alliances. Journal of Product Innovation Management. 2003;20(6):468-485

[92] Gulati R. Does familiarity breed trust? The implications of repeated ties for contractual choice in alliances. Academy of Management Journal. 1995;38(1):85-112

[93] Valencia JB, Ortiz EPG. El análisis de redes sociales como ventaja competitiva. Revista de Investigación en Ciencias de la Administración. 2017;7(12):26-38

[94] Septiem M, Martin-Rios C. Innovación en gestión de recursos humanos: La relevancia de las redes inter-organizativas de intercambio de conocimiento. Journal of Technology Management \& Innovation. 2017;12(3):96-107

[95] Burt RS, Minor MJ, Associates, editors. Applied Network Analysis: A
Methodological Introduction. Beverley Hills, CA: Sage; 1983

[96] Capaldo A. Network structure and innovation: The leveraging of a dual network as a distinctive relational capability. Strategic Management Journal. 2007;28(6):585-608

[97] Cullen JB, Johnson JL, Sakano T. Success through commitment and trust: The soft side of strategic alliance management. Journal of World

Business. 2000;35(3):223-240

[98] Nooteboom B. Inter-firm

Collaboration, Learning and Networks: An Integrated Approach. London: Psychology Press; 2004

[99] Balestrin A, Verschoore JR. Réplica-Redes são Redes ou Redes são Organizações? RAC-Revista de Administração Contemporânea. 2014;18(4):523-533

[100] Höher R, Tatsch AL. Redes de cooperação: $O$ caso da Rede Imobiliárias de Santa Maria, no Rio Grande do Sul. Perspectiva Econômica. 2011;7(1):15-26

[101] Provan KG, Kenis P. Modes of network governance: Structure, management, and effectiveness. Journal of Public Administration Research and Theory. 2008;18(2):229-252

[102] Zaefarian G, Henneberg SC, Naudé P. Resource acquisition strategies in business relationships. Industrial Marketing Management. 2011;40(6):862-874

[103] Cossío-Silva FJ, Revilla-Camacho MÁ, Vega-Vázquez M, PalaciosFlorencio B. Value co-creation and customer loyalty. Journal of Business Research. 2016;69(5):1621-1625

[104] Im S, Workman JP Jr. Market orientation, creativity, and new 
product performance in high-

technology firms. Journal of Marketing. 2004;68(2):114-132

[105] Arranz N, de Arroyabe JCF. The choice of partners in R\&D cooperation: An empirical analysis of Spanish firms. Technovation. 2008;28(1):88-100

[106] Boaventura JMG, Carnaúba AAC, Todeva E, Azevedo AC, Armando E. Governance structures and trust: A study of real estate networks. Journal on Chain and Network Science. 2016;16(2):157-170

[107] Nelson RR. US technological leadership: Where did it come from and where did it go? Research Policy. 1990;19(2):117-132

[108] Mehrabani SE, Shajari M. Knowledge management and innovation capacity. Journal of Management Research. 2012;4(2):164-177

[109] Wolfe RA. Organizational innovation: Review, critique and suggested research directions. Journal of Management Studies. 1994;31(3):405-431

[110] Van den Hooff B, Van Weenen FD. Committed to share: Commitment and CMC use as antecedents of knowledge sharing. Knowledge and Process Management. 2004;11(1):13-12

[111] Lavie D, Stettner U, Tushman ML. Exploration and exploitation within and across organizations. The Academy of Management Annals. 2010;4(1): 109-155

[112] Beck M, Schenker-Wicki A. Cooperating with external partners: The importance of diversity for innovation performance. European Journal of International Management. 2014;8(5):548-569

[113] Leiponen A, Helfat C. Innovation objectives, knowledge sources, and the benefits of breadth. Strategic Management Journal. 2010;31:224-236

[114] Van Beers C, Zand F. R\&D cooperation, partner diversity, and innovation performance: An empirical analysis. Journal of Product Innovation Management. 2014;31(2):292-312

[115] Narver JC, Slater SF. The effect of a market orientation on business profitability. The Journal of Marketing. 1990:20-35

[116] Kohli AK, Jaworski BJ. Market orientation: The construct, research propositions, and managerial implications. The Journal of Marketing. 1990;54(2):1-18

[117] Kirca AH, Jayachandran S, Bearden WO. Market orientation: A meta-analytic review and assessment of its antecedents and impact on performance. Journal of Marketing. 2005;69(2):24-41

[118] Gatignon H, Xuereb JM. Strategic orientation of the firm and new product performance. Journal of Marketing Research. 1997;34(1):77-90

[119] Day GS. The capabilities of marketdriven organizations. The Journal of Marketing. 1994;58(4):37-52

[120] Calantone RJ, Cavusgil ST, Zhao Y. Learning orientation, firm innovation, and firm performance. Industrial Marketing Management. 2002;31(6):515-524

[121] Sinkula JM, Baker WE, Noordewier T. A framework for marketbased organizational learning: Linking values, knowledge, and behaviour. Journal of the Academy of Marketing Science. 1997;25(3):305-318

[122] Westerlund M, Rajala R. Learning and innovation in inter-organizational network collaboration. Journal of Business and Industrial Marketing. 2010;25(6):435-442 
[123] Grinstein A. The relationships

between market orientation and

alternative strategic orientations.

European Journal of Marketing.

2008;42(1/2):115-134

[124] Paladino A. Analyzing the

effects of market and resource orientations on innovative outcomes

in times of turbulenc. Journal of

Product Innovation Management.

2008;25(6):577-592 


\title{
Empowerment of the Sales Forces in 2000s
}

\author{
Leslier Maureen Valenzuela Fernández and \\ Francisco Javier Villegas Pinuer
}

\begin{abstract}
This chapter discusses the importance of customer value orientation to achieve good results from the sales team. The text analyzes how the management of several variables in human resources is fundamental towards good performance of the sales force. Their behavior and attitude is essential in helping companies develop longterm profitable relationships with customers. Hence, by assessing employee perceptions on incentive policies, and the training they have received, positive impacts on job satisfaction and customer orientation can be found. The career stage of the sales force has a relevant effect on management decisions as the life cycle influences the expectations of the sales force, the type of training, the incentive policies, and the level of commitment to the organization. In order to achieve good performance, it is essential to consider the dynamic and changing context where the omnichannel variable has a high presence in the reality of the sales area. For this reason, this chapter presents a model that can contribute to the empowerment of the sales force.
\end{abstract}

Keywords: sales force, empowerment, customer value orientation, sales force effectiveness and motivation

\section{Introduction}

Customer value-oriented management is a higher-level marketing approach in which the company places the customer at the center of the business, prioritizing its interaction with them to bring financial success and competitive advantages [1]. The philosophy bases itself on the premise that resources are scarce, and must therefore be carefully assigned to those who hold more value to the company, thus ensuring business success [2]. Hence, customer value-oriented management is a critical and relevant variable in the marketing field.

Customer-oriented firms are willing to prioritize customer interests and develop business strategies aimed at understanding them and satisfying their needs [3]. This corporate philosophy is important to embrace as a better understanding of the clients can produce positive changes in portfolio management [4-6] and sales results $[7,8]$.

This is achieved by careful management of the sales force. In respect to the strategy, the former should increase customer-orientation by working on maintaining close relationships with them with the aim of getting information to create long term competitive advantages. Customer-oriented sales personnel should avoid conducting actions that artificially alters the interests of clients. This includes actions either, for the purpose of improving the likelihood of making an immediate sale [9] 
or of generating a new sale in the foreseeable future. Workers and managers are motivated to protect their client's interests as this will be compensated by positive customer reciprocity (word-of-mouth, loyalty), which generates new customers hence greater value for stakeholders $[10,11]$.

This chapter discusses customer-oriented management as a fundamental approach to achieve sales volume and profitability. Through the literature review, authors analyze how the management of the sales force-focused on specific human resource variables-is relevant to achieve good performance from the sales team. This motivates sellers, satisfying them to continue contributing to the organizational goals. The authors have also specifically analyzed relevant variables such as incentive policies, training, motivation, and perception of the sales force regarding involvement and job satisfaction.

It is important to note the authors have raised the discussion regarding changes in the paradigms of the sales processes, and models of empowerment for the sales force. Sales have changed substantially in the last 15 years, product of digitalization which has become an ever more important factor in the field. As consequence, dynamism in company business models has flourished, actively taking into consideration new trends; for instance, the thorough breakdown of geographical barriers in relation to sales [12].

Since consumers are constantly changing and incorporating the new trends, they affect the way and time of consumption of goods and/or services. This takes into account that (currently) there are new methods and systems to encourage consumption, possibilities that did not exist a few years ago; for example, companies incorporate mobile applications to "activate" the consumption of their customers.

Hence, the way in which companies conduct the sales process should also be updated to this dynamism, where the costs of change for consumers are increasingly lower considering the range of supply and the underlying competitiveness.

\section{Factors influencing sales force's effectiveness}

\subsection{Customer value orientation}

Customer value can be defined as a subjective notion of an individual customer's judgment on the value of a product or service [1]. People's perceptions depends on sellers or workers who provide the service. Thus, managers can influence the customer-value-perception through worker management and human resource practices. Schneider [13] recognizes how this can increase the extent to which sales people care about customer service experience. This aspect is key as it helps create the foundations for employees to deliver corresponding customer service.

By understanding sales people as human resources, and taking into account human resource management practices, business profitability can increase through value-delivered to the customers. Stanton et al. [14] affirms that employee perception regarding the relevancy of service to business success, sustained with implemented human resource management practices, effectively affects the degree of the sales people's customer-orientation level.

Zoltners et al. [15] suggests that the sellers' skills, abilities, values and motivation influences customer behavior, having an impact on organizational performance. This indicates that the characteristics and attitudes of a worker will have an effect in customers' perception regarding their orientation.

According to Qualitas-Hispania [16], a company needs the sales force to understand the business, customers, trends, and market implications to develop customer orientation. This helps build and maintain good relations with the clients, 
differentiating themselves from the competition. Another advantage of this method is that the company will better optimize resources thus ensuring proper interaction with its customers. Qualitas also states that it is crucial for a company to possess a sales force that accompanies the client to advise and listen to their concerns, formulate solutions, and to find ways to make profits. Thus, it is necessary to work with the sales force to improve customer value orientation.

Schneider [13] proposes that human resource management practices facilitate a more positive experience for sales people within the company, increasing the prospects to deliver quality-service. Hence, the chapter suggests that human resource management practices affects customer-value-orientation in the company through the sales force.

\subsection{Incentive policies}

Milkovich and Newman [17] notes that employee remuneration plays a key role in company-employee relationships, being the source of good results by the sales force. One component of remunerations are incentives, which come in the following frequent forms: commissions, bonuses, benefits, and non-monetary incentives.

Special commissions and bonuses are important for workers, making them feel secure to their contributions to the organization by: placing them in a position to face financial burdens, setting their standard of living, achieving targets for employment and social status [18].

Many studies in the literature analyze the effects of incentive policies on management of sales $[19,20]$. In regard to this, authors have discovered that among the affected elements the key ones are: low personnel rotation and increased sales productivity [21], positive changes in employee behavior [17], and positive changes in seller behavior-even during critical moments for companies-[22]. Other studies demonstrate that incentive policies must be a combination between monetary incentives and non-monetary incentives to impact intrinsic motivation [19, 23-25]. This has an effect on employee job satisfaction [26]. Hence, the sales force's perception regarding company incentive policies would be positively related to perception of employee job satisfaction.

Zoltners et al. [15] explains that incentive policies represent an investment greater than the sum aimed at advertising, affecting a company's financial benefits. For an incentive system to be effective it is crucial to be designed in accordance to the characteristics of an organization such as customer preference and buying behaviors and relevant changes in customer environment [27-30]. The effects of incentives on a company's profitability is obtained only when the remuneration policy is designed on a long term and consistent method [21, 23]. Thus, incentive policies become a key factor in management of sales since output-performed by the sales force—is linked to their performance, thus affecting their productivity.

Good incentives policies should also improve worker performance, motivating them to align their behavior to the established goals to improve their salaries. When a company marketing strategy is customer-value-orientated, the sales force must devote considerable resources to fully adopt their roles and satisfy customer needs [31]. Jones et al. (2003) suggests that training, market information, and incentives are important artifacts to the sales force in managing their roles regarding customer orientation. According to the aforementioned evidence of previous studies, it is possible to conclude the following: Seller perception of a company's incentive policy would be positively related to their perception of customer-value-orientation regarding employee sales. Marking it more important than the sales force job satisfaction perception. 


\subsection{Training}

Training is one tool that companies have to successfully acquire knowledge and skills for their members to perform better at their jobs. This can be done informally by introducing those who join the company into the company's defined working behavior, or formally by keeping the employee in continuous training. In different cultural contexts such as the United States, Europe [32], Asia [33], and Africa [34], company policies become crucial in firms that have applied them when compared to others that have not.

Thus, sales force training programs must be focused on raising employee ability and capabilities while also motivating them to improve their service delivery skills. This allows a company to claim that it has been providing training to their sales force to improve their motivation and involvement in their jobs. The perception of the sales force regarding training is positively related to employee perception of job involvement.

Schlesinger and Heskett [35] note that it is ideal for a company to decide to develop a customer-oriented philosophy. To this matter companies should provide training, resources, and good reward systems to support and motivate the sales force. Firms must also provide tools to generate an effective oriented customer value sales force. Babin and Boles [36] explain that the supply of key resources, such as equipment and training, is crucial to facilitate good employee performance. Koka and Hein [37] conclude that training encourages employees and that through this their work performance can improve. Kushnir et al. [38]; Longenecker [39]; Martin [40]; Stone [41] conclude with similar arguments, highlighting that a good training level can motivate employees to increase productivity and performance in their job. Empirical evidence supports the claims as training level is an important factor that influences the degree of customer orientation.

To this end marketing and sales training serve in maximizing customer lifetime value (CLV), which is understood as the present value of all future benefits generated by customers [42]. Valenzuela et al. [43] and Valenzuela and Villegas [44] empirically corroborate that the behavior of a sales force oriented to CLV is essential in increasing company customer equity. Thus, managers must train and closely monitor CLV orientation of the sales force in their duties. This establishes profitable long-term relationships with the clients with the greatest business potential.

A number of promising approaches that promote CLV-oriented behaviors among the sales force exist in the literature. One obvious approach focuses on CLV-oriented attitudes when hiring new employees. This means that applicants are screened in terms of their CLV orientation, which is developed through training, coaching, and incentive programs $[34,39,40]$. It is thus implied that the sales force should be educated on the importance of CLV orientation, and its relevance to them and the firm.

By observing CLV-oriented leadership styles, the sales force can learn CLVoriented attitudes from their supervisors [45]. Therefore, their perception regarding the company's provided training would be positively related to their perception regarding employee customer value orientation. This is more important to employee job involvement perception.

\subsection{Job involvement and job satisfaction}

Employees with high degrees of job involvement will have more attention to their tasks and will feel that their jobs are a central aspect in their lives [27, 46]. Empirical evidence shows that job satisfaction depends on involvement, which is the degree to which individuals psychologically identify themselves to their work 
$[25,47,48]$. In this matter, job involvement has been found to be related to the efforts of any person to achieve his/her company business objectives and goals. These findings are based on several different studies regarding [49] absenteeism [23], degree of boredom, job satisfaction [4], and customer value orientation of an organization [50]. Hence, a sales force perception on employee job involvement would be positively related to perception of employee job satisfaction.

Rabinowitz and Hall's [51] model proposes a method where job involvement is part of employee disposition (employee's attitude toward their work), context (work environment), and interactions (employment effects). In addition, individuals who are more involved in their jobs tend to display higher levels of job skills (Abutayeh and Al-Qatawneh [52]) and manage better their work.

As authors believe that job involvement influences the attitudes of the employees, this is a critical factor for the quality of management sales and delivered-service to the customer. Therefore the sales force perceptions regarding a company's job involvement would be positively related to the perception of employee customervalue-orientation. This is more important than employee job involvement perception.

Stanton's et al. [14] theory and evidence in the literature give credit to the idea that the level of customer-value-orientation possessed by a sales team also depends on job satisfaction. This is understood as a function of the perceived relationship between what one wants in a job and what is offered, thus involving all the characteristics of the job and its environment where sellers can feel more/less satisfaction. Therefore, if the degree of satisfaction is higher, the commitment to the organization and to the customer will be higher [53]. Empirical evidence supports that the sales force perceptions on employee job satisfaction is positively related to perception of employee customer value orientation.

\section{Motivating the sales force}

The concept of motivation is used to explain what causes certain behaviors in people. There are different visions both in the conceptual and in the empirical fields. Robbins [54] defines motivation as a willingness to exert a high level of effort towards organizational goals, conditioned by the capacity of the effort to satisfy some individual need, thus introducing the concept of objectives in the organizational scope. Johnston and Marshall [55] define motivation as the desire and willingness of sales people to spend their efforts on performance and achievement of results in a visible manner. Fu [56] defines motivation as an individual choice, as sellers cannot be motivated unless they want it. Hence, motivation represents a critical driver of work performance, generated by the impulses of the individual and by the environment that determines if the behavior is akin to satisfy a need, objective, or goal.

According to the theory of expectations or VIE model [57], motivation is a cognitive representation that considers humans as a thinking and rational being focused on results or rewards. Thus, the actions of an individual are driven by the expected consequences according to their calculations and/or expectations.

The VIE model is composed of individual desires toward specific rewards (Valencia), performance of activities, perception of the received rewards (Instrumentality), and belief that certain behaviors will allow the acquirement of certain rewards (expectations). These will guide the efforts to complete the activity, performance, achievement of results, satisfaction, and valence [57].

Valence is understood as the attractiveness, preference, indifference, or rejection of a result for a particular person. Strictly defined, it is the recognition that 
people have desires or needs. Valence can be positive, negative or indifferent depending on the benefit it provides, as well as the anticipated satisfaction of a result. A person who chooses or wishes to achieve a result is defined as positive valence (represented by +1 ); A person who refuses or refuses to reach a result is defined as negative valence (represented by -1 ); a the result that does not represent any interest for the person in question (or if he/she is indifferent to it) is represented with the value "0" [57].

Effort is the visible action of individuals who focus on a particular end. The goal is performance, and effort is an internal reaction that can be observed in the form of behaviors ranging from tasks, duties, and responsibilities (performance) [58]. The level of effort depends on the goal and on which individual wants to invest so much to achieve that particular goal or reward.

Performance is the behavior of an individual that is given in terms of their ability and qualities to perform a job, as well as the willingness to do so with an objective in mind [59]. Both effort and performance are uniquely different, but similar in the nature that both pursue an end. For instance, when an employee is tested for a position, it is understood that they will attempt to pass the test. In respect to this, passing the exam is the goal/objective, while the qualification obtained will be equivalent to the performance of the pursued goal.

According to the theory of expectations, sellers are subject to the influences of many personal and environmental factors. This theory explains that motivation is a process of choices made between different behaviors that are under the control of people. Employees will behave in a certain way if they want to receive a raise or other reward. The theory of expectation dates from several decades, finding itself present in the empirical representation of motivation. Hence, the human component in sales will continue to have a preponderant role; however, it will be increasingly moderated by new technologies, and by the evolution of the decision-making processes of the consumers.

An important factor highlighted by researchers and managers when considering the career of sellers is the life cycle that said careers have in the field. For instance, aging in the sales force means gaining more experience, accumulating more knowledge, and sharpening sales skills. Furthermore, as a person's family grows, financial obligations likely change. Consequently, younger and less experienced sellers may have different estimates of expectations and reward preferences than older and more experienced sellers. Sales managers and training professionals need to pay particular attention to the unique needs of each sales force team to find the best motivational strategies. Table 1 identifies and conceptualizes the four stages of the sales force career: (1) exploration, (2) establishment, (3) maintenance and (4) disconnection [55].

The start of a seller's career is the exploration stage. At this stage they have less experience, possess little skill development, and are often not sure if selling is the right occupation for them. Thus, sellers in the exploration stage tend to have low expectations and estimates of instrumentality.

Sellers in the establishment stage are usually preoccupied with monetary and non-monetary incentives. These are relevant motivational factors that generate trust in them to be able to progress in the development of their careers.

Sellers in the maintenance stage (which generally happens at the age of 40) seek for different motivations such as caring of safeguarding their position and finding respect from their experience in the organization.

The disconnection stage is understood as the moment when sellers are approaching retirement and have lower levels of concerns (approaching 60 years of age). They no longer show an attachment to incentives, but can continue to be a contribution to the organization until they fully withdraw from their work. This process is 


\begin{tabular}{ll}
\hline $\begin{array}{l}\text { Stages of the seller's career } \\
\text { development }\end{array}$ & How to manage it \\
\hline Exploration & $\begin{array}{l}\text { Focus on product knowledge } \\
\text { Communicate company policies } \\
\text { Deliver and level the team's sales skills } \\
\text { Deliver feedback in a constant and timely manner }\end{array}$ \\
\hline Establishment & $\begin{array}{l}\text { Focus on financial incentives (bonuses, rewards) } \\
\text { Determine the most relevant non-monetary incentives (psychological } \\
\text { rewards) }\end{array}$ \\
\hline Maintenance & $\begin{array}{l}\text { Motivate through respect } \\
\text { Consider their needs so that their motivation allows them to develop their } \\
\text { work efficiently and effectively }\end{array}$ \\
\hline Disconnection & $\begin{array}{l}\text { Consider them in the process of forming the sales teams delivering their } \\
\text { experience } \\
\text { Deliver your knowledge to sales force in training }\end{array}$ \\
\hline Source: Johnston and Marshall [55]. &
\end{tabular}

Table 1.

Stages of the sales force career and incentives related to their growth.

different for each provider, and companies must be aware of the signs of behavior, perceptions and needs of the suppliers.

Depending on the stage that a seller is in their career, a relevant strategy is required to determine the efficient way to motivate them. An example of this is that for new sales force members, feedback from their superiors and clients can be more valuable as they are in search of confidence and security in their career development. For sellers in the establishment stage, incentives of the extrinsic type are more valuable such as bonuses and commissions.

Hence, knowing how managers and trainers influence motivation of their sales force is crucial to improving productivity. In general, sellers are constantly being evaluated by their managers and their clients.

While the evaluation from clients is based on more subjective aspects such as the quality of attention, kindness, and cordiality, evaluation from headquarters is often merely objective and measured the number of clients, amounts of sales, and time taken in the sales process.

Thus, managers must ask themselves: Are the incentives and goals enough to motivate the sales force? Will this complex context be the real cause of the demotivation of the sales force? These questions must take into consideration that there is probably a high level of ignorance on the part of the managers or chief executives regarding what happens in the sales process, with little to no direct feedback coming from the sales force themselves.

For instance, $\mathrm{Fu}$ [56] raises the theory of motivation as an action-reward analysis. Motivation in the sales force is much more likely to come from the constant wave of feedbacks they receive from very disconnected people. This produces a highly stressful environment due to the characteristics of their work, the pressure that customers sometimes exert, and being forced to solve problems without being responsible or possessing the resources to attend them properly [60].

Thus, training professionals requires adjustment in communication and strategies according to the different career stages of a sales force member. This best optimizes the effectiveness of their training intervention and attainment of compliance for the vendors. For sellers in the exploration stage, focus should be on product knowledge, company policies, and basic sales skills. Providing feedback in a timely manner is also critical for these rookie vendors to gain much needed experience. 
Sellers in the established stage should focus on financial incentives such as bonuses and psychological rewards in the form of recognition associated with performance and personal improvements. In retrospect, it is fundamental to show respect and recognition to sellers in the maintenance and disengagement stages. This implies that managers should take advantage of remembering that they are active workers who are valuable employees with a wealth of experience to share. Following this, turnover of the sales force can happen in an organic way by incorporating that experience into the sales training programs.

Although maintenance vendors respond positively to recognition, it is not the same for disconnection vendors. Sellers in the disconnection stage may be motivated by the opportunity to share their experience and war stories with other sales force members. Hence, one option to motivate them is to involve them in the same company sales training programs.

\subsection{The sales force in the omnichannel context}

At present, the consumer intervenes in different stages of the sales process, according to their degree of involvement with the product and/or service. For some consumers, this process begins with the search for information through different information channels (digital, in person, reference groups, membership, among others). Brynjolfsson et al. [12] states that the differences perceived by consumers between online distribution channels and the face-to-face ones have been steadily disappearing.

In the case of consumers, for some this process begins in the evaluation of alternatives (since they have enough information and are not limited by their set of options at the beginning of this stage), while for others it begins at the purchase of an already selected product in some distribution channel (face-to-face, online or online inside the store).

Based on the aforementioned, companies should consider these changes in consumers in the formation of their sales teams and specifically, in the role of the sellers. In this context, the concept of omnichannel is becoming increasingly important in the business world; Cummins et al. [61] defines omnichannel in the field of sales as the synergistic integration of the points of contact of consumers and sellers. This interaction gives the opportunity to generate a unified brand experience for consumers, independent of the usual sales channels or platforms. Thus, sales no longer have a linear structure as people can be informed by many means, and can evaluate and buy in (or from) different locations. Furthermore, people participate in different instances of the sales process based on their degree of involvement in the purchase.

An important element within the omnichannel concept is the case of online sales, as it incorporates a new feature within the decision of purchase by the consumer such as reputation. Thompson and Haynes [62] explain that reputation becomes important as consumers now have much more information at their disposal than before to determine and/or establish a level of reliability regarding the place of purchase, and distribution channel among others. This comparative capability for the consumer in the decision-making process is based on the massification of online comparison sites that introduce a new scenario that greatly facilitates the process of evaluating alternatives for the consumer; where people can find comparison sites segmented by industry, types of services, products, among others. This becomes a relevant factor that affects the willingness to pay due to transparent information being provided in a simple and easy way to understand.

There is another important aspect that relates to reduction of information asymmetry and professionalization of purchase by the consumers. The concept 
of functionality of a product and/or service means that buyers are unconsciously concerned regarding the performance of delivery, and how they can verify the truth in a given value proposition.

For example, when a consumer is going to buy a drill for domestic use, the sellers can meet an occasional consumer who uses it sporadically to solve problems in the low frequency household, where the evaluation process of alternatives is preferable given by recommendations. However, there are worries regarding functionality such as duration, and convenience, among others. At the same time, the sellers can find another type of consumer that uses the product more intensively and with a more "professional" look even for domestic use, which considers other relevant variables such as performance, safety, more technical functionalities, and product reinforcement. Although one can see these consumers differently, they have a point in common; they both have a concept of "metric" behind their choices, either from a simple or a more technical aspect. Regardless, the consumers are becoming more professional in their choices.

Nonetheless, the appearance and consolidation of a greater number of distribution channels generate a greater possibility of points of contact between companies and consumers. This implies that companies must increase the interconnection and compatibility between their strategies, as well as considering the different life cycles that their consumers may have [61].

So ... What about the sellers in the omnichannel context in which the sale is located?

\subsection{Changing paradigms in selling}

Within the context of the omnichannel, researchers find themselves faced with several key questions, such as: Does the need for a vendor diminish in the context where digital tools and distribution channels have proliferated enormously, helping more and more the sales process for the consumer? When a customer goes to a shop for a product, many times they will visually confirm how the product is whilst also already having decided to buy online. Thus, what elements does omnichanneling require to be successful and what role does the sales force play in that success?

In addition, omnichannel also affects the relationship between sales, consumers, and profitability. So what happens after a sale is made? Who takes charge of the customer? How is customer retention affected? What aspects of returns and profitability are modified? Is the client's life value altered? And although these questions do not have a single answer, one thing is clear, the seller's role must evolve.

Sellers have different points of interaction to relate to a consumer, therefore, it is important to understand what role the seller must fulfill in the sales process [63]. The consumer considers that the seller's intervention in this stage is, in many occasions, a specific source of referential information on the decision making process. This means that the authors should not think that the seller ceases to have relevance, even if managers are wondering how to transform the role in this stage into the sales process. This means that managers must understand the role as a "consultant" rather than a sales force executive, with a greater level of specialization than usual. The seller must be able to deliver solutions and recommendations to the consumer rather than just information. Nevertheless, the seller's role can be influenced by contextual variables and characteristics.

Figure 1 shows this relationship; the type of market (customers or companies) establish the complexity of the process and the knowledge level of the buyer. The characteristics of the product and/or service is relevant. A key element is the stage of the sales process (it is different for a seller to interact with an already informed customer who is looking to evaluate their decisions and alternatives, 


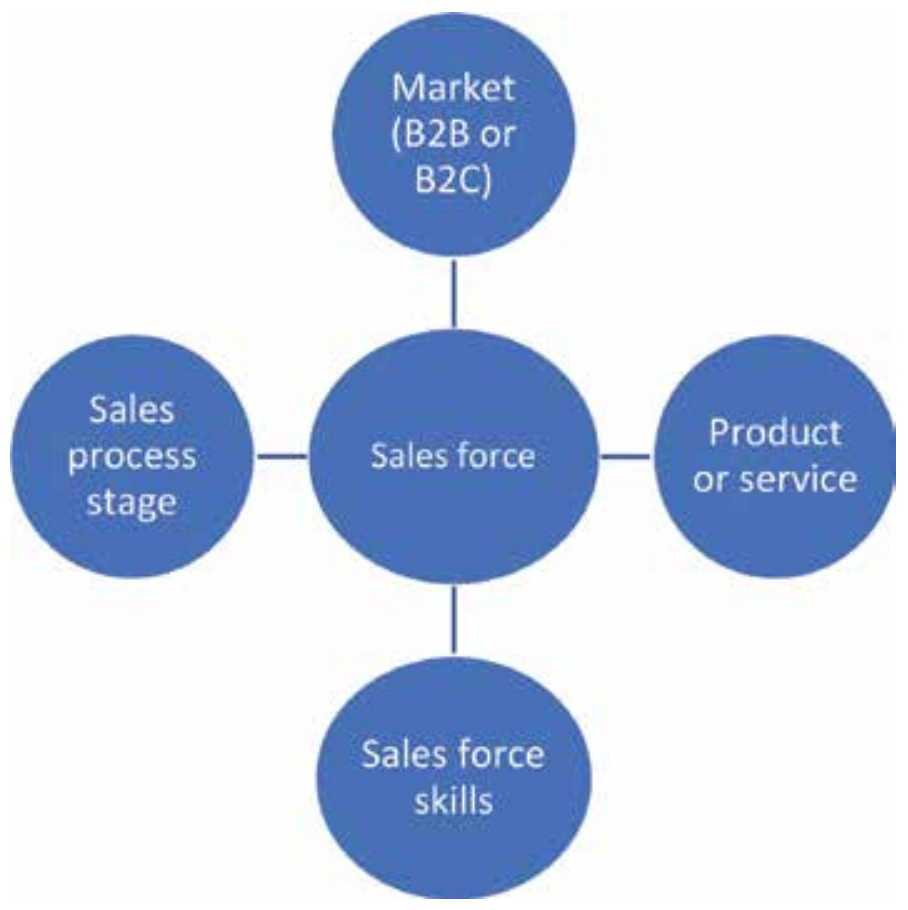

Figure 1.

Variables and characteristics that affect the seller's role. Source: Self-elaboration based on [61, 63].

than a customer that has not researched information on what they want or need). Furthermore, the skills of the seller (personality, experience) are important in developing and exploiting their potential. Figure 1 conceptualizes the importance of these relationships where these variables affect the development of the sales force $[61,63]$.

\section{A model of empowerment for the sales force}

When exposing the questions about the role of the sales force, the big question becomes, what tools can the authors give to the sellers to be a contribution in the companies in the dynamic and changing context in which the market is located?

A first step is the motivation of the sales force, for this, the authors must consider three important variables: direction, intensity and persistence.

For sellers to be motivated, they must have a clear direction, that is, have guidelines that allow them to focus on his/her work. In addition, there must be intensity, as the effort it puts into the relationship of its work, as well as persistence, is measured through the perseverance it places in the development of its work [64]. All the aforementioned points means that the seller must use their efforts in the appropriate tasks; a better seller is not one who works more, but one that has a clear direction to perform their work. It is important how the authors work each of these points with the sellers.

It is important to note that all sellers are different, so their perceptions regarding the three mentioned elements are moderated by different aspects such as their personality, background, experiences, and knowledge, among others. As any type of perception, these could be changed through training and incentives. Therefore, an important factor in the stage of the sales force career, like all work careers, is a development cycle with different stages. When a sales force starts his/her career, 


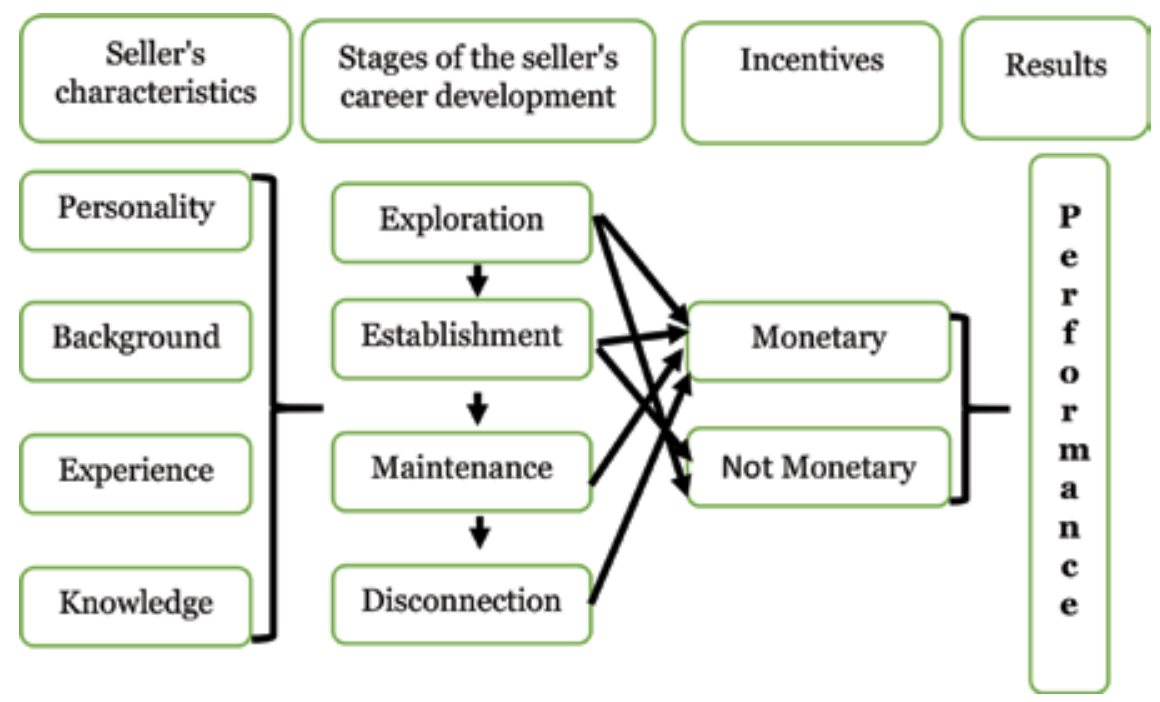

Figure 2.

Scheme of empowerment of the sales force. Source: Self-elaboration based in [56, 64].

they gain knowledge and accumulate a series of experiences that improves his/her skills as a sales force member from the professional side. At the personal level, his/ her needs grow as his/her family and financial stage is also becoming more demanding. Therefore, expectations and the type of compensation that they expect will also be different, so companies should be aware of these differences in the type of needs that sellers are presenting to find the best strategies and tactics of motivation in each particular case that helps the development and personal growth as well as the intensity, and persistence of the seller.

In that context, the authors propose a scheme of empowerment for the sales force based on the seller's background, their development in time [56], and their relationship with the stages of the seller's career development [64]. Figure 2 shows the importance of considering the seller's characteristics in their professional development and the connection with the incentives. This generates a combination of performance that can be sustainable over time $[56,64]$.

\section{Conclusions}

In general, the sales force receive continuous pressure from managers based on sales goals. This complex environment grounded on results and not good practices generates confusion, perverse incentives, and work stress in many sales teams. Additionally, the establishment of individual and group goals based on figures fosters a competitive and often uncomfortable environment even for the client. From the point of view of management, unrealistic goals generate frustration in sales teams. The changes that the client has experienced in their decision-making process, as well as the way they uses the sales channels, generate a complex maelstrom of management which is reflected in the disconnection of executives with the market and ignorance of the possible seasonality of sales. From the sellers' point of view, the sales force mostly faces consultative and complex buyers.

Therefore, it becomes crucial for the sales force to become aware that customer value orientation (CVO) is essential to achieve efficient performance and long-term profitable customer relationships. Likewise, a leadership style on the part of senior management focused on customer value generates a positive perception of the sales 
force team on the company, which produces greater satisfaction, involvement, and motivation. This would allow the creation of positive experiences that generate sustainable competitive advantages.

With regard to incentive policies, they play an important role in the relationship between sales force and senior management being an important factor to generate good results. Determining the best incentive structure (monetary, non-monetary) will depend, among other factors, on the career cycle of the sales force, the environment, and personal expectations. In that sense, employee empowerment has an important role as alignment in this level of organizations can lead to better performance [56].

Training is a valuable management tool for the growth of the sales force not only in technical aspects of their work, but also for the increase of their motivation and involvement with the development of their work. Managers must remember that the training process must take into account the profile of the vendor, the life cycle of the career, the type of market, the profile of the client portfolio, and the cultural context, among others. In addition, training generates a meeting space for the sales team that helps contribute to business growth and the organizational climate.

A consequence of the good management of the aforementioned variables is the degree of involvement and job satisfaction that the sales force has in a company. In that sense, how the employees can be empowered through the correct skills, abilities, and the support of the organization is key for their commitment and achieving corporate goals. This makes it easier for the sales force to have greater commitment to organizational objectives and greater customer orientation. That is, if the managers are able to achieve that when the company achieves its objectives, the sales force will feel these results as their own. This generates a greater sense of belonging and cohesion in the team, for which, each time the company obtains a good performance, this will also be for the sales force, thus generating a source of sustainable competitive advantage organically over time.

Taking into consideration the variables described and their effects on the development and performance of the sales force, managers must not forget the dynamism of the competitive and technological context in which find ourselves. In effect, consumers have countless alternatives when it comes to finding information, evaluating alternatives, and purchasing decisions (regardless of the degree of involvement that the purchase generates), which is why it is preponderant that the sales force have a high understanding of these phenomena, and have the skills to use information and communication technologies according to the field in which they operate. This nonetheless being relevant to the management of customer feedback and customer relations proactively and efficiently, with the aim at reducing uncertainty and anxiety with which the sales force coexists in their day to day.

The stage of a sales force member's career is a relevant point when it comes to generating a better interaction between a company and its customers. The authors must consider that sellers have different objectives according to their stage of development, and that these stages are influence by personal development (family and social) that generates different needs and expectations in the sellers. Therefore, it is necessary that the management and administration of these human needs be incorporated into the policies of incentives, guidelines, and guidelines of the sales force in the organizational field. This comes with the purpose of generating motivation, involvement, and job satisfaction, all relevant variables to achieve sustainability and sustainable performance in companies.

In this context, training professionals has the opportunity of contributing significantly to sales motivation, a fact generally ignored by executives and even coaches. The experience and frequent interaction that training professionals can establish with sales force allows them to be important motivators. However, coaches 
need to recognize that they do not have line authority over sellers. Therefore, coaches should strive to build relationships with sales managers and work together to motivate the sales force.

In relation to the aforementioned, it is important to take into consideration Burnout Syndrome, described as "the exhaustion of energy experienced by workers when they feel overwhelmed by the problems of others" [65]. This depletion of energy is the hidden demotivation and the open secret of the sales field since the work has to be done regardless of existing conditions.

Thus, leading and motivating a sales force is one of the biggest challenges facing the sales managers in present times. This not only considers the economic motivation, but also takes into account empathy, teamwork, segmentation according to the life cycle of the career, needs and expectations, training, incentive policies, and knowledge of the work that needs to developed. Today, the empowerment of sales forces has an important place in satisfying the consumers' needs and wants in a best way.

\section{Author details}

Leslier Maureen Valenzuela Fernández ${ }^{1}$ and Francisco Javier Villegas Pinuer ${ }^{2 *}$

1 Department of Business Administration, School of Economics and Business, University of Chile, Santiago, Chile

2 Faculty of Economy and Enterprise, Autonomous University of Barcelona, Barcelona, Spain

*Address all correspondence to: fvillegasp@fen.uchile.cl

\section{IntechOpen}

(C) 2019 The Author(s). Licensee IntechOpen. This chapter is distributed under the terms of the Creative Commons Attribution License (http://creativecommons.org/licenses/ by/3.0), which permits unrestricted use, distribution, and reproduction in any medium, provided the original work is properly cited. (cc) BY 


\section{References}

[1] Huber F, Herrmann A, Morgan R. Gaining competitive advantage through customer value oriented management. Journal of Consumer Marketing. 2001;18:41-53. DOI: 10.1108/07363760110365796

[2] Valenzuela L, Mulki J, Jaramillo F. Impact of customer orientation, inducements and ethics on loyalty to the firm: Customers' perspective. Journal of Business Ethics. 2010;93:277-291. DOI: 10.1007/s10551-009-0220-z

[3] Luo X, Hsu M, Liu S. The moderating role of institutional networking in the customer orientation-trust/ commitment-performance causal chain in China. Journal of the Academy of Marketing Science. 2008;36:202-214. DOI: 10.1007/s11747-007-0047-z

[4] Behruz A, Ghader V, Hasan G. Interdisciplinary. Journal of Contemporary Research in Business. 2011;3:1332-1338

[5] Mulhern F. Customer profitability analysis: Measurement, concentration, and research. Journal of Interactive Marketing. 1999;13:25-40. DOI: 10.1002/ (SICI)1520-6653(199924)13:1<25::AIDDIR3>3.0.CO;2-L

[6] Niraj R, Gupta M, Narasimhan C. Customer profitability in a supply chain. Journal of Marketing. 2001;65: 1-16. DOI: 10.1509/jmkg.65.3.1.18332

[7] Brown T, Mowen J, Donavan D, Licata J. The customer orientation of service workers: Personality trait effects on self- and supervisor performance ratings. Journal of Marketing Research. 2002;39:110-119. DOI: 10.1509/ jmkr.39.1.110.18928

[8] Jaramillo F, Grisaffe D. Examining the impact of servant leadership on salesperson's turnover intention.
Journal of Personal Selling and Sales Management. 2009a;29:351-365. DOI: 10.2753/PSS0885-3134290404

[9] Saxe R, Weitz B. The SOCO scale: A measure of the customer orientation of sales force. Journal of Marketing Research. 1982;19:343-351. DOI: $10.2307 / 3151568$

[10] Kumar V, Venkatesan R, Reinartz W. Performance implications of adopting a customer-focused sales campaign. Journal of Marketing. 2008;72:50-68. DOI: $10.1509 /$ jmkg.72.5.50

[11] Macintosh G. Customer orientation, relationship quality, and relational benefits to the firm. Journal of Services Marketing. 2007;21:150-157. DOI: 10.1108/08876040710746516

[12] Brynjolfsson E, Hu Y, Rahman M. Competing in the Age of Omnichannel Retailing. Cambirdge: MIT; 2013

[13] Schneider B. Organizational climate and culture. Pfeiffer. San Francisco: Jossey-Bass; 1990

[14] Stanton W, Buskirk R, Spiro R. Ventas. Conceptos, Planificación and Estrategias. 9aa.ed. Colombia: McGraw Hill; 1997

[15] Zoltners A, Sinha P, Lorimer S. Sales force effectiveness: A framework for researchers and practitioners. Journal of Personal Selling and Sales Management. 2008;28:115-131. DOI: 10.2753/

PSS0885-3134280201

[16] Qualitas-Hispania. Estudio del Nivel de Orientación al Cliente de la Empresa Española. España: Edición; 2005

[17] Milkovich G, Newman J. Compensation. Irwin McGraw-Hill: Boston, Estados Unidos; 1996 
[18] Martocchio J. Strategic

Compensation. New Jersey: PrenticeHall, Inc; 1998

[19] Chang P, Chen W. The effect of human resource management practices on firm performance: Empirical evidence from Taiwan's High-Tech firms. International Journal of Management. 2002;19:622-631

[20] King-Kauanui S, Ngoc S, AshleandCotleur C. Impact of human resource management: SME performance in Vietnam. Journal of Development Entrepreneurship. 2006;11:79-95. DOI: $10.1142 / \mathrm{S} 1084946706000271$

[21] Huselid C. The impact of human resource management practices on turnover, productivity and corporate financial performance. Academy of Management Journal. 1995;38:635-672. DOI: $10.5465 / 256741$

[22] Murphy W. In pursuit of short-term goals: Anticipating the unintended consequences of using special incentives to motivate the sales force. Journal of Business Research. 2004;57:1265-1275. DOI: 10.1016/S0148-2963(02)00447-2

[23] Carlson D, Upton N, Reaman S. The impact of human resource practices and compensation design on performance: An analysis of familyowned SME's. Journal of Small Business Management. 2006;44:531-543. DOI: 10.1111/j.1540-627X.2006.00188.x

[24] Gneezy U, Rustichini A. Pay enough or don't pay at all. Quarterland Journal of Economics. 2000;115:791-810

[25] Kanungo R. Measurement of job and work involvement. Journal of Applied Psychology. 1982;67:341. DOI: 10.1037/0021-9010.67.3.341

[26] Gómez-Mejía L, Balkin D. La eficacia de individuales and agregados, Estrategias de compensación. Relaciones
Laborales. 1989;28:431-445. DOI: 10.1111/j.1468-232X.1989.tb00736.x

[27] Elias S, Mittal R. The importance of supervisor support for a change initiative: An analysis of job satisfaction and involvement. International Journal of Organizational Analysis. 2011;19:305-316. DOI: $10.1108 / 19348831111173432$

[28] Gerhart B, Milkovich G. Employee compensation: Research and practice. In: Dunnette MD, Hough LM, editors. Handbook of Industrial Psychology. Palo Alto, CA: Consulting Psychologists Press; 1992. pp. 481-569

[29] Montemayor E. Congruence between pay policy and competitive strategy in high-performing firms. Journal of Marketing. 1996;22:889-908. DOI: $10.1177 / 014920639602200605$

[30] Rajagopalan N. Strategic orientations, incentive plan adoptions, and firm performance: Evidence from electric utility firms. Strategic Management Journal. 1997;18:761-785. DOI: 10.1002/(SICI)10970266(199711)1 8:10<761::AID-SMJ906>3.0.CO;2-2

[31] Jones E, Busch P, Dacin P. Firm market orientation and salesperson customer orientation: Interpersonal and intrapersonal influences on customer service and retention in business-tobusiness buyer-seller relationships. Journal of Business Research. 2003;56:323-340. DOI: $10.1016 /$ S0148-2963(02)00444-7

[32] Hoque K. Human resource management and performance in the UK hotel. Industry British Journal of Industrial Relations. 1999;37:419-443. DOI: 10.1111/1467-8543.00135

[33] Boselie P, Paauwe J, Jansen P. Human resource management and performance: Lessons from the Netherlands. International Journal of Human Resource 
Management. 2001;12:1107-1125. DOI: 10.1080/09585190110068331

[34] Ghebregiorgis F, Karsten L. Human resource management and performance in a developing country: The case of Eritrea. International Journal of Human Resource Management. 2007;18:321-332. DOI: $10.1080 / 09585190601102547$

[35] Schlesinger L, Heskett J. The service-driven service company. Harvard Business Review. 1991;69:71-81

[36] Babin B, Boles J. The effects of perceived co-worker involvement and supervisor support on service provider role stress, performance and job satisfaction. Journal Retail. 1996;72:57-75

[37] Koka A, Hein V. Perceptions of teacher's feedback and learning environment as predictors of intrinsic motivation in physical education. Psychology of Sport and Exercise. 2003;4:333-346. DOI: 10.1016/ S1469-0292(02)00012-2

[38] Kushnir T, Ehrenfeld M, Shalish Y. The effects of a coaching project in nursing on the coaches training motivation, training outcomes, and job performance: An experimental study. International Journal of Nursing Studies. 2008;45:837-845. DOI: 10.1016/j.ijnurstu.2006.12.010

[39] Longenecker C. Coaching for better results: Key practices of high performance leaders. Industrial and Commercial Training. 2010;42:32-40. DOI: $10.1108 / 00197851011013698$

[40] Martin H. Improving training impact through effective follow-up: Techniques and their application. Journal of Management Development. 2010;29:520-534. DOI: $10.1108 / 02621711011046495$

[41] Stone F. Your role as a coach. Coaching, counseling and mentoring:
How to choose and use the right technique to boost employee performance. New York: AMACOM; 2007. pp. 11-13

[42] Gupta S, Lehmann D. Customers as assets. Journal of Interactive Marketing. 2003;17:9-24. DOI: 10.1002/dir.10045

[43] Valenzuela L, Torres E, Hidalgo P, Farías P. Salesperson CLV orientation's effect on performance. Journal of Business Research. 2014;67:550-557. DOI: 10.1016/j.jbusres.2013.11.012

[44] Valenzuela L, Villegas F. Influence of customer value orientation, brand value, and business ethics level on organizational performance. Revista Brasileira de Gestão de Negócios. 2016;18:5-23. DOI: 10.7819/rbgn. v18i59.1701

[45] Stock R, Hoye W. An attitudebehavior model of sales force's customer orientation. Journal of the Academy of Marketing Science. 2005;33:536. DOI: 10.1177/0092070305276368

[46] Frone M, Russell M, Cooper M. Job stressors, job involvement and employee health: A test of identity theory. Journal of Occupational and Organizational Psychology. 1995;68:1-11. DOI: 10.1111/ j.2044-8325.1995.tb00684.x

[47] Darden W, Mckee D, Hampton R. Salesperson employment status as a moderator in the job satisfaction model: A framework of reference perspective. Journal of Personal Selling and Sales Management. 1993;13:1-15

[48] Lawler E, Hall D. Relationship of job characteristics to job involvement, satisfaction, and intrinsic motivation. Journal of Applied Psychology. 1970;54:305-312. DOI: $10.1037 /$ h0029692

[49] Brown S, Chandrashekaran M. Customer evaluations of service complaint experiences: Implications 
for relationship marketing. Journal of Marketing. 1998;62:60-76. DOI: $10.2307 / 1252161$

[50] Dursun T, Kilic C. Exploring occupational and strategic drivers of individuals customer orientation. Journal of Business and Economics Research. 2011;9:55-66. DOI: 10.19030/ jber.v9i5.4242

[51] Rabinowitz S, Hall D.

Organizational research on job involvement. Psychological Bulletin. 1977;84:265-288. DOI: 10.1037/0033-2909.84.2.265

[52] Abutayeh B, Al-Qatawneh M. The effect of human resource management practices on job involvement in selected private companies in Jordan. Canadian Social Science. 2012;8:50-57

[53] Ugboro I, Obeng K. Top management leadership, employee empowerment, job satisfaction, and customer satisfaction in TQM organizations: An empirical study. Journal of Quality and Management. 2004;5:247-272. DOI: 10.1016/ S1084-8568(01)00023-2

[54] Robbins S. Comportamiento Organizacional. Pearson Educación: México; 2009

[55] Johnston M, Marshall G. Sales Force Management: Leadership, Innovation, Technology. New York: Routledge; 2013

[56] Fu F. Motivate to improve sales force performance: The sales training perspective. Performance Improvement. 2015;54:31-35. DOI: 10.1002/pfi.21474

[57] Vroom V. Work and Motivation. Vol. 18. New York: John Wiley and Sons; 2005

[58] De Cenzo D, Robbins S.

Administración de recursos humanos.

México: Limusa Wiley; 2006
[59] Queipo B, Useche M. El desempeño laboral en el departamento de mantenimiento del ambulatorio la Victoria. Revista de Ciencias Sociales. 2002;8:486-496

[60] Sager J, Wilson P. Clarification of the meaning of job stress in the context of sales force research. Journal of Personal Selling \& Sales Management. 1995;15:51-63

[61] Cummins S, Peltier J, Dixon A. Omni-channel research framework in the context of personal selling and sales management: A review and research extensions. Journal of Research in Interactive Marketing. 2016;10:2-16. DOI: 10.1108/

JRIM-12-2015-0094

[62] Thompson S, Haynes M. The value of online seller reputation: Evidence from a price comparison site. Managerial and Decision Economics. 2017;38:302-313. DOI: 10.1002/ mde. 2777

[63] Baumann J, Le Meunier-Fitzhugh K. Trust as a facilitator of co-creation in customer-salesperson interaction-An imperative for the realization of episodic and relational value? AMS Review. 2014, 2014;4:5-20. DOI: 10.1007/ s13162-013-0039-8

[64] Mallin M, Gammoh B, Pullins E, Johnson C. New perspective of salesperson motivation and sales force outcomes: The mediating role of salesperson-brand identification. Journal of Marketing Theory and Practice. 2017;25:357-374. DOI: 10.1080/10696679.2017.1345597

[65] Freudenberger H. Staff burn-out. Journal of Social Issues. 1974;30: 159-165. DOI: 10.1111/j.1540-4560.1974. tb00706.x 
